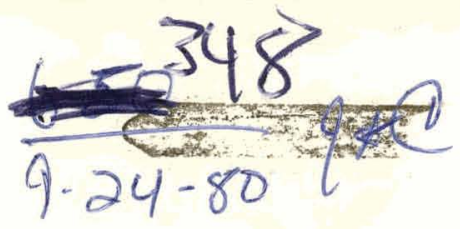

$$
\text { Dri: } 1967
$$

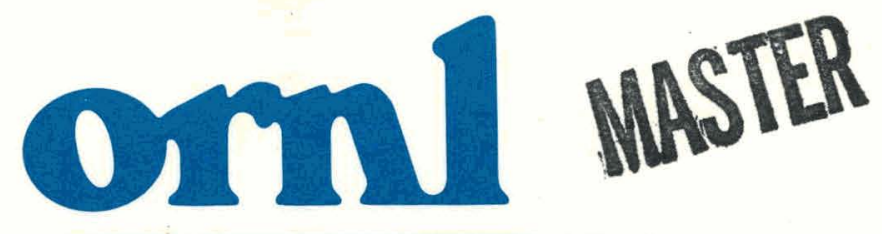

\title{
A State-of-the-Art Report on Low-Level Radioactive Waste Treatment
}

\section{UNION \\ CARBIDE}

\author{
A. H. Kibbey \\ H. W. Godbee
}

OPERATED BY

UNION CARBIDE CORPORATION

FOR THE UNITED STATES

DEPARTMENT OF ENERGY 


\section{DISCLAIMER}

This report was prepared as an account of work sponsored by an agency of the United States Government. Neither the United States Government nor any agency Thereof, nor any of their employees, makes any warranty, express or implied, or assumes any legal liability or responsibility for the accuracy, completeness, or usefulness of any information, apparatus, product, or process disclosed, or represents that its use would not infringe privately owned rights. Reference herein to any specific commercial product, process, or service by trade name, trademark, manufacturer, or otherwise does not necessarily constitute or imply its endorsement, recommendation, or favoring by the United States Government or any agency thereof. The views and opinions of authors expressed herein do not necessarily state or reflect those of the United States Government or any agency thereof. 


\section{DISCLAIMER}

Portions of this document may be illegible in electronic image products. Images are produced from the best available original document. 


\section{Printed in the United States of America. Available from National Technical Information Service \\ U.S. Department of Commerce \\ 5285 Port Royal Road, Springfield, Virginia 22161 \\ NTIS price codes-Printed Copy: A08 Microfiche A01}

This report was prepared as an account of work sponsored by an agency of the United States Government. Neither the United States Government nor any agency thereof, nor any of their employees, makes any warranty, express or implied, or assumes any legal liability or responsibility for the accuracy, completeness, or usefulness of any information, apparatus, product, or process disclosed, or represents that its use would not infringe privately owned rights. Reference herein to any specific commercial product, process, or service by trade name, trademark, manufacturer, or otherwise, does not necessarily constitute or imply its endorsement, recommendation, or favoring by the United States Government or any agency thereof. The views and opinions of authors expressed herein do not necessarily state or reflect those of the United States Government or any agency thereof. 
Contract No. W-7405-eng-26

CHEMICAL TECHNOLOGY DIVISION

NUCLEAR WASTE PROGRAMS

Low Level Waste Management Program

(Activity No.: AR 0515150 , Project No. ONL-WL12)

A STATE-OF-THE-ART REPORT ON LOW-LEVEL RADIOACTIVE WASTE TREATMENT

A. H. Kibbey

H. W. Godbee

Date Published: September 1980

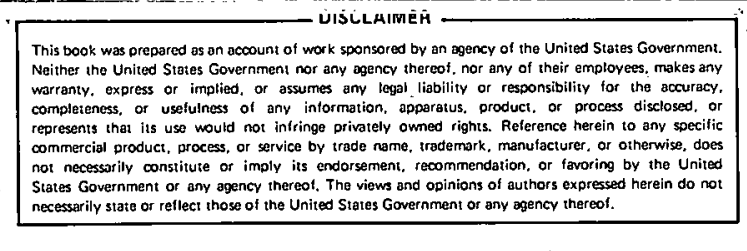

OAK RIDGE NATIONAL LABORATORY

Oak Ridge, Tennessee 37830

operated by

UNION CARBIDE CORPORATION

for the

DEPARTMENT OF ENERGY 
THIS PAGE WAS INTENTIONALLY

LEFT BLANK 
CONTENTS

Page

ABSTRACT . . . . . . . . . . . . . . . . . . . . 1

1. INTRODUCTION . . . . . . . . . . . . . . . . .. 2

1.1 References for Section 1............. 2

2. SOURCES, AMOUNTS, AND CHARACTERISTICS OF LOW-LEVEL

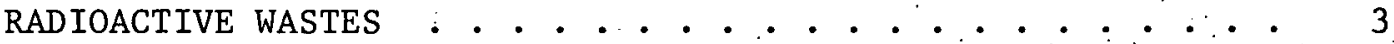

2.1 Government Sources of Low-Level Wastes.. . . . . . . 5

2.2 Commercial Sources of Low-Level Wastes . . . . . . . 8

2.2.1 Fuel cycle wastes . . . . . . . . . . . . 8

2.2.1.1 Power plants............ 9

2.2.1.2 UF6 production . . . . . . . . . 10

2.2.1.3 Uranium enrichment ......... 10

2.2.1.4 Fue1 fabrication . . . . . . . . 10

2.2.1.5 Away-from-reactor spent fuel

storage ............. 11

2.2.2 Nonfuel cycle wastes . . . . . . . . . . 12

2.3 Summary of Amounts of Waste Generated and Their

Sources ..................... 14

2.4 References for Section 2 ............. . 16

3. METHODS USED TO TREAT OR CONDITION LOW-LEVEL WASTES AT GOVERNMENT AND COMMERCIAL FACILITIES . . . . . . . . . . . . 19

3.1 Dry Wastes. . ... . . . . . . . . . . . . . 21

3.1.1. Physical treatment methods . . . . . . . . 22

3.1.2 Chemical treatment methods . . . . . . . . . . 24

3.1.2.1 Excess-air (in-drum) cyclone

incinerator ........... 25

3.1.2.2 Controlled-air (two-chamber)

incinerators . . . . . . . . . 27

3.1.2.3 Acid-digestion incinerator . . . . . 37

3.1.2.4 Molten-salt incinerator ........ 40

3.1.2.5 Slagging-pyrolys is incinerator... . . 40

3.1.2.6 Molten-glass incinerator (electro-

melter or joule-heated furnace) . . . 42

3.1.2.7 Other incinerators at DOE sites . . . 46

3.1.2.8 Fluidized-bed dryer/incinerator . . . 46

3.1.2.9 Fludiized-bed calciner/incinerator. . . 49

3.1.3 Summary of the development status of waste

incinerators .............. 51

3.2 Wet Wastes............... 54

3.2.1 Physical treatment methods ......... 56

3.2.1.1 Evaporation ............ 56

3.2.1.2 Filtration ............ 61

3.2.1.3 Centrifugation .......... 63

3.2.1.4 Reverse osmosis . . . . . . . 63

3.2.1.5 Ultrafiltration ......... 67 
3.2.2 Chemical treatment methods . . . . . . . 69

3.2.2.1 Ion exchange .. . . . . . . . . 69

3.2.2.2 Incineration ............. 72

3.2.2.3 Biological treatment . . . . . . . 72

3.2.3 Combined methods . . . . . . . . . . . 73

3.2.3.1 Coagulation/flocculation/ sedimentation ......... . 73

3.2.3.2 Filtration/demineralization ..... 74

3.2.4 Solidification methods ........... 75

3.2.4.1 Sorbents............. . 75

3.2.4.2 Cements .............. . . 76

3.2.4.3 Asphalts . . . . . . . . . . . . 78

3.2.4.4 Thermosetting organic polymers . . . . 80

3.2.5 Conditioning wet waste residues for

shipment/disposal ............ 84

3.2.j.1 Filter cartridges ......... 86

3.2.5.2 Spent resins............ 86

3.2.5.3 Slurries and sludges ........ . 87

3.2.5.4 Aqueous concentrates . . . . . . . 88

3.2.5.5 special aqueous solutions . . . . . 89

3.2.5.6 0ils .............. . 90 90

3.2.5.7 Other organic liquids. . . . . . . 90

3.2.5.8 0ther, wet solid wastes ....... . 91

3.3 References for Section 3.............. 92

4. RECOMMENDED RESEARCH, DEVELOPMENT, AND DEMONSTRATION . . . 103

4.1 Volume Reduction of Waste After Generation . . . . . . . 103

4.1.1 Dry wastes . . . . . . . . . . . . . . 103

4.1.1.1 Physical methods........... 104

4.1.1.2 Chemical methods . . . . . . . . 104

4.1.2 Wet wastes ................ 105

4.1.2.1 Physical methods .. . . . . . . 105

4.1.2.2 Chemical methods.......... 107

4.2 Metallic Waste Treatment . . . . . . . . . . 108

4.2.1 Hazardous metals .. . . . . . . . . . 108

4.2.2 Fotentially reusable metals . . . . . . . . 109

4.2.2.1 Surface contaminated metals . . . . 109

4.2:2.2 Irradiated metals ......... 109

4.3 Upgrading Solidification Systems for Low-Level

Wastes . . . . . . . . . . . . . . . 109

4.3,1 Limitations of currently uscd solidification

agents ................. . 110

4.3.2 Exploration for new solidification methods . : . 111

4.3.3 Maximizing the amount of waste incorporated

per unit volume of solidified product . . . . . 112

4.3.4 Detection of free (unbound) liquid in sealed

waste packages .............. . 112

4.3.5 Determination of leaching properties . . .. . 114

4.4 References for Section 4.............. 115 
Appendix A - OTHER INCINERATORS IN RADIOACTIVE SERVICE . . . . . 117

Appendix $\dot{B}$ - SOME REPRESENTATIVE RADIOACTIVE LIQUID-WASTE TREATMENT SYSTEMS AT SELECTED DOE SITES AND A FORMERLY USED COMMERCIAL FUEL REPROCESSING

PLANT . . . . . . . . . . . . . . . . 121

Appendix C - OTHER EQUIPMENT BEING MARKETED IN THE UNITED STATES FOR SINGLE-STEP VOLUME REDUCTION AND SOLIDIFICATION OF RADIOACTIVE LIQUID WASTES . • • • 137 
An attempt is made to identify the main sources of low-level radioactive wastes that are generated in the United States. To place the waste problem in perspective, rough estimates are given of the annual amounts of each generic type of waste [i.e., government and commercial (fuel cycle and nonfuel cycle)] that is generated. Most of the wet solid wastes arise from the cleanup of gaseous and liquid radioactive streams prior to discharge or recycle. The treatment of the process streams and the secondary wet solid wastes thus generated (e.g., filter cartridges, filter sludges, and spent ion exchange resins) is described for each type of government or fuel cycle installation. Similarly, the institutional wet wastes are also described. The dry wastes from all sources have similar physical and chemical characteristics in that they can be classified as compactible, noncompactible, combustible, noncombustible, or combinations thereof. The various treatment options for concentrated or solid wet wastes and for dry wastes are discussed. Among the dry-waste treatment methods are compaction, baling, and incineration, as well as chopping, cutting, and shredding. Organic materials [liquids (e.g., oils or solvents) and/or solids] can usually be incinerated or, in some cases, biodegraded. The filter sludges, spent resins, incinerator ashes, and concentrated liquids (e.g., evaporator concentrates) are usually solidified in cement, urea-formaldehyde, or unsaturated polyester resins prior to burial. Asphalt has not yet been used as a solidification agent in the United States, but it probably will be used in the near future. The treatment of radioactive medical and bioresearch wastes is described, but the waste from radiochemical, pharmaceutical, and other industries is not well defined at the present time. Recovery of waste metals and treatment of hazardous contaminated wastes are discussed briefly. Some areas appearing to need more research, development, and demonstration are specifically pointed out. 


\section{l. INTRODUCTION}

The purpose of this report is to present an overview of current treatment, volume reduction, and conditioning practices or methods that are applicable to low-level radioactive waste. Up to now there has been no concerted effort to compile and integrate the information available from both government and commercial (fuel cycle and nonfuel cycle) sources. This survey is confined to those methods that are used to prepare radioactive wastes for shipment, storage, or burial. The waste handling procedures and the storage or disposal methods are not within the purview of this study; they are covered in separate reports. ${ }^{1,2}$ This study was undertaken to help establish the proper perspective in Implementing a National Low-Level Waste Management Program in accordance with the recommendations put forth by the President's Interagency Revicw Group (IRG). ${ }^{3}$ A discussion of areas where more research, development, and demonstration activities could lead to improved waste treatment methods or more reliable waste product forms is included.

\subsection{References for Section 1}

1. NUS Corporation, State-of'the-Art Report on Waste Handling, NUS-3465, under contract with EG\&G, Idaho (1979).

2. Gilbert/Commonwealth Companies, State-of-the-Art Review of Alternatrves to Shallow Land Burial of Low-Level Radioactive Waste, ORNL/SUB-79/13837 (Apri1 1980).

3. U.S. Department of Energy, Report to the President by the Interagency Review Group on Nuclear Waste Management, TID-29442, Washington, D.C. (March 1979). 


\section{SOURCES, AMOUNTS, AND CHARACTERISTICS OF LOW-LEVEL RADIOACTIVE WASTES}

Low-level waste is defined in the IRG report ${ }^{1}$ as follows:

Low Level Wastes (LLW) contain less than ten nanocuries of transuranic containments per gram of material, or they may be free of transuranic contaminants, require little or no shielding, have low, but potentially hazardous, concentration or quantities of radionuclides. Low level wastes are generated in almost all activities involving radioactive materials and are presently being disposed of by shallow land burial.

However, this definition excludes many of the waste types that were formerly referred to as intermediate or medium level. Earlier, the International Atomic Energy Agency (IAEA) had attempted to define waste categories (numbered 1 to 5) based on the state (i.e., solid, liquid, or gas), the concentration of radioactivity, the radiation rate, the shielding. required, and the complexity of the treatment method employed. ${ }^{2}$ This scheme has not been widely used in the United States. The definition used in this study is

Low-1evel waste comprises that radioactive waste which is not spent fuel or high-level waste ${ }^{3}$ and which contains less than $10 \mathrm{nCi}$ of transuranics per gram of material.

In this survey, LLW is treated in two broad categories, namely, dry and wet wastes. Dry radioactive wastes generally contain trash comprised of such items as paper, rags, plastics, rubber, wood, glass, and metals that can be classified as combustible or noncombustible and compactible or noncompactible, or as combinations thereof. A more complete discussion of dry waste treatment is presented in Sect. 3.1. Most of the wet wastes are derived from cleanup of aqueous process or waste streams prior to recycle or discharge. Some of the more conventional physical and chemical methods used to treat radioactive liquid process and/or waste streams are summarized in Table 2.1. These methods (e.g., centrifugation, evaporation, filtration, reverse osmosis, ultrafiltration, coagulation, flocculation, and sedimentation) effectively decontaminate the bulk of the wastewater to activity levels that can be discharged 
Table 2.1. Conventional treatment methods used with low-level radioactive liquid wastes $a, b$

\begin{tabular}{|c|c|}
\hline Physical Methods & Chemical Methods \\
\hline Centrifugation & Coagulation/flocculation \\
\hline Evaporation & Ion exchange \\
\hline Filtration & Precipitation \\
\hline & Combined Methods \\
\hline Reverse osmosis & Coagulation/flocculation/sedimentation \\
\hline U1trafiltration & Filtration/demineralization \\
\hline $\begin{array}{l}\quad{ }_{\text {Conventiona }} \\
\text { been used on a co } \\
\text { low-1evel radioac } \\
\text { b Treatment i } \\
\text { used to remove se } \\
\text { from a stream, al } \\
\text { volume of the ori }\end{array}$ & $\begin{array}{l}\text { to indicate that these methods have } \\
\text { scale for several decades or years with } \\
\text { es. } \\
\text { indicate that the method is primarily } \\
\text { terials (e.g., innocuous or volatile) } \\
\text { may also provide some reduction in the } \\
\text { te. }\end{array}$ \\
\hline
\end{tabular}


directly to the environment or recycled.within the facility. The radioactive contaminants are, however, concentrated in the liquid or solid residues (wet wastes) that often require further conditioning, such as volume reduction or immobilization, prior to storage or disposal. The wet wastes, which include ion exchange resin slurries, filter cartridges, filter sludges, evaporator concentrates, oils, solvents, and other miscellaneous materials, can sometimes be classified according to combustibility (e.g., resins, oils, and other organics), but compactibility per se rarely applies; any volume reduction, if possible at all, is usually accomplished by removing associated water by physical means, such as decantation, filtration, centrifugation, or evaporation. In the near future, however, calcination, incineration, or some type of drying can be expected to be in common use for treating wet wastes. Wet residues are frequently immobilized by sorption on or mixing with an inorganic sorbent material or incorporation in a matrix of solidification agent. A more detailed discussion of wet wastes is presented in Sect. 3.2. All installations (government or commercial) that process or use radioactive isotopes generate dry radioactive wastes and at least some of the previously mentioned types of wet wastes. A general summary of the sources of radioactive LLW and the types of wastes generated is given in Table 2.2.

\subsection{Government Sources of Low-Level Wastes}

The federal government operations that generate LLW include defense activities as well as basic research and development (R\&D) studies at several Department of Energy (DOE) sites. These activities (fuel fabrication, reactor operation, spent fuel storage and chemical processing, and various kinds of $R \& D$ work) have generated a total of $21.4 \times 10^{6} \mathrm{~m}^{3}$ to $>2.9 \times 10^{6} \mathrm{~m}^{3}\left(250.8 \times 10^{6} \mathrm{ft}^{3}\right.$ to $\left.>103.8 \times 10^{6} \mathrm{ft}^{3}\right)$ of LLW over the past 4 decades as reported in refs. 1 and 4, respectively. The apparent discrepancy between the IRG ${ }^{1}$ and the Nuclear Regulatory Commission $(\mathrm{NRC})^{4}$ estimates is probably due to different interpretations of what constitutes LLW. At any rate, these government wastes, for the most part, have been disposed of by shallow land burial at DOE sites. In recent years, some DOE-generated LLW has been shipped to commercial 
Table 2.2. Sources and types of low-level radioactive wastes (as indicated by circles).

\begin{tabular}{|c|c|c|c|c|c|c|c|c|c|c|c|c|c|}
\hline \multirow[b]{3}{*}{ SOURCES } & \multicolumn{13}{|c|}{ TYPES OF WASTE GENERLTED } \\
\hline & \multicolumn{2}{|c|}{ COMBUSTIBLE } & \multicolumn{2}{|c|}{ NONCJMBUST,BLE } & \multirow{2}{*}{$\begin{array}{l}\text { FILTER } \\
\text { OAR - } \\
\text { IRIOGES } \\
\end{array}$} & \multirow[b]{2}{*}{$\begin{array}{l}\text { SPENT } \\
\text { RESINS } \\
\end{array}$} & \multirow{2}{*}{$\begin{array}{l}\text { SLURRIES } \\
\text { AND } \\
\text { SLUDSES } \\
\end{array}$} & \multirow{2}{*}{$\begin{array}{l}\text { AQUEOIS } \\
\text { CONCEN- } \\
\text { TRATES } \\
\end{array}$} & \multirow{2}{*}{\begin{tabular}{|l|} 
SPECIAL \\
AOUEOUS \\
SOLUTIONS \\
\end{tabular}} & \multirow[b]{2}{*}{ OILS } & \multirow{2}{*}{$\begin{array}{l}\text { OTHER } \\
\text { ORGANIC } \\
\text { LIOUIDS }\end{array}$} & \multirow[b]{2}{*}{$\begin{array}{l}\text { MEM- } \\
\text { BRANES }\end{array}$} & \multirow[b]{2}{*}{$\begin{array}{l}\text { B OLO } \\
\text { G CAL }\end{array}$} \\
\hline & $\begin{array}{l}\text { COMPA:- } \\
\text { TIBLE }\end{array}$ & $\begin{array}{l}\text { NONCON- } \\
\text { PACTIBLE }\end{array}$ & $\begin{array}{l}\text { COMPAC- } \\
\text { TIBLE }\end{array}$ & \begin{tabular}{|l|} 
NOMCOM- \\
PACTIELLE \\
\end{tabular} & & & & & & & & & \\
\hline $\begin{array}{l}\text { GOVERNMENT } \\
\text { DEFENSE }\end{array}$ & - & - & - & - & D & - & - & - & - & - & - & - & \\
\hline $0 \& 0^{C}$ & e & - & 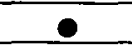 & e & & - & & & $\bullet$ & & & & \\
\hline RDO O D & - & e & e & $a$ & & - & - & - & - & - & - & - & - \\
\hline $\begin{array}{l}\text { COMMERCIRL } \\
\text { FUEL CYCLE } \\
\text { MINING }\end{array}$ & - & a. & - & a & & & - & - & & & & & \\
\hline MILLING & $\bullet$ & e & - & e & & & - & - & & & & & \\
\hline$U F_{6}$ PRODU:TTION & - & - & 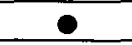 & e & & & 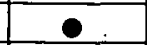 & & & & & & \\
\hline ENRICHMENT & $\bullet$ & - & - & a & & & e & & & - & - & & \\
\hline FUEL FABRICATION & - & - & - & 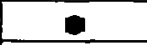 & & & e & & & 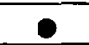 & & & \\
\hline POWER PLANTS & $\bullet$ & - & $\bullet$ & a & - & - & $\bullet$ & - & 으 & $\bullet$ & & - & \\
\hline SPENT FUEL STORAGE & $\bullet$ & - & $\bullet$ & 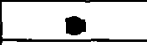 & & - & - & & & & & & \\
\hline 080 & $\bullet$ & e. & $\bullet$ & - & & - & & & - & & & & \\
\hline $\begin{array}{l}\text { NONFUEL CYCLE } \\
\text { MEDICAL }\end{array}$ & - & & - & - & & & & - & & & - & . & - \\
\hline PHARMACEUTICAL ${ }^{\circ}$ & - & & & - & & & & & & & - & & $\bullet$ \\
\hline UNIVERSITIES & - & & - & - & & - & & & & & $\bullet$ & & - \\
\hline OTHER INDLSTRIES ${ }^{\circ}$ & - & & & - & & $\bullet$ & & & & & & & \\
\hline
\end{tabular}

- decontamination, pickl ng. etching, elegtrópolishing, etc. So_utions.

- MEMBRANES FROM PROCE.SSES SUCH AS ULTRAFILTRATION (UF) aUd REVERSE OSMOSIS (RO).

C DECONTAMINATION AND C.ECOMMISSIONING ([.80) OPERATIONS.

a REsearch,. DEVElopment, aNo demonstration :Ro o ch programs.

- DATA ON THESE WASTES ARE INCOMPLETE LND DIFFICULT to OBTAIN. 
burial grounds for disposal. The total current LLW generation rate for all DOE sites combined is probably $\geqslant 2.8 \times 10^{4} \mathrm{~m}^{3} / \mathrm{yr}\left(1 \times 10^{6} \mathrm{ft}^{3} / \mathrm{yr}\right) .^{5}$ As older facilities are decontaminated and decommissioned, the amounts of LLW generated in these operations will probably increase this annual total. The radioactivity usually associated with DOE defense-type LLW is made up of mixed fission and activation products; tritium; naturally. occurring, long-lived alpha emitters; and traces of transuranic elements. The fission products of most concern are ${ }^{90} \mathrm{Sr}$ (pure beta emitter) and ${ }^{137} \mathrm{Cs}$ (strong gamma emitter), which have half-lives of 28 and $30 \mathrm{yr}$, respectively. Of the activation products, ${ }^{60}$ Co (strong gamma emitter with a 5-yr half-life) is the nuclide with the greatest hazard potential. Wastes containing ${ }^{3} \mathrm{H}$ (pure beta emitter with a 12.6-yr half-1ife) in liquid form are prominent among the by-products of defense activities. Low-activity tritiated waste liquids are collected and treated separately from other liquid LLW. The elemental sodium wastes produced in the. Experimental Breeder Reactor (EBR) program ${ }^{6}$ are not so much a radiation problem $\left({ }^{24} \mathrm{Na}\right.$ half-life is only $\left.15 \mathrm{hr}\right)$ as they are a chemical problem. Also, the low levels ( $\mathrm{pCi} / \mathrm{g}$ ). of induced activities that occur in the scrapped, highly purified metallic parts of nuclear accelerators (e.g., $\mathrm{Ni}, \mathrm{Al}, \mathrm{Cu}$, or stainless steel) put these wastes in a special category. The naturally occurring long-lived alpha emitters are mainly uranium and thorium isotopes and their respective daughters. The transuranics ( $\mathrm{Pu}$, $\mathrm{Np}, \mathrm{Cf}, \mathrm{Am}, \mathrm{Cm}$, etc.), as mentioned earlier, are present in quantities $\leqslant 10 \mathrm{nCi} / \mathrm{g}$ in LLW. The solid LLW derived from liquid and gaseous stream treatment 1s made up mostly of spent ion exchange resins, reverse osmosis or ultrafiltration membranes, charcoal, silica gel or zeolites, and solidified nitrate, chloride, and fluoride salts or sludges. At DOE sites, wastewater treatment is often accomplished by standard watertreatment techniques (coagulation, flocculation, precipitation, sedimentation, and filtration) and by use of settling basins or holding ponds. These wastes normally have very low activity levels. Some of the spent resins and sludges from in-plant process-stream cleanup, however, tend to be the most radioactive of the LLWs, and frequently they require some blological shielding. Liquid LLWs that have high solids contents are 
usually treated by evaporation. The overheads, after further purification by ion exchange, are clean enough for discharge to the environment. The radioactive contaminants remain in the evaporator bottoms (concentrate) or are deposited on the condensate polishing resin. The concentrate and resin are LLW. The LLWs originating from treatment of weapons-grade plutonium and uranium contain essentially no fission product beta-gamma $(B-\gamma)$ activity and therefore require no radiation shielding, although protection against inhalation or ingestion is necessary during packaging and handling. In general, the packaged dry wastes, immobilized liquids, and precipitated sludges and salts have radiation dose rates low enough ( $\leqslant 200 \mathrm{mr} / \mathrm{h}$ at the surface of the package) to permit safe manual contact. Stored organic solvents and oils pose a special disposal problem that requires more R\&D work at this point. Some DOE sites also have solid biological-type wastes that are generated in various research and development studies. These LLWs include such things as animal bedding, excreta, carcasses, and microorganism cultures.

\subsection{Commercial Sources of Low-Level Wastes}

Commercially generated LLW arises from fuel cycle operations, ${ }^{7-10}$ from pharmaceutical and other industrial uses of radioisotopes, from institutional R\&D efforts, and from diagnostic and therapeutic practices in radiomedicine. 11 Approximately $4.5 \times 10^{5} \mathrm{~m}^{3}\left(15.8 \times 10^{6} \mathrm{ft}^{3}\right)$ of commerclal LLWs has been buried over the last 2 decades, 1 most of it in commercial burial grounds. The current total combined generation rate for all commercial LLW is on the order of $5.7 \times 10^{4}$ to $8.5 \times 10^{4} \mathrm{~m}^{3} / \mathrm{yr}$ $\left(2 \times 10^{6}\right.$ to $\left.3 \times 10^{6} \mathrm{ft}^{3} / \mathrm{yr}\right) \cdot 8-10$

\subsubsection{Fuel cycle wastes}

By far, the 265 operating light-water-cooled reactor (LWR) power plants are the greatest generators of. L.LW in the nuclear fuel cycle (mining and milling excluded); they account for more than $2.8 \times 10^{4} \mathrm{~m}^{3} / \mathrm{yr}$ $\left(1 \times 10^{6} \mathrm{ft}^{3} / \mathrm{yr}\right) .^{8}$ The LLW from commercial fuel fabrication is estimated to be about one-fifth this volume, 10 while the other fuel cycle operations [i.e., $\mathrm{UF}_{6}$ production, uranium enrichment (not a commercial operation), 12 
and away-from-reactor (AFR) spent fuel storage ${ }^{13}$ ] generate even smaller volumes of LLW. The fuel cycle LLWs are similar to the defense wastes with respect to the radionuclides they contain, although the amounts and ratios of these nuclides may differ significantly. For the most part, however, the power plant wastes are chemically quite different from the other fuel cycle and defense wastes in that they usually contain little or no nitrate or halide. 14

2.2.1.1 Power plants. In a nuclear power plant, as in the other steps of the nuclear fuel cycle, over half of the LLW is generated from routine cleanup of liquid process or waste streams that are recycled within or discharged from the plant. The solid wastes thus generated are comprised of filter sludges (sometimes including filter aids) as we11 as spent ion exchange resins, 15,16 reverse osmosis (RO) or ultrafiltration membranes, and filter cartridges. At these plants the largest volume of dry LLW is usually generated during refueling and/or maintenance operations. Normally, at the so-called deep-bed (referring to beds of bead resins used in primary coolant cleanup) boiling-water-reactor (BWR) plants, the largest LLW volume fraction is solidified $\mathrm{Na}_{2} \mathrm{SO}_{4}$ solutions from regeneration of ion exchange resins. ${ }^{10}$ Filter-demineralizertype (e.g., Powdex) BWRs do not regenerate their resins, and dewatered filter/demineralizer sludges account for the largest volume fraction of their wet LLW. ${ }^{10}$ At pressurized-water-reactor (PWR) plants, solidified boric acid concentrates from the coolant and chemical-and-volume-control system are the major LLW. ${ }^{10}$ Disposable cartridge filters, rather than precoat filters, are widely used in PWR plants. 1 \% The spent filter cartridges, while small in volume, contain a large portion of the activity removed from the process and wastewater streams. Some PWRs use condensate polishers (resin beds) in the secondary loop to clean the water for recycle, and these PWR regenerant solutions are similar to those from a BWR. In the event of leakage from the primary to the secondary system, radioactive fission products collect on the condensate polisher resıus, but usually these resins are noi radioactive. In general, PWRs generate less LLW (volume/MW output) than BWRs. ${ }^{8}$ All nuclear power plants generate some waste oils. 
2.2.1.2 $\mathrm{UF}_{6}$ production. The only significant solid LLWs generated in $\mathrm{UF}_{6}$ production plants using the Dry Hydrofluorination Process are present as nonvolatile fluorides in the hydrofluorination ash or originate from the aqueous scrubbers in the off-gas system. The spent scrubber solutions contain fluoride that is precipitated as $\mathrm{CaF}_{2}$ by the addition of lime. At $\mathrm{UF}_{6}$ plants that use the Wet Solvent Extraction Process, most of the waste materials occur as soluble fluorides or nitrates in the liquid effluent streams. Here, also, the fluorides are precipitated by addition of lime. At the Wet Process plants, the $\mathrm{CaF}_{2}$ solids and waste nitrate solutions are retained in onsite settling or holding ponds. The solids could be recovered for packaging and offsite shipment. No decision on final disposal of these wastes has yet been made. Only small amounts of natural uranium and its daughters are associated with the LLW from a $U_{6}$ production facility. 18

2.2.1.3 Uranium enrichment. The gaseous diffusion uranium enrichment plants have retained liquid waste solutions, including those from equipment cleanup, in onsite holding ponds.18,19 The slightly radioactive sludges that settle out and accumulate in these outdoor ponds are retained onsite. Future plans include removal of the sludges with subsequent fixation in a solidified form suitable fur burial or aboveground storage. 19 The enrichment plants also generate solid wastes arising from equipment replacement as well as waste oils. The amount of solid wastes from equipment replacement may increase when centrifuges are used for the enrichment process.

2.2.1.4 Fuel fabrication. The LLW from fuel fabrication operations is similar to the $\mathrm{UF}_{6}$ production wastes in that it is largely composed of $\mathrm{CaF}_{2}$ solids which are allowed to settle out for retention in onsite holding ponds. The $\mathrm{CaF}_{2}$ is precipitated from waste process streame and/or off-gas scrubber solutions. Some of the scrap recovery wastes that are also discharged to the holding ponds have high nitrate concentrations because $\mathrm{HNO}_{3}$ is used to dissolve dirty $\mathrm{UO}_{2}$ scrap material prior to purification by solvent extraction. The other chemical contaminant of importance in the liquid waste from fuel fabrication is the ammonium ion $^{18}$ that is derived from the ammonium diuranate (ADU) precipitation 
step used in the conversion of $\mathrm{UF}_{6}$ to $\mathrm{UO}_{2}$. Combustible fuel fabrication wastes that are contaminated with low levels of radioactive material are usually volume-reduced by incineration. Incineration ashes and lowlevel filter sludges are incorporated into a solidification agent and shipped to a commercial burial ground. In uranium fuel fabrication for commercial LWR power plants, the wastes contain only $234,235,238 \mathrm{U}$, ${ }^{234} \mathrm{Th}$, and ${ }^{234} \mathrm{~Pa}$, all of which are naturally occurring isotopes. ${ }^{18}$ Fuel fabrication plants also generate some waste oils and solvents.

\subsubsection{Away-from-reactor spent fuel storage. The wastes from} onsite spent fuel storage at commercial reactor plants are included in the previous discussion of power plant wastes. It is the waste from spent fuel storage at privately owned and operated AFR fuel pools 20,21 that is considered here. The importance of such installations is iikely to grow if commercial fuel reprocessing is not permitted, and no other decision on the fate of spent fuel ${ }^{22}$ is made in the near future. Thus far, the volume of LLW from the AFR spent-fuel storage pools at Morris, Illinois, 20 and West Valley, New York, 21 has been minor in comparison with the total volume of other fuel cycle wastes. The only wastes that have been shipped offsite are dry wastes that are compacted whenever possible. At the West Valley plant, most of the LLW now being generated is due to decontamination operations that require large volumes of water. This wastewater is processed in the liquid LLW treatment facility where the radioactive contaminants are concentrated in the form of a precipitated ferric hydroxide sludge, which is drumed and buried onsite. The spent-fuel storage facility at West Valley is now on standby, and no additional spent fuel shipments have been accepted for several years. ${ }^{22}$ Surface contamination on the spent fuel assemblies is the chief source of radioactivity in the commercially operated storage pool water since no disassembly operations are now taking place. At the Morris fuel storage facility, all liquid LLWs from cask washing and fuel pool cleanup are routed to a common collection tank in the low-activity waste (LAW) vault. The fuel pool wastes are powdered ion exchange resin and zeolite sludges that constitute the backwash from the screen-tube precoat filter ${ }^{3}$ through which the pool water is circulated. The monthly input 
to the LAW vault ranges from 58,000 to $78,000 \&(15,000$ to 20,000 gal $), 13$ and $\sim 7800 \&$ (2000 gal) of that amount is from fuel pool cleanup. ${ }^{3}$ Excess water in the LAW collection tank is removed by pumping to a naturalcirculation evaporator and discharging the evaporator overheads to the environment. The evaporator concentrates are routed back to the LAW vault. All the sludge generated since start-up in 1973 is stored onsite, but future plans call for installation of a solidification facility to prepare this waste for offsite shipment, 13 The West Valley plant has a LAW vault and evaporator arrangement ${ }^{21}$ that is similar to the one at Morris.

\subsubsection{Nonfuel cycle wastee}

Only within the last 2 to 3 yr has there been any attempt to define and categorize the nonfuel cycle commercial LLWs.11,14,24-26 In concert with these efforts and with better identification of commercial fuel cycle wastes, the NRC, as part of its responsibility for establishing regulations for radioactive waste disposal, has contracted for the development of a radioactive waste classification system. The classification system being proposed 27 is based on the requirements for safe disposal. Safety was defined on the basis of dose limitations recommended by the International Commission on Radiological. Protection (LCKY). $\$ 0$ Unce environmental pathways were determined, waste categories for the classification system and recommended disposal guides for each category were formulated. The proposed categories are based on the length of administrative control required, accessibility of the waste, and hydrologic conditions.

A large volume fraction of these wastes arises from the use of radioisotopes in industrial (including pharmaceutical) applications that are varied and therefore difficult to classify. Of the so-called institutional wastes (e.g., those from hospitals, clinics, medical schools, universities, and colleges), the bioresearch conducted at medical schools generates the largest portion. 25 The total volume of LLW associated with medical uses, including diagnostic, therapeutic, teaching, and research applications, that is shipped to commercial burial grounds, 
amounts to $21.4 \times 10^{4}$ to $1.8 \times 10^{4} \mathrm{~m}^{3} / \mathrm{yr}\left(470,000\right.$ to $\left.600,000 \mathrm{ft}^{3} / \mathrm{yr}\right) .11,24$ The total volume of all institutional wastes probably exceeds $1.9 \times 10^{4} \mathrm{~m}^{3} / \mathrm{yr}\left(670,000 \mathrm{ft}^{3} / \mathrm{yr}\right) .11,14,24,25$. The sealed source and accelerator target wastes generated in both physical and life science research have a relatively insignificant volume, but they do have radioactive properties that require special packaging and/or shielding (e.g., high levels of ${ }^{137} \mathrm{Cs},{ }^{90} \mathrm{Sr}$, or ${ }^{3} \mathrm{H}$ ). The volume of LLW generated by the pharmaceutical industry is not included in this estimate because the types and volumes of such wastes have not yet been clearly defined or estimated. Pharmaceutical wastes are usually generated in the private sector and therefore are often in the proprietary category. However, the annual volume might well be as large as $3.0 \times 10^{3}$ to $5.5 \times 10^{3} \mathrm{~m}^{3} / \mathrm{yr}$ $\left(100,000\right.$ to $\left.200,000 \mathrm{ft}^{3} / \mathrm{yr}\right)$. Generally, the industrial radiochemical and pharmaceutical wastes that are shipped to commercial burial grounds have higher activity levels than the bioresearch and clinical or hospitaltype medical wastes. The radiopharmaceutical wastes shipped for commercial burial can be expected to consist mainly of organic compounds "tagged" with relatively long-lived beta emitters such as ${ }^{35} \mathrm{~S}$. (88 d), ${ }^{45} \mathrm{Ca}$ $(165 \mathrm{~d})$, and ${ }^{3} \mathrm{H}(12.6 \mathrm{yr})$ and the very long-lived beta emitter, ${ }^{14} \mathrm{C}(5700 \mathrm{yr})$. On the other hand, most of the organic bioresearch wastes are composed of nonradioactive solvents such as toluene or xylene mixed with scintillation fluid to which only small quantities $\left(10^{-4}\right.$ to $<10^{-2} \mu \mathrm{Ci} / \mathrm{ml}$ ) of radioactivity, usually ${ }^{14} \mathrm{C}$ or ${ }^{3} \mathrm{H}$, have been added. The majority of the diagnostic and therapeutic medical wastes contain induced radluactivities, usually gamma-emitting nuclides, with half-lives $\$ 60 \mathrm{~d}$, which are allowed to decay prior to disposal. The decayed wastes are frequently disposed of in municipal sewer or landfill systems. A significant fraction (at least 30 to $40 \%$ ) of the medical (as distinct from bioresearch) wastes do, however, contain low levels of longer-lived radionuclides (mostly laboratory assay wastes or leftover radiopharmaceut1cal reagents or residues) which are shipped offsite for burial. The toxicity and hazard potential of the institutional wastes may be of more concern than the contained radioactivity. Probably $<10 \%$ of the total institutional radioactive waste is of a biological nature, including animal carcasses, bedding, excreta, etc. An estimaled 40 to $50 \%$ of the 
medical waste is dry contaminated materials such as paper, cloth, or plastics. The organic materials in the medical and pharmaceutical wastes are suspected to be capable of causing radicnuclide migration through formation of soluble complex ions if they are not segregated from fuel cycle wastes in a burial ground.

\subsection{Summary of Amounts of Waste Generated and Their Sources}

A summary of the foregoing waste generation data is presented in Table 2.3. Included are the approximate total volumes of LLW accumulated from major DOE and commercial sources through 1978 and estimated current amounts buried annually for each waste source. Numerous estimates of waste volumes have been made by many organizations and agencies, and often the values arrived at are based on forecasts or projections that do not necessarily have the same presuppositions. As pointed out earlier, a lack of firm definition of the composition of LLW and lack of a universally accepted system of categorization and classification that embraces DOE and commercial wastes make the intercomparison of volume data most difficult. The values presented here are meant only to indicate the order of magnitude of the waste volumes being managed. The total LLW annual generation of close to $8.4 \times 10^{4} \mathrm{~m}^{3}\left(3 \times 10^{6} \mathrm{ft}^{3}\right)$ Indicates that volume reduction by every possible means is desirable. This is especially true since the closing of three (West Valley, New York; Maxey Flats, Kentucky; and Sheffield, Illinois) of the six licensed commercial burial grounds and limitations on the volumes of waste accepted at another (Barnwell, South Carolina). The closings and restrictions have limited the available space and have forced transport of much of the waste over longer distances for birial. The rapidly escalating costs of both transportation and burial over the lact fcw years have given impetus to the development of several volume-reduction techniques. 
Table 2.3. Estimated accumulated low-level-waste volumes buried and present amounts shipped to burial annually

\begin{tabular}{|c|c|c|c|c|}
\hline \multirow{2}{*}{ Source } & \multicolumn{2}{|c|}{$\begin{array}{l}\text { Total } \\
\text { accumulation } a\end{array}$} & \multicolumn{2}{|c|}{$\begin{array}{c}\text { Present annual } \\
\text { burial rate }\end{array}$} \\
\hline & $\mathrm{m}^{3}$ & $f t^{3}$ & $\mathrm{~m}^{3}$ & $\mathrm{ft}^{3}$ \\
\hline Government & $1.4 \times 10^{6}$ & $50.8 \times 10^{6}$ & $22.8 \times 10^{4}$ & $21 \times 10^{6}$ \\
\hline Commercial $^{b}$ & $4.5 \times 10^{5}$ & $15.8 \times 10^{6}$ & $>5.6 \times 10^{4}$ & $>2 \times 10^{6}$ \\
\hline Fue1 cycle: & & & $3.4 \times 10^{4}$ & $1.2 \times 10^{6}$ \\
\hline Reactor operation & & & $22.8 \times 10^{4}$ & $\sim 1 \times 10^{6}$ \\
\hline Fuel fabrication & . & & $25.7 \times 10^{3}$ & $22 \times 10^{5}$ \\
\hline Other steps & & . & Small & Small \\
\hline Nonfuel cycle: & & & $22.2 \times 10^{4}$ & $27.8 \times 10^{5}$ \\
\hline Institutional & & & $21.9 \times 10^{4}$ & $26.7 \times 10^{5}$ \\
\hline Medical & & & $21.8 \times 10^{4}$ & $26.4 \times 10^{5}$ \\
\hline Academic & & & $\geqslant 7.5 \times 10^{2}$. & $\geqslant 2.6 \times 10^{4}$ \\
\hline $\begin{array}{l}\text { Industrial and other } \\
\text { research (including } \\
\text { pharmaceutical) }\end{array}$ & & . & $23 \times 10^{3}$ & $>1.1 \times 10^{5}$ \\
\hline Total & $1.9 \times 10^{6}$ & $66.6 \times 10^{6}$ & $28.4 \times 10^{4}$ & $\sim 3 \times 10^{6}$ \\
\hline
\end{tabular}




\subsection{References for Section 2}

1. U.S. Department of Energy, Report to the President by the Interagency Review Group on Nuclear Waste Management, TID-29442, Washington, D.C. (March 1979).

2. International Atomic Energy Agency, Standardization of Radioactive Waste Categories, Technical Report Series No. 101, IAEA, Vienna, 1970 .

3. Code of Pederal Regulations, Title 10, Part 50, Appendix F.

4. U.S: Nuclear Regulatory Commission, Regulation of Federal Radioactive Waste Activities, a report to Congress, NUREG-0527 (Sèptèmber 1979).

5. J. E. Dieckhoner, "Sources, Production Rates and Characteristics of ERWA Low-Level Wastes," in Management of Low-Level Radioactive Waste, vol. 1, M. W. Carter, A. A. Moghissi, and B. Kahn, eds., Pergamon, New York, 1979.

6. L. C. Whitbeck and R. M. Fryer, Waste Production and Management at EBR-II, ANL 79-14 (Apri1 1979).

7. C. W. Alexander and J. O. Blomeke, "Origins and Characteristics of Low-Lcvel Nontransuranic Waste from the Nuclear Fuel Cycle," in Management of' Low-Level Radioactive Waste, vol. 1, M. W. Carter, A. A. Moghissi, and B. Kahn, eds., Pergamon, New York, 1979.

8. A. H. Kibbey, H. W. Godbee, and E. L. Compere, A Review of solid Radioactive Waste Practices in Light-Water-Cooled Nuclear Reactor Power Plants, NUREG/CR-0144, ORNL/NUREG-43 (October 1978).

9. D. G. Ébenhack, "Uperational Experience at Chem-Nuclear's Barnwell Facility," in Proceedings of the Health Physics Society 12 th Midyear Topical Symposium on Low-Level Radioactive Waste Management, Feb. 11-15, 1979, Williamsburg, Va., EPA 520/3-79-002 (May 1979).

10. J. Phillips et al., A Waste Inventory Report for Reactor and Fuel Fabrication Facility Wastes, ONWI-20, NUS 3314, prepared by NUS Corporation for the Office of Nuclear Waste Isolation, BattelleColumbus (March 1979). 
11. R. L. Andersen, T. J. Beck, L. R. Cooley, and C. S. Strauss, Institutional Radioactive Wastes, NUREG/CR-0028, University of Maryland (March 1978).

12. U.S. Energy Research and Development Administration, U.S. Nuclear Power Export Activities, Final Environmental Statement, ERDA-1542 (April 1976).

13. K. J. Eger and G. E. Zima, Commentary on Spent Fuel Storage at Morris Operation, NUREG/CR-0956, PNL-3065 (July 1979).

14. A. H. Kibbey and H. W. Godbee, "Sources, Amounts, and Characteristics of Low-Level Radioactive Solid Wastes," in Proceedings of the Health Physics Society 12th Midyear Symposium on Low-Level Radioactive Waste Management, Feb. 11-15, 1979, Williamsburg, Va., EPA 520/3-79-002 (May 1979).

15. K. H. Lin, Use of Ion Exchange for the Treatment of Liquids in Nuclear Power Plants; ORNL-4792 (December 1973).

16. W. E. Clark, The Use of Ion Exchange to Treat Radioactive Liquids in Light-Water-Cooled Nuciear Reactor Power Plants, NUREG/CR-0143, ORNL/NUREG/TM-204 (August 1978).

17. A. H. Kibbey and H. W. Godbee, The Use of Filtration to Treat Radioactive Liquids in Light-Water-Cooled Nuclear Reactor Power Plants, NUREG/CR-0141, ORNL/NUREG-41 (September 1978).

18. U.S. Atomic Energy Commission, Environmental Survey of the Nuclear. Fuel Cycle, WASH-1248 (April 1974).

19. C. P. McGinnis, "Solid Waste Disposal Study," in Compization of Papers Presented at the 1979 UCC-ND Waste Management Seminar, Mar. 6-7, 1979, K/C-1347, M. E. Mitchell, compiler, ORGDP (March 1979).

20. General Electric Company, Consolidated Safety Analysis Report for Morris Operation, Morris, IlZinois, Sect. 6, NEDO-21326 (January 1979). 
21. Nuclear Fuel Services, Inc., Safety Analysis Report, NFS' Reprocessing Plant, West Valley, New York, Docket No. 50-201, Sect. V-8, vol. I (1973).

22. Comptroller General of the United States, Report to the Congress: Federal Facilities for Storing Spent Nuclear Fuel - Are They Needed?, EMD-79-82 (June 1979).

23. Gilbert/Commonwealth Companies, State of the Art Review of Radioactive Waste Volume Reduction Techniques for Commercial Nuclear Fower Flaints, URNL/SUB-\%9/13837/2 (April 1980).

24. G. A. Benda, "Non-fuel Cycle Waste," in Proceedings of Waste Management 179, Feb. 26.to Mar. 1, 1979, Tucson, Ariz., R. G. Post, ed., University of Arizona, 1979.

25. T. Beck, L. Cooley, and M. McCampbell, Institutional Radioactive Waste - 1977, NUREG/CR-1137, University of Maryland (October 1979).

26. Preliminary State-by-State Assessment of Low-Level Radioactive Wastes Shipped to Commercial Burial Grounds, NUS-3440, prepared by NUS Corporation for EG\&G, Idaho (August 1979).

27. V. C. Rogers, A Radioactive Waste Disposal Classification System, vol. 1, NUREG/CR-1005, Ford, Bacon \& Davis Utah Inc., Sa1t Lake C1ty, Utah (Seprember 1979).

28. ICRP Publication 26, Recommendations of the International Commission on Radiological Protection, Pergamon, New York, 1977; adopted Jan. 17, 1977 . 


\section{METHODS USED TO TREAT OR CONDITION LOW-LEVEL WASTES AT GOVERNMENT AND COMMERCIAL FACILITIES}

The amounts and characteristics of the radioactive LLW generated at a facility, as well as the subsequent handling procedures required, have a direct bearing on the choice of an appropriate treatment or conditioning method. Some of the physical and chemical volume-reduction (VR) methods suggested for dry LLW, including most waste metals, and for wet waste concentrates and residues are listed in Table 3.1. For most organic materials (solid and liquid), some type of incineration appears to be a logical choice. The VR methods that seem most promising for aqueous wastes are calcination, crystallization, drying, thin-film evaporation, or an appropriate form of incineration. These methods yield residues that require some type of immobilization or solidification. All VR methods must ultimately take into account any secondary wastes (e.g., off-gas scrubber solutions) that may be generated in the process, as well as any treatment that may be required to convert such secondary wastes to a form suitable for storage and/or disposal. There are both similarities and some marked differences in the treatment methods used at government installations and those used in commercial fuel cycle plants or private institutions, as will be shown in the following discussion.

Government installations generate many of the same types of LLW that commercial fuel-cycle installations do. These include dry, compactible, and/or combustible wastes, solid noncombustibles, wet wastes including resins, disposable filter cartridges and filter sludges, evaporator concentrates or salt slurries, contaminated soil, and organic liquids such as oils and solvents. Not all government installations generate exactly the same kinds of LLW because each installation differs somewhat in the types of activities performed. In some cases, however, more than one installation may be charged with a similar operation, although the individual approach may differ to some degree. Two comprehensive compilations of site-specific LLW management practices at DOE installations as of 1976 have been published recently.1,2 In this current study, an attempt has been made to update, broaden, and extend 
Table 3.1. Some volume reduction methods suggested for use with low-level, radioactive dry-waste and wet-waste residues

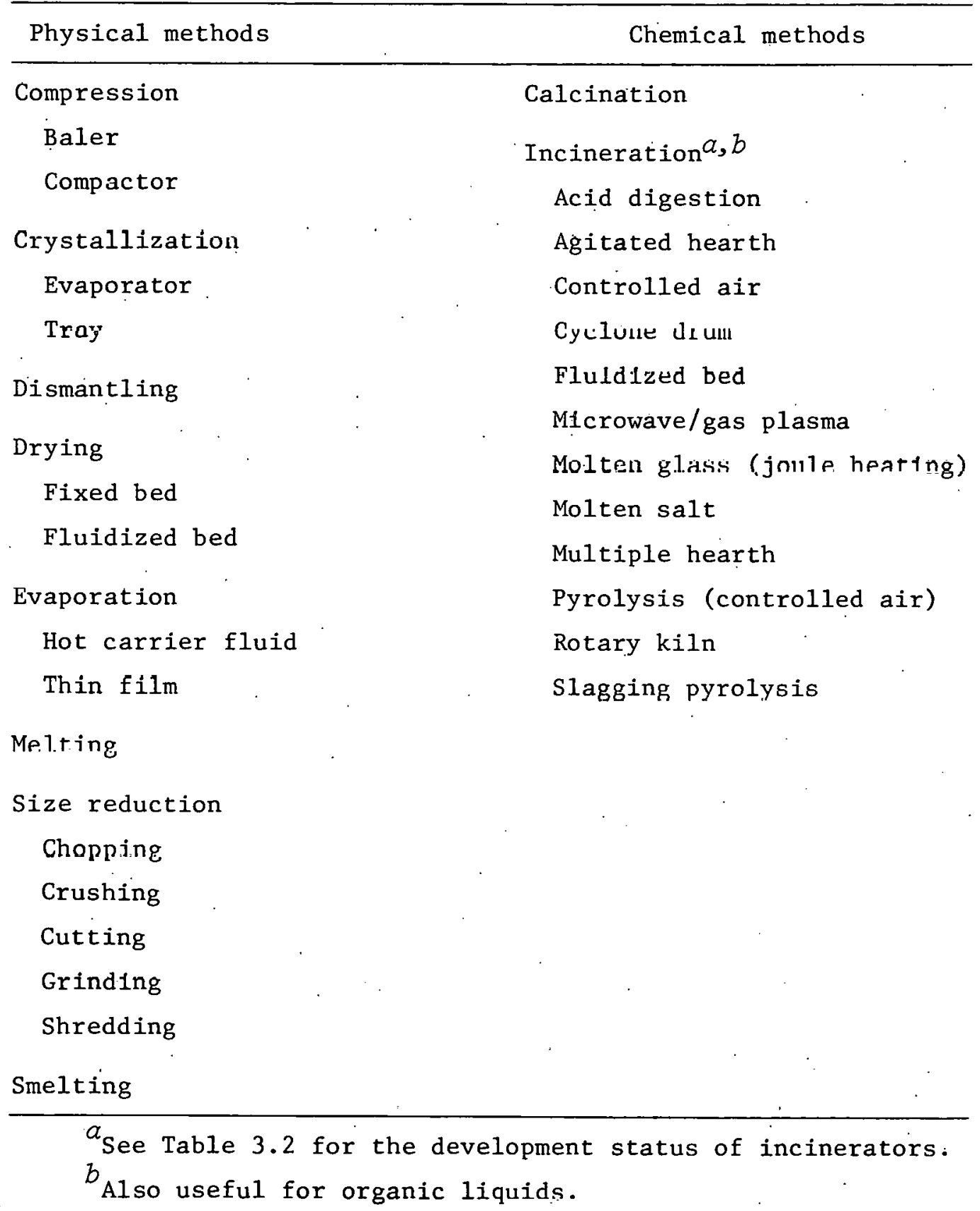


some of the waste treatment information presented in those earlier reports. The LLWs have been divided, in general, into two main categories - dry and wet - because different unit operations are needed to treat each of these types, whether the wastes arise from government activities or from commercial sources.

A type of waste that requires special treatment is LLW with high hazard potential (e.g., sodium). The elemental sodium waste generated at the ANL-West Experimental Breeder Reactor (EBR-II) is being stored onsite pending development of a facility for disposal of the sodium. The treatment method eventually adopted will probably be applicable to the sodium wastes from any commercial sodium-cooled reactor that might be built. Presently, the bulk-form sodium is placed in $3.8-\ell$ (1-gal) cans which, in turn, are placed in metal drums and covered with sand. 3 It is planned that in the future the sodium will be reacted with water and water/alcohol followed by evaporation of the water and recovery of the alcohol by distillation. ${ }^{3}$ The acceptability of sodium alcoholates by the Radioactive Waste Management Complex (RWMC) at Idaho National Engineering Laboratory (INEL) has not yet been established. Compared, on a volume basis, to the dry and wet wastes discussed below, the wastes in this category are relatively insignificant at this time.

\subsection{Dry Wastes}

Noncompactible and/or noncombustible LLW of ten require special treatments, depending on their particular individual characteristics. They can range in size from small pieces of scrap or waste metal to very large pieces of discarded equipment. The radioactive contamination may be deposited only on the surface, or it may be distributed throughout the entire structure. These wastes, to date, have represented a relatively small fraction of all the LLW generated, but increasing decommissioning activities are steadily adding to their generation rate. For example, 4 a large LWR is expected to generate about one-third as much LLW $\left[\sim 1: 7 \times 10^{4} \mathrm{~m}^{3}\left(6 \times 10^{5} \mathrm{ft}^{3}\right)\right]$ during decommissioning as in an expected $40 \mathrm{yr}$ of normal operation $\left[5.1 \times 10^{4} \mathrm{~m}^{3}\left(1.8 \times 10^{6} \mathrm{ft}^{3}\right)\right]$. Practically all of this decommissioning waste will be noncompactible and/or noncom- 
bustible. Decomissioning of other nuclear facilities are described in refs. 5 to 8 .

The huge total volume of dry compactible and/or combustible waste generated in all radioactive operations suggests the need for suitable VR methods. 'l'his is especially true for installations that have little or no accommodation for onsite burial. Until a DOE directive issued October 26, 1979, stopped the practice, several government facilities, particularly in the East and Midwest, were for a time shipping their LLW to commercial burial grounds. They were therefore sharing some of the same problems experienced in the commercial sector of the nuclear industry. The closing of the West Valley, Maxey Flats, and Shcffield disposal sites has resulted in sharply increased waste transportation cosis and, in turn, has provided greater incentive toward volume reduction. A line diagram showing the options for volume reduction and subsequent immobilization of dry, radioactive LLWs is given in Fig. 3.1.

\subsubsection{Physical treatment methods}

Small, contaminated, noncompactible and/or noncombustible waste items usually require no special treatment before packiaging for disposal. Larger pieces of equipment sometimes require surface decontamination by chemical means, or perhaps by electropolishing or eandblasting, prior to size reduction by dismantling or torch-cutting. An electropolishing or sandblasting technique is sometimes nsed to reduco metal surface cuntamination to the point where reuse or recycle is possible instead of discard. Also, surface-contaminated scrap metals are sometimes res.1aimed by smelting, as in the case of aluminum and nicke1 at Paducah. ${ }^{9}$ The reclamation of the highly purified metals from used accelerator or reactor parts (e.g., $\mathrm{Cu}, \mathrm{Ni}, \mathrm{Al}$, or stainless steel) poses a special problem vecause the induced activities, although very low in concentration, are distributed throughout the material. Furthermore, since the activation products usually have properties similar to those of the surrounding metal mass, they are not removed by ordinary smelting procedures. Such residual activities could cause problems if they were recycled and were to find their way into sensitive instrumentation. No decision has been 
ORNL OWO BO-9BR3

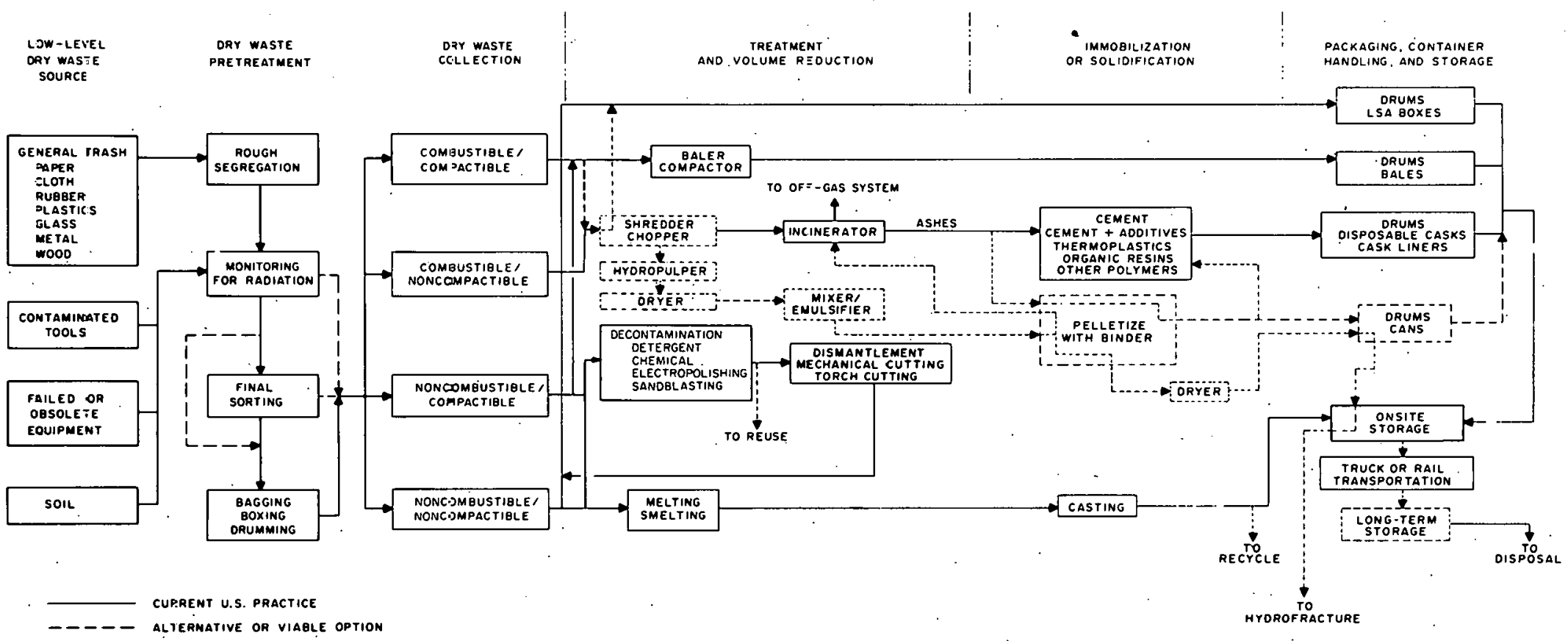

Fig. 3.1. Flow diagram illustrating the management of dry low-level radioactive wastes. 
made to recycle such metals and, at present, large stocks are accumulating in aboveground storage at such locations as Brookhaven and Argnnne National Laboratories (BNL and ANL).

Among the physical means most commonly employed at DOE sites for treating dry compactible and/or combustible wastes are chopping or shredding, baling, and compaction. Commercial facilities normally use in-drum compaction for these wastes. Bulk volume reduction factors of 2 to 3 for chopping or shredding and 3 to 10 for baling and compaction are usually attainable.10,11 DOE sites that do have ample onsite burial. space, as well as a few utilities and some institutions; sometimes depend on natural in-trench compaction to reduce the volume of such dry wastes. In this case, the wastes are merely bagged or boxed for transport to the burial ground and ultimate disposal. In-trench compaction is said to yield an average VR factor of at least 4.10 At ANL, some small compactible objects are placed inside 10-cm-diam $\times 23-\mathrm{cm}-\mathrm{high}$ (4-in.-diam $\times$ 9-in.-high) cans, which are then sealed and compacted around the waste material with a VR factor of 4 to 5 . The filled compacted cans are then collected in a drum for disposal. This method provides an extra barrier against the escape nf radioactivity to the environment in a burial ground.

At Oak Ridge National Laboratory (ORNL), a new system for treating dry combustible wastes is being developed. The sorted wastes are first shredded, then fed to a hydropulper, and subsequently dried. After drying, the pulverized waste is mixed with an organic binder, pelletized, and dried again. The pellets might be collected and stored in drums or cans and eventually mixed with cementitious grout in preparation for onsite disposal by shale bed hydrofracture.12,13 Alternatively, the pellets could be burned in an incinerator, the advantage being that a uniform feed tu the burn chamber would not only simplify the feeding mechanism, but would also increase the ability to control the burning operation.

\subsubsection{Chemical treatment methods}

The dominant chemical method used for treating dry LLW is incineration. In the U.S. commercial fuel cycle, only one small nuclear power 
plant (Yankee Rowe) 14 now uses an incinerator for combustion of essentially nonradioactive wastes, although several fuel fabrication plants use incineration routinely. ${ }^{15}$ A number of commercial institutions (e.g., hospitals or medical schools) incinerate their radioactive LLW, but obtaining a license to do so has apparently been quite difficult. 16 However, a recent survey by the $\mathrm{NRC}^{17}$ indicates that incineration of scintillation counting fluids, which comprise the major volume portion of institutional wastes, is among the most viable alternatives for disposing of these wastes. Several DOE sites have had active incineration $R \& D$ programs over the last few years, each investigating a selected type of incinerator. In 1977, an exhaustive study and evaluation of these and other commercially available incinerators was made in an effort to facilitate decision making with respect to treatment of retrieved INEL transuranic (TRU) wastes. 18 Even though the radiochemical properties of government wastes may be somewhat different from those of combustible commercial wastes, the same incineration methods might be applicable if some modifications are made. Treatment of the off-gases from burning commercial radioactive wastes may be more complex because they are likely to contain higher concentrations of volatile radioactive fission and activation products than TRU wastes. The radioactive heavy metals in TRU wastes form nonvolatile oxides. The nature of the retrieved Idaho wastes (especially the high soil content). imposes unique constraints on the treatment process that are not necessarily required in processing other radioactive wastes. A brief description of the incineration processes studied at each DOE site, the types of waste each is meant to treat, and some possible limitations are given in the following discussion.

3.1.2.1 Excess-air (in-drum) cyclone incinerator. At Mound Facility, an excess-air cyclone incinerator that uses a 200- $\ell$ (55-gal) drum as the burning chamber has been developed 19,20 and demonstrated.21 Temperatures within the drum reach 1100 to $1200^{\circ} \mathrm{C}$ during the burning operation. As shown in Fig. 3.2, the off-gas from the combustion chamber is cooled, scrubbed, and neutralized in a spray-type deluge tank before passing on to a venturi scrubber for further particulate removal. The solids that collect in the deluge tank and venturi are removed as the scrub solutions. 


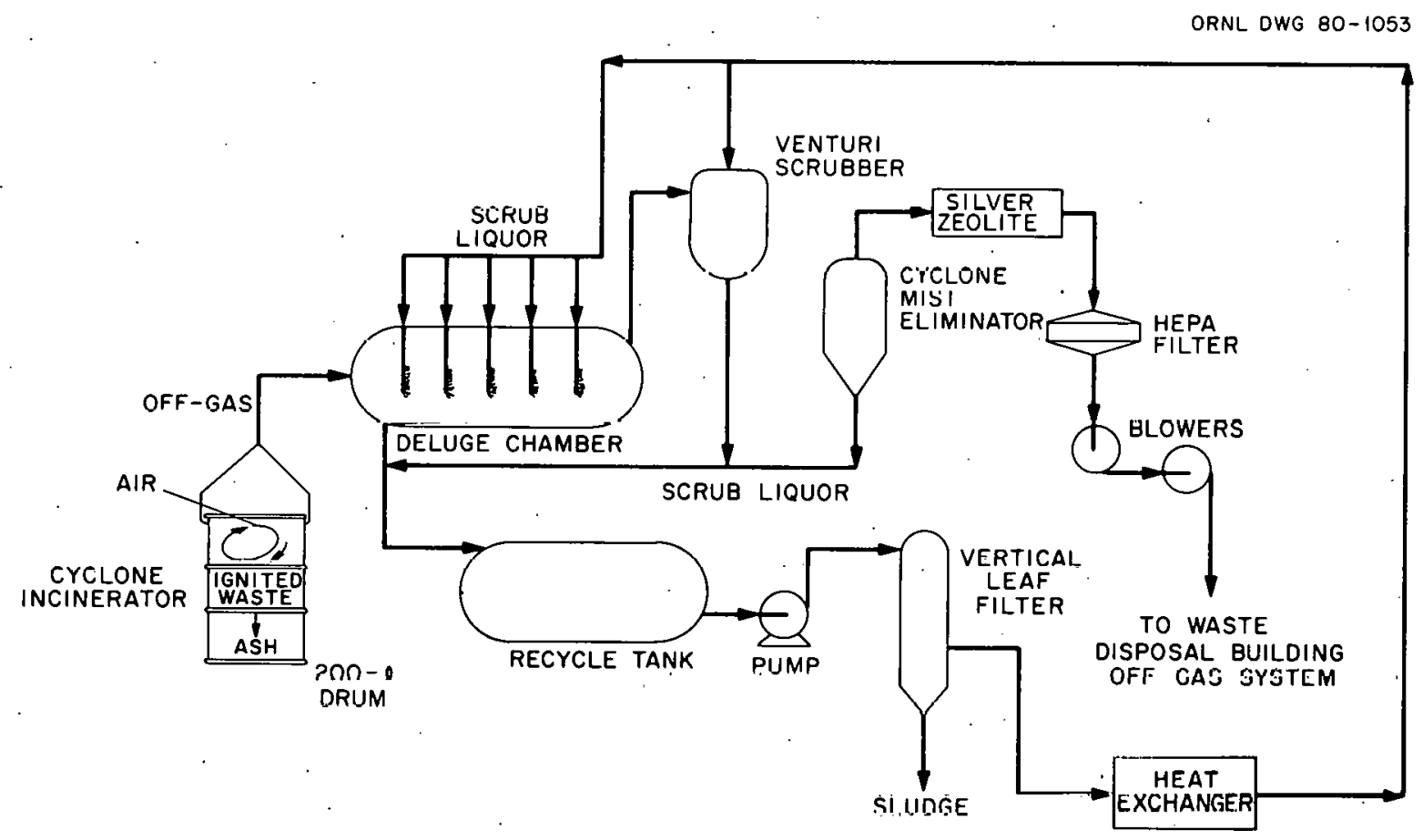

Fig. 3.2. Mound Facility cyclone incinerator. 
are recycled through a vertical leaf filter. As of this year, all the backlog of dry, compacted LLW that had accumulated at the site since December 1976 has been burned. Modifications to the feeding system are now under way that should expand the versatility of the incinerator by permitting continuous burning of either solid or liquid wastes. 22 Recently, a short trial burn using the new continuous feed system was conducted by starting with a batch-type burn of $95 \mathrm{~kg}$ of low specific activity (LSA) waste to which $70 \mathrm{~kg}$ of shredded waste was pneumatically introduced. An overall burning rate of $\sim 180 \mathrm{~kg} / \mathrm{h}$ was achieved. ${ }^{23}$ It was also demonstrated that smooth burning of scintillation vials occurred when they were hand-fed into the pneumatic injection system at a rate of 100 in 8 min. ${ }^{23}$ A preliminary conceptual design has been formulated for a system to deliver vials containing scintillation fluid from their storage containers to the existing air inlet of the incinerator for pneumatic injection into the chamber. Entrained moisture in the off-gas has resulted in shortened high-efficiency particulate air (HEPA) filter life, and several options for solving the problem are under consideration. 22 A bench-scale cyclone incinerator has been constructed for burning lowlevel $\beta-\gamma$ wastes, and studies on off-gas decontamination are planned. Some preliminary work has been done on treating the secondary wastes produced by the in-drum cyclone incinerator, namely, the aqueous scrubber solution and wet filter sludge. At the Mound Facility, these two byproduct wastes are simply added to the plant liquid-waste treatment system, but to broaden application of the cyclone incinerator to other sites, some form of drying (e.g., using a spray, thin-film, or rotary vacuum dryer) is contemplated. The main problems encountered with these selected drying techniques using simulated wastes have been product entrainment and less-than-satisfactory powder discharge. 20 Feasibility studies on upgrading the scrubber system by modification or replacement of the primary deluge tank to relieve the burden on the secondary venturi scrubber are in progress. 22 l' lhe preliminary design criteria tor batch mode operation of the revised Mound cyclone incinerator have now been formulated. 24

\subsubsection{Controlled-air (two-chamber) incinerators. The Savannah} River, Los Alamos, and Rocky Flats sites have been studying two-chamber, 
controlled-air incinerators equipped with wet scrubbers in the off-gas treatment system. The use of electric heaters to produce flameless combustion is a feature unique to the Savannah River incinerator process. Except for Los Alamos Scientific Laboratory (LASL), the incinerators at these DOE sites were designed specifically to handle TRU wastes having 1ittle or no $\beta-\gamma$ activity. The LASL incinerator technology is now available for transfer to private industry for use in radioactive service. 25 Waste segregation into combustible and noncombustible fractions is necessary at all these sites. The hand-sorted Savannah River combustible wastes are shredded and placed in plastic bags, which are later dropped into the primary burning chamber. At Rocky Flats Plant (RFP) the combustible wastes fed to the agitated-hearth incinerator are similarly packaged, but only minimal or no shredding is needed. The ram-charged rotary kiln requires only rough shredding. At Los Alamos, segregated untreated combustible wastes in cardboard boxes are introduced into a glove-boxed feed line and scanned for gamma radioactivity as well as $x$-rayed for metals and liquids. Any packages exceeding the preset radioactivity limits or containing detectable noncombustibles are manually removed before they can be pushed horizontally into the primary chamber by a ram feeder. Combustible wastes normally contain plastics [e.g., polyvinyl chloride (PVC)] and rubbers that yield corrosive-acid (e.g., $\mathrm{HCl}$ or $\mathrm{H}_{2} \mathrm{SO}_{4}$ ) combustion products that must be removed from the off-gas stream. Again, as mentioned previously, wet scrubbing gives rise to a secondary waste. In this case, it is a radioactive salt solution that may require evaporation to dryness with subsequent incorporation of the dry salt into a solidification agent. A different type of two-chamber, controlled-air incinerator also being tested at RFP (i.e., the fluldized bed) features in-her nelitralization of the combustion products and a dry off-gas system. The fluidizcd bed incineratur lequlres careful sorting of the waste and essentially complete removal of metals from a finely shredded feed. More detailed discussion of the aforementioned incinerator studies is presented below.

Savannah River. The Savannah River nuclear waste incineration study has been in progress since 1974. The emphasis to date has been directed solely toward treating the TRU wastes that have been accumulating 
onsite at the Savannah River Plant (SRP) since about 1965.26 For over 20 months, small pilot-scale incineration studies have been under way using simulated nonradioactive wastes. ${ }^{27}$ The $0.5-\mathrm{kg} / \mathrm{h}$, electrically heated, two-chamber pilot unit is based on earlier work done at Windscale in the United Kingdom. This unit, shown in Fig. 3.3, is ceramic lined throughout, except for the roof of the primary chamber, which is Inconel. The temperature gradient in the oxygen-deficient primary chamber varies from $400^{\circ} \mathrm{C}$ at the entrance to $1000^{\circ} \mathrm{C}$ at the exit, where the ashes drop into a drawer and the pyrolysis gases enter the second horizontal U-shaped chamber below. There they are burned to completion in excess air at $1000^{\circ} \mathrm{C}$. The off-gases are scrubbed, neutralized, dehumidified, and passed through a HEPA filter before discharge to the atmosphere. The fundamental experimental data obtained with this small pilot unit served as the basis for design of a somewhat similar full-scale $(5-\mathrm{kg} / \mathrm{h})$ R\&D incinerator that has been undergoing cold (nonradioactive) shakedown tests since March 1979.28 This larger incinerator has a 15-m tortuous path in the second chamber (afterburner) and a more sophisticated wetscrubber off-gas treatment system. Eventually, this unit will be used as the Incinerator Component Test Facility (ICTF) for the actual waste incinerator, which is expected to be on-line in 1983 for processing the TRU solid waste that is retrievably stored at SRP. The off-gas from the actual waste processing incinerator will pass through a sand filter enroute to the plant stack. 'Development work on the incineration of accumulated $\beta-\gamma$ wastes (including stored solvents) is now under way. A $180-\mathrm{kg} / \mathrm{h}$ nonradioactive prototype $\beta-\gamma$ incinerator of the same general design as the one for TRU, is scheduled to begin test operations late this year. The installation of the radioactive unit is expected to be completed during the early 1980s. In conjunction with the work at Savannah River Laboratory (SRL), supplementary bench-scale studies on combustion kinetics and off-gas composition are being conducted at the University of South Carolina. 29

Los AZamos. The commercially available $45-\mathrm{kg} / \mathrm{h}$ controlled-air incinerator being tested at Los Alamos ${ }^{25}$ is designed with the afterburner located above the primary chamber, as shown in Fig. 3.4. The oxygendeficient primary chamber of the gas-fired unit operates at 800 to $1000^{\circ} \mathrm{C}$, 


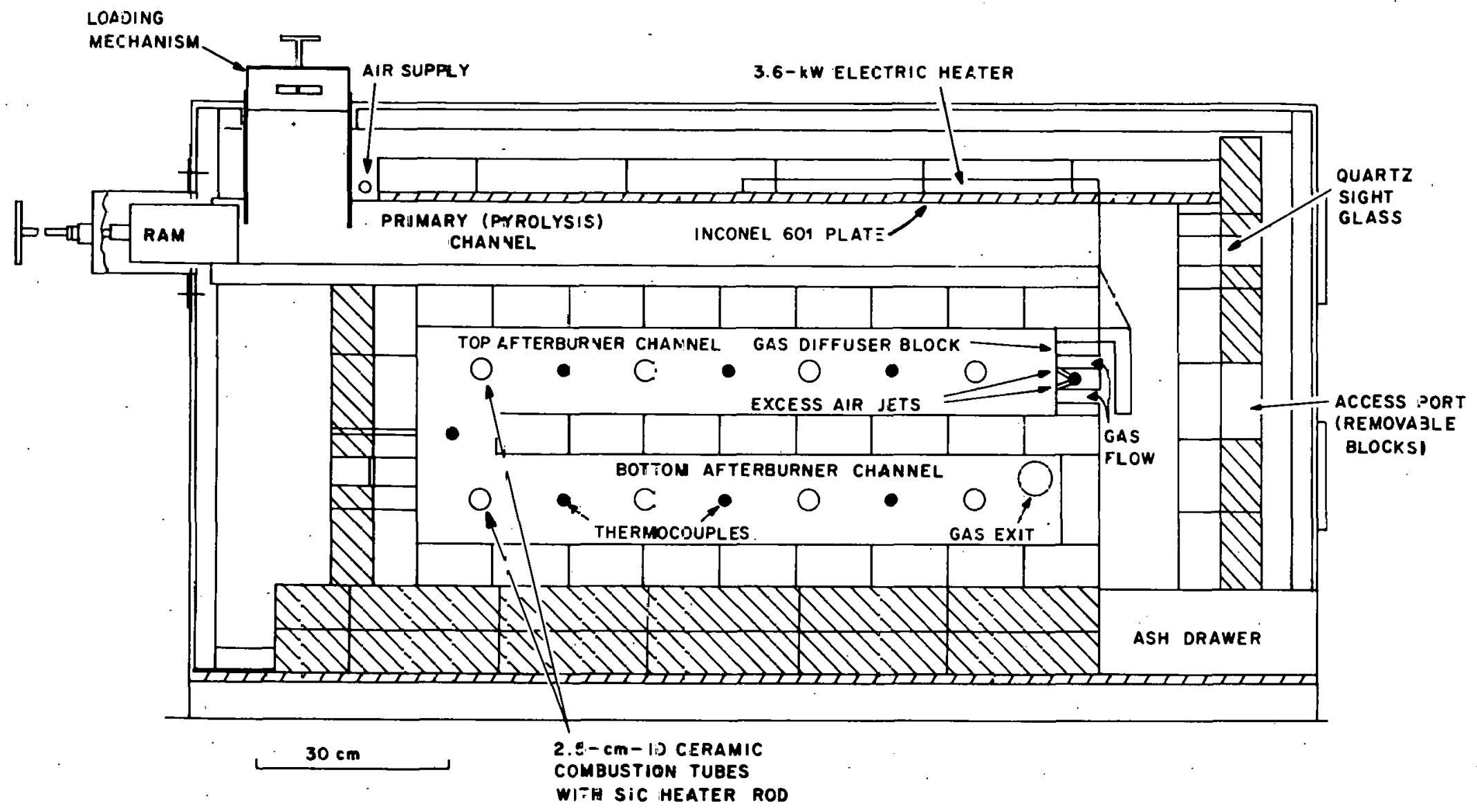

Fig. 3.3. Cross section of Savannah River smai1-piloz-scale incinerator. 


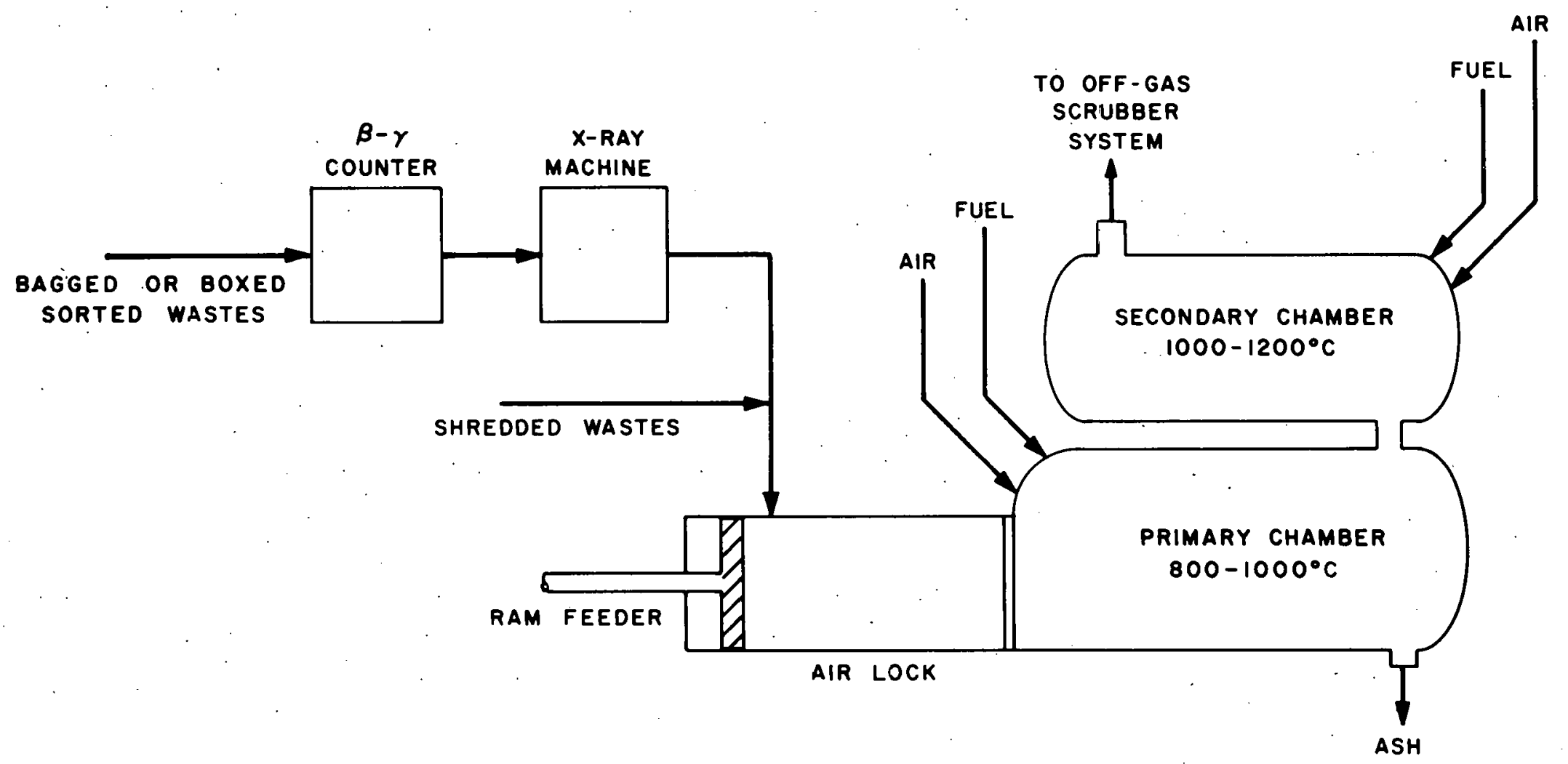

Fig. 3.4. Los Alamos Scientific Laboratory controlled-air incinerator. 
with a limited air input to minimize suspension of particles in the exiting gases. The secondary chamber operates at a nominal temperature of $1100^{\circ} \mathrm{C}$, with an excess of air to complete combustion of the gaseous products generated in the first chamber. To improve combustion, the temperature and the waste, fuel, and air feed rates to the system are controlled. The incinerator lining in both chambers and the hearth are made of refractory material. Because there is no provision for complete positive removal of ash from the primary chamber hearth, extra precautionary measures may sometimes be required to prevent criticality. Rocky Flats. Three types of incinerators have been stultierl and evaluated at the RFP: rotary kiln, agitated hearth, and fluidized bed.1,18,30 The first two types (Fig. 3.5) have some similar features, namely, both have neutral or slightly reducing atmospheres maintained at 600 to $800^{\circ} \mathrm{C}$ in a primary burning chamber followed by a $1000^{\circ} \mathrm{C}$ oxygenrich secondary chamber in which the exhaust gases from the first chamber are burned to completion. Also, both are equipped with wet off-gas treatment systems consisting of appropriate arrangements of venturi scrubbers and final HEPA filters. Furthermore, both have moving mechanical parts and refractory-lined interiors and/or hearths. The rotarykiln and agitated-hearth incinerators are being constructed to treat production-line wastes at the RFP. The fluidized-bed incinerator also has a primary chamber and afterburner, but a flow of gas is used to suspend a mixture of a noncombustible bed material and the radioactive waste during the combustion process. It is used to treat the other LLWs that are generated throughout the site.

(Folary $k i(r)$ ). The diesel tuel-fired, $40-\mathrm{kg} / \mathrm{h}$ rotary-kiln incinerator for high-specific-activity plutonium waste is a demonstration unit now nearing completion. It is based on earlier nnnradioactive pilot-ocalc (2=k.g/h) etudico. After sorting, only ruugh ohredding of the waste llay be required. The dry waste is ram-charged to the inclined, horizontal kiln that rotates at a rate of 1 to $2 \mathrm{rpm}$ around its longitudinal axis [Fig. 3.5(a)]. The waste material is burned as it cascades through the unit, and ash discharge is continuous. This incinerator is also able to accommodate liquids and other wet wastes such as resins and filter sludges. 


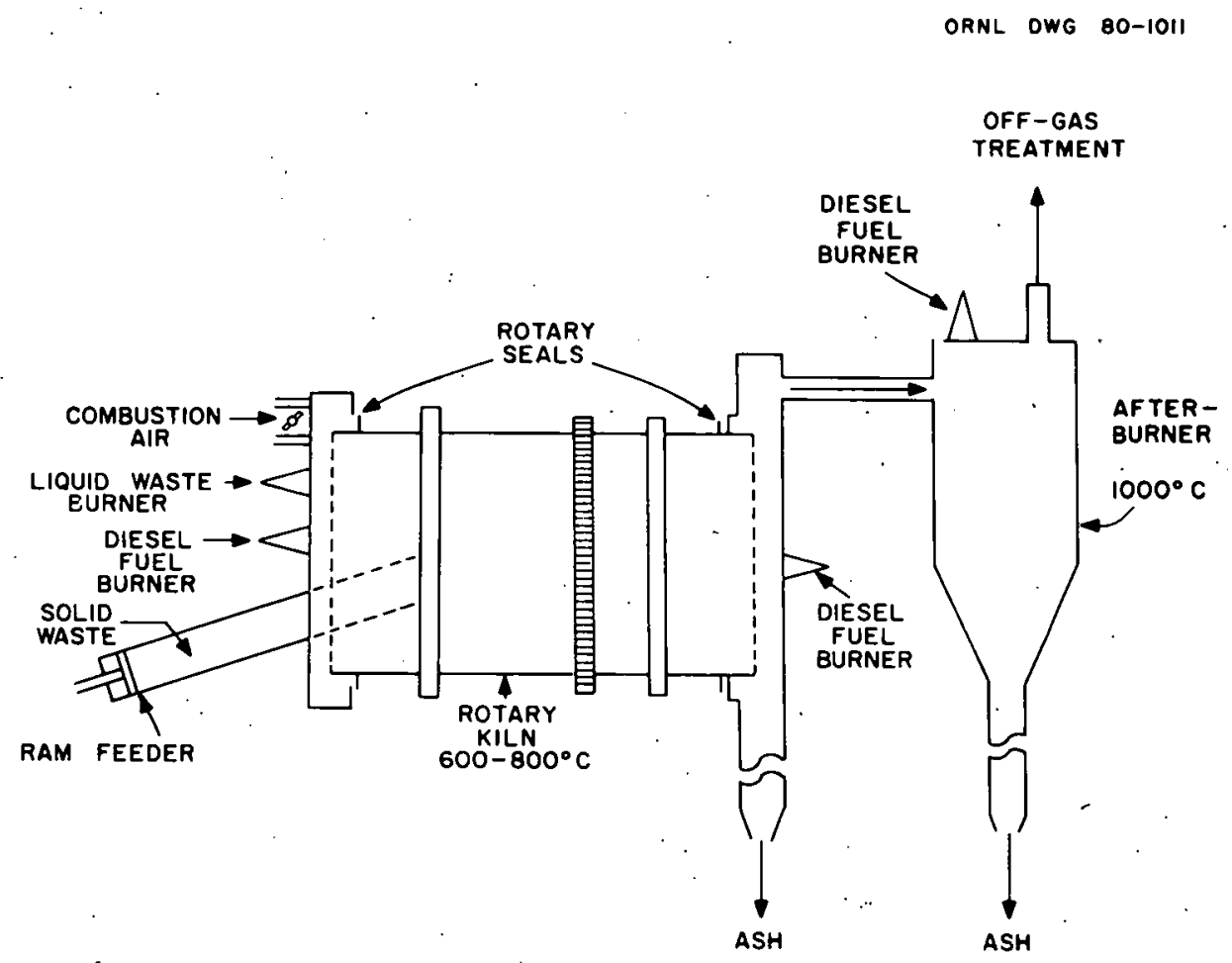

(a) Rotary-kiln incinerator

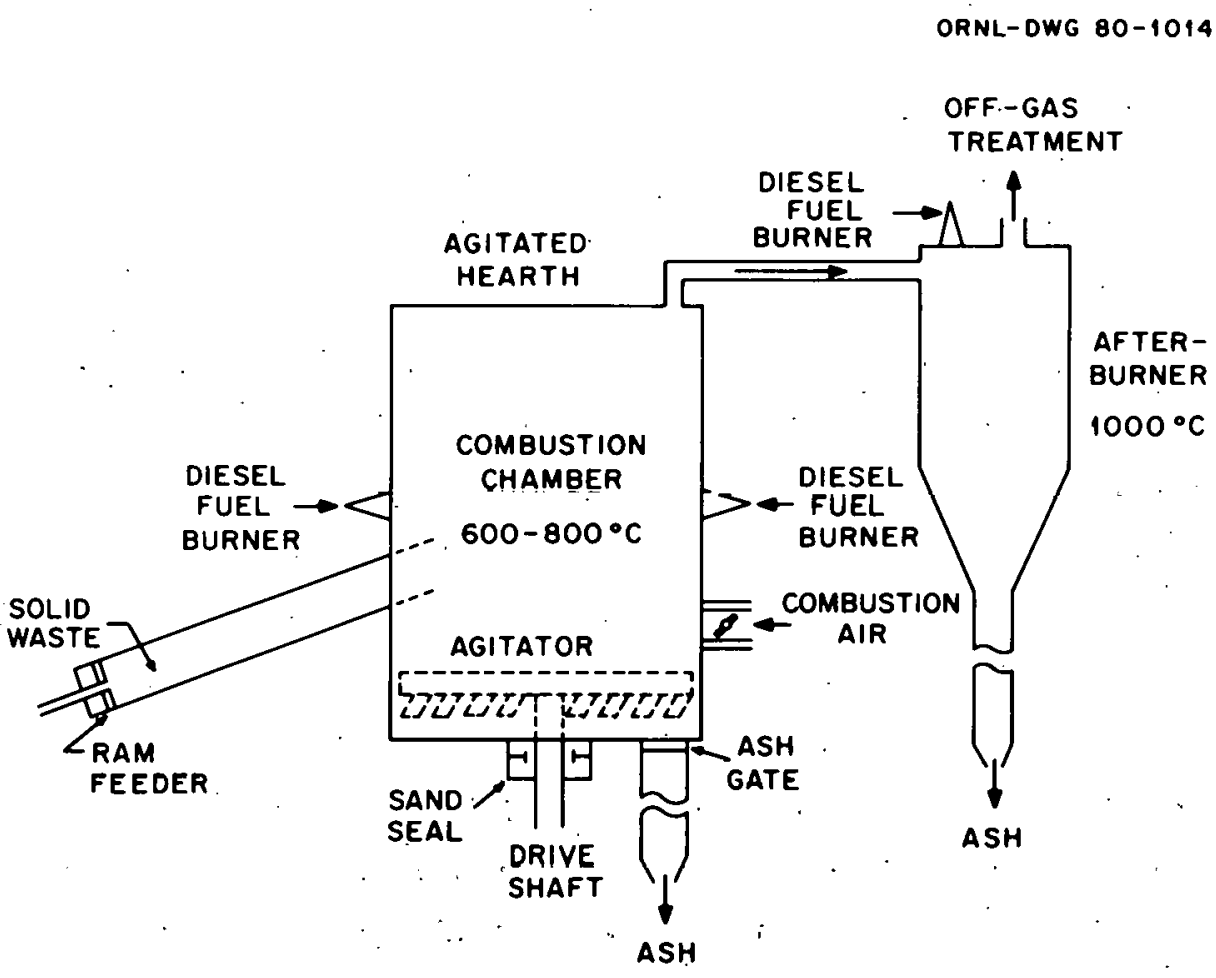

(b) Agitated-hearth incinerator

Fig. 3.5. Rotary-kiln and agitated-hearth incinerators at the Rocky Flats Plant. 
(Agitated hearth). The oil-fired agitated-hearth incinerator with a planned capacity. of $70 \mathrm{~kg} / \mathrm{h}$ operates in a batchwise fashion and is limited to treating only solid wastes containing no more than $0.003 \mathrm{mg}$ of plutonium per gram of waste. Sorting and shredding of the waste are not always necessary. In operation, a single batch consists of $\sim 300 \mathrm{~kg}$ of waste charged to the incinerator in 150 separate $\sim 2-\mathrm{kg}$ packages at 2 -min intervals, thus requiring a $5-\mathrm{h}$ charging time. The waste packages on the hearth are tumbled through the combustion zone by rotating rabble arms [Fig. $3.5(\mathrm{~b})$ ]. Burnout time is $1 \mathrm{~h}$, and another $1 / 2 \mathrm{~h}$ is required for ash removal.

(Fluidized bed). The fluidized-bed incinerator now in operation at the RFP is an $82-\mathrm{kg} / \mathrm{h}$ demonstration unit for burning low-level plutoniumcontaminated waste. The successful operation of a similar 9-kg/h pilot plant ${ }^{31}$ was the basis for design. The unit (Fig. 3.6) incorporates three concepts that set it apart from conventional incineration: (1) nonflaming low-temperature combustion throughout the system; (2) completion of combustion in a catalytic afterburner; and (3) in situ neutralization of acid gases which are end products from combustion of PVC or rubber. ${ }^{32}$ After initially hand-sorting the waste for removal of large-size tramp metal, the combustibles are fed into a low-speed, cutter-type shredder for coarse shredding. Small pieces of tramp metal that were undetected by liand-sorting are shredded along with the combustibles. The coarse shredded material passes through an air classifier for removal of most of the remaining tramp metal. Metal separated by the classifier is collected for disposal. The waste, containing trace amounts of metal, is pneumatically transferred into a second shredder for final sizing prior to incineration. The shredded waste is screw fed into a primary reactor of heated $\mathrm{Na}_{2} \mathrm{CO}_{3}$ granules that are fluidized by a flow nf rompressed air and nitrogen gas. Within the hnt fluidized bed, the wastc is decomposed by partial combustion and pyrolysis, which produces sufficient heat to maintain a bed temperature of $550^{\circ} \mathrm{C}$. The air-tonitrogen ratio of the fluidization gas is adjusted to permit combuation without open-flame burning. Within the fluidized bed of $\mathrm{Na}_{2} \mathrm{CO}_{3}$, in situ neutralization of acid gases is accomplished to produce $\mathrm{NaCl}, \mathrm{CO}_{2}$ gas, 
ORNL OWG 80-1012

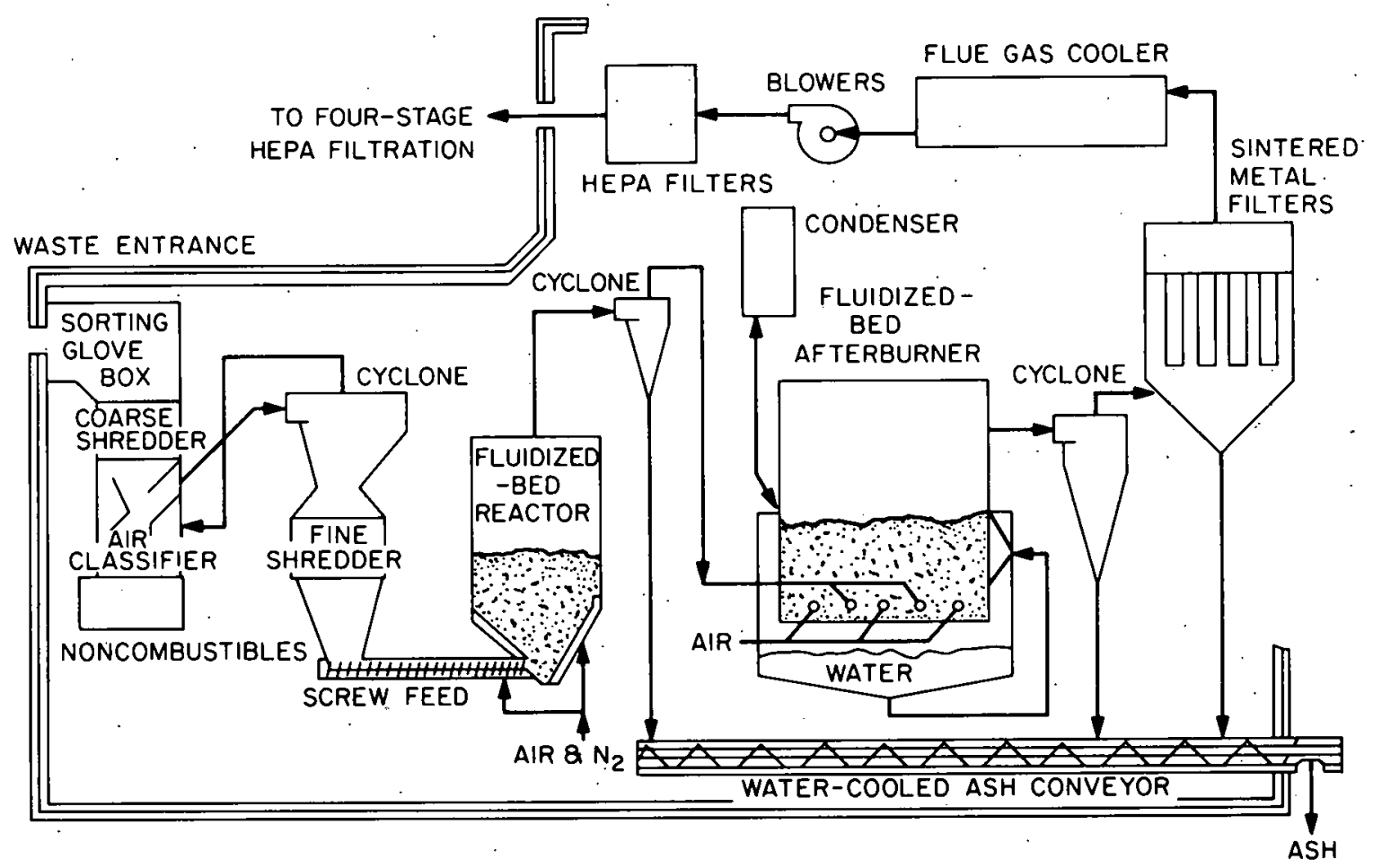

Fig. 3.6. Rocky Flats Plant fluidized-bed incinerator. 
and water vapor. Off-gas from the primary reactor passes into a cyclone separator, where most of the entrained solids are removed hefore the gas is introduced into the catalytic afterburner. In the afterburner chamber, combustion air is added to the gas stream as it passes through a fluidized bed of oxidation catalyst (e.g., chromic oxide). Here, complete combustion is achieved, again without open-flame burning. A bed temperature of $600^{\circ} \mathrm{C}$ is maintained by a water-jacket heat transfer system.

Flue gas leaving the catalytic afterburner contains fly ash, catalyst dust, and small amounts of $\mathrm{Na}_{2} \mathrm{CO}_{3}$ and $\mathrm{NaCl}$ fines, which are removed by passing the gas stream through a second cyclone separator and a bank of sintered metal filters prior to cooling to $50^{\circ} \mathrm{C}$ in a watercooled heat exchanger. The cooled flue gas is pulled into air ejectors (which have replaced the original high-speed blowers) that provide motive force for the process flow and maintain a slightly negative pressure throughout the system. Off-gas from the process passes through banks of HEPA filters before exiting the building. The dust removed by cyclone separation and sintered-metal filtration is cooled in a screw conveyor that transfers the residue into a drum for dispnsal. Testing of the demonstration unit with simulated wastc was begun in June 1978 . By the end of June 1979, two cold tests totaling nearly $80 \mathrm{~h}$ and a test of 106-h duration using contaminated waste had been completed. To date, solid materials, including PVC, polyethylene, paper. rubber, wood, leather, cloth, HEPA filters, reverse osmosịs membranes, and ion exchange resins, as well as liquids including naphtha, hydrazine, tributyl phosphate (IBP), oil, methylene chloride, methyl cellulose, and other waste chemicals, have been burned. ${ }^{33}$ The data obtained with the demonstration unit will provide the scale-up information needed for production plant desigu. Although the dry neutralization and off-gas cleanup systems of the fluidized-bed incinerator eliminate the secondary wastes associated with wet scrubbing systems, the combustion product is a mixture of salts, catalyst, and ashes. Also, these ashes may havc a higher carbon content than those from the other incinerators described above. One of the main advantages of the fluidized bed is that stainless steel 
construction without need for refractory lining is completely adequate because the operating temperatures are relatively low.

3.1.2.3 Acid-digestion incinerator. Incineration of combustible wastes by acid digestion is being developed and tested at Hanford Engineering Development Laboratory (HEDL). 1 In this process, the combustible materials are converted to gaseous end products (e.g., $\mathrm{CO}_{2}, \mathrm{HCl}$, and $\mathrm{H}_{2} \mathrm{O}$ ) and insoluble sulfate or oxide residues by digestion in hot concentrated $\mathrm{H}_{2} \mathrm{SO}_{4}$ in the presence of $\mathrm{HNO}_{3}$ oxidant. Containment vessels are constructed of glass or are glass- or Teflon-lined. ${ }^{4}$ The Acid Digestion Test Unit (ADTU) pilot plant is a full-scale, albeit abbreviated, model of the Radioactive Acid Digestion Test Unit (RADTU) that has been constructed at the Hanford 200-Area waste treatment facility. The RADTU, now being upgraded from $100-$ to $240-\mathrm{kg} / \mathrm{d}$ capcity, is equipped with an acid recycle system which the ADTU does not yet have. The scope of the RADTU mission has been changed from strictly demonstration to a joint $R \& D /$ production function. ${ }^{34}$ It will eventually be used to process defense TRU waste from the Rockwel1. Z-Plant as well as wastes from the other contractors at the Hanford site. While the RADTU is being revised and tested, development work is continuing at the ADTU pilot plant.

In the acid-digestion process, large noncombustible and potentially hazardous materials are removed from the feed waste by hand. The combustible waste is then shredded and pneumatically sorted to eliminate any remaining noncombustible metals. The shredded combustible solids are introduced into the glass-1ined digester by. an extrusion feeder that delivers a $200-\mathrm{g}$ batch every 1 to $2 \mathrm{~min}$ (i.e., $\simeq 10 \mathrm{~kg} / \mathrm{h}$ ). The liquid volume in the pilot plant unit is approximately 90 \& ( $25 \mathrm{gai}$ ) and is comprised of concentrated $\mathrm{H}_{2} \mathrm{SO}_{4}$ at $250^{\circ} \mathrm{C}$, to which $\mathrm{HNO}_{3}$ is slowly added. This mixture chars and oxidizes the solid wastes and does not nitrate them under these conditions of temperature and $\mathrm{H}_{2} \mathrm{SO}_{4}$-to- $\mathrm{HNO}_{3}$ ratios. The system operates under slight vacuum [i.e., about $-18 \mathrm{~cm}(-7 \mathrm{in.}) \mathrm{H}_{2} \mathrm{O}$ above the digester to $-51 \mathrm{~cm} \cdot(-20$ in. $) \mathrm{H}_{2} \mathrm{O}$ in the alkaline off-gas scrubber]. The "Standard B Waste" used in testing contains neoprene, gum rubber, polyethylene, PVC, and fluorinated/sulfonated polyethylene. 
In addition to such combustible solids, some organic liquids can also be burned. The nonvolatile inorganics form insoluble oxides and/or sulfate salts; the organics are converted to $\mathrm{CO}_{2}, \mathrm{H}_{2} \mathrm{O}$, and other gaseous products. The acid reaction end products $-\mathrm{SO}_{\mathrm{x}}$ and $\mathrm{NO}_{\mathrm{x}}-$ and other volatile reaction products (e.g., $\mathrm{HCl}$ from $\mathrm{PVC}$ ) are removed from the off-gas stream with an aqueous alkaline scrubber. The off-gas discharged to the atmosphere meets local emission requirements, but a larger system might require catalytic treatment. The liquid scrubber, as in previously mentioned cases, will necessarily be a source of secondary waste. The acidified scrubber solution can, however, be distilled to recover the $\mathrm{HNO}_{3}$ and $\mathrm{H}_{2} \mathrm{SO}_{4}$ for recycle to the digcater vessel. The digester, as shown in Fig. 3.7, is actually two separate vessels in annular configuration [77.2-cm 0.D., 63.5-cm I.D. (30-in. 0.D., 25-in. I.D.)] because criticality must be taken into account when TRU-contaminated wastes are treated; a single vessel could be used for non-TRU wastes. The pilot-plant reactor vessel is filled or emptied only about once each year. The digester acid ( $20 \mathrm{wt} \%$ solids) is evaporated to dryness in an expendable light-weight stainless steel pot, and the $\mathrm{H}_{2} \mathrm{SO}_{4}$ is recovered for reuse. The acid digestion decontamination factors (DFs) obtained for $\mathrm{I}, \mathrm{Ru}$, and $\mathrm{Cs}$ are 21000 , and there is no fly ash, tar, or soot in the residue.

The rapid evolution of gas that occurs with oxidation of some organics can cause severe foaming. However, this condition may be alleviated by agitation with air, controlled feed rate, and/or higher temperacure. Foaming was a development problem, especially in the incineration of ion exchange resins, but spent anion and cation resins have both been oxidized successfully by controlling the feed rate. The acid digestion of chemically or radin1yrically dogradcd resins is beluy scouted on subcontract, and the associatcd safety questiuns are being analyzed and evaluated. The acid digester could probably handle lubricating oils by introducing them under the liquid surface to prevent flash-off, thus increasing residence time. Some laboratory studies on the destruction of non-paraffin hydrocarbons (e.g., hexone and TBP) are under way. To date, the HEDL studies have been directed mainly 
ORNL-DWG $80-1010$

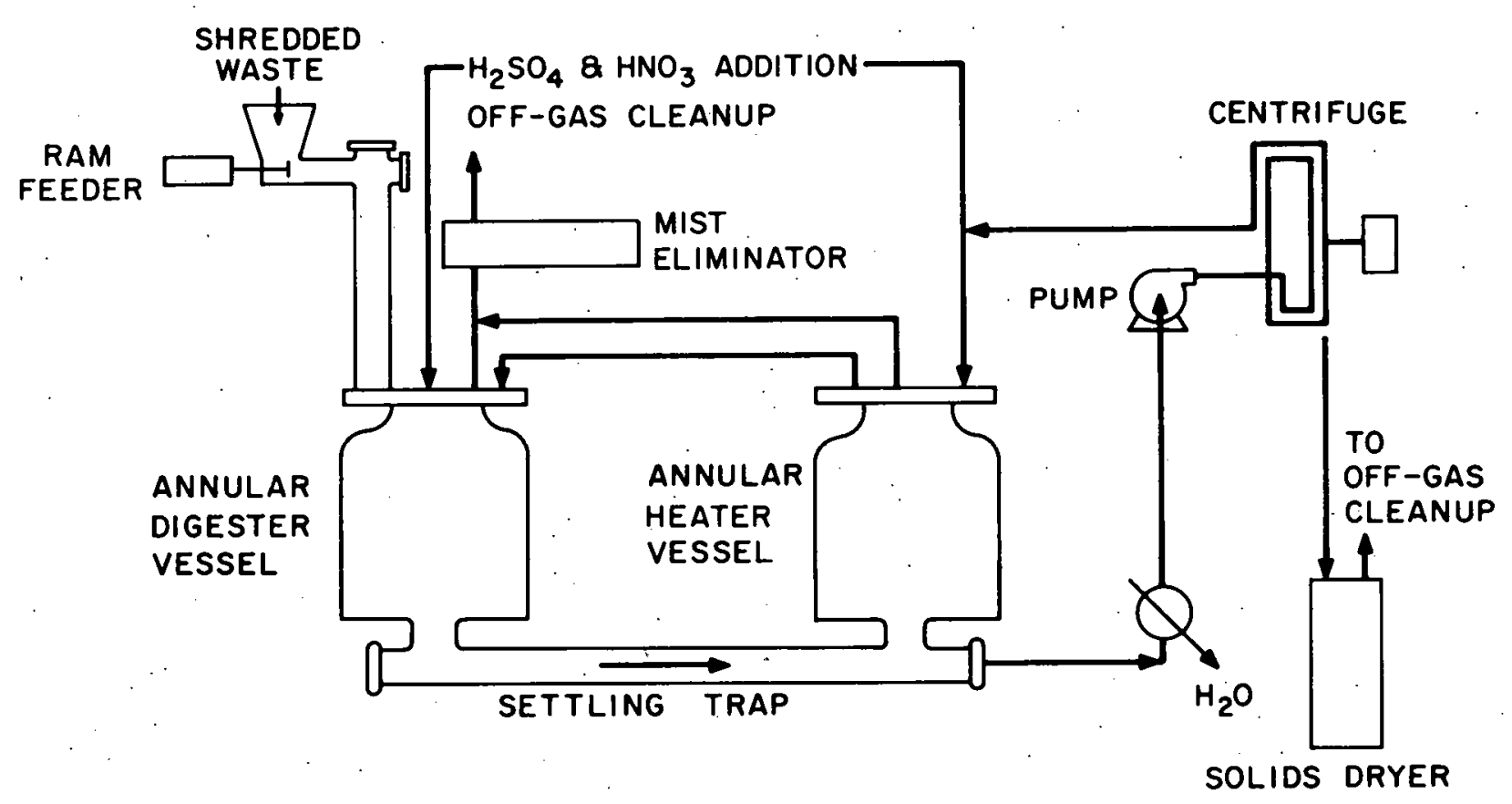
unit.

Fig. 3.7. Hanford Engineering Development Laboratory acid-digestion 
toward treating TRU wastes, which impose restrictions on throughput because of criticality. If these studies were directed toward LLW, instead of TRU waste, throughput could be significantly increased because criticality would not be a problem.

\subsubsection{Molten-salt incinerator. A molten-salt incinerator for} burning radioactive LLW at the INEL Radioactive Waste Management Complex (RWMC) was designed by Atomics International. The basis for design included considerable bench-scale and ful1-scale pilot-plant studies using simulated nonradioactive waste. ${ }^{35}$. The production unit, which was never built, is shown in Fig. 3.8. It was designed to handle $50 \mathrm{~kg} / \mathrm{h}$ of finely shredded dry waste fed to the combustor through a pneumatis conveying line. The combustion chamber of the molten-salt incinerator consists of an alumina-brick-lined cylindrical vessel containing molten $\mathrm{Na}_{2} \mathrm{CO}_{3}$ (plus some $\mathrm{Na}_{2} \mathrm{SO}_{4}$ catalyst) ${ }^{18}$ at 800 to $850^{\circ} \mathrm{C}$. An off-gas system consisting of a spray cooler, bag house, and HEPA filters is used. The start-up fuel is propane, but provision has been made for coke addition to maintain temperature during operation. Acid end products from waste combustion are neutralized and retained in the molten salt along with the solid combustion residues. Organic materials are oxidized to $\mathrm{CO}_{2}$ and $\mathrm{H}_{2} \mathrm{U}$. 'l'he ash content gradually builds up in the salt bath, thus necessitating periodic drainage and replacement of the salt. The ashladen salt can be fused-cast into drums for disposal or, alternatively, the salt can be recovered for reuse, with the insoluble inciñerator ash being incorporated into a.glass or other solidification agent. A stury 36 determined that the molten-salt incinerator would be unsuitahle for treating retrieved TRU waste at INEL, primarily because of its inability to handle large noncombustible items or significant amounts of soil.

\subsubsection{Slagging-pyrolysis incinerator. The slagging-pyrolysis} incinerator (SPI) has been selected as the most likely to be used for treating retrieved TRU waste at INEL. ${ }^{37,38}$ It is designed to handle large quantities $\geqslant 64$ metric tons/day), requires little or no waste sorting, and can accept relatively large amounts of soil in the waste feed. The TRU waste will be mixed with coal and bark in proportions that will 
ORNL DWG 80-1007

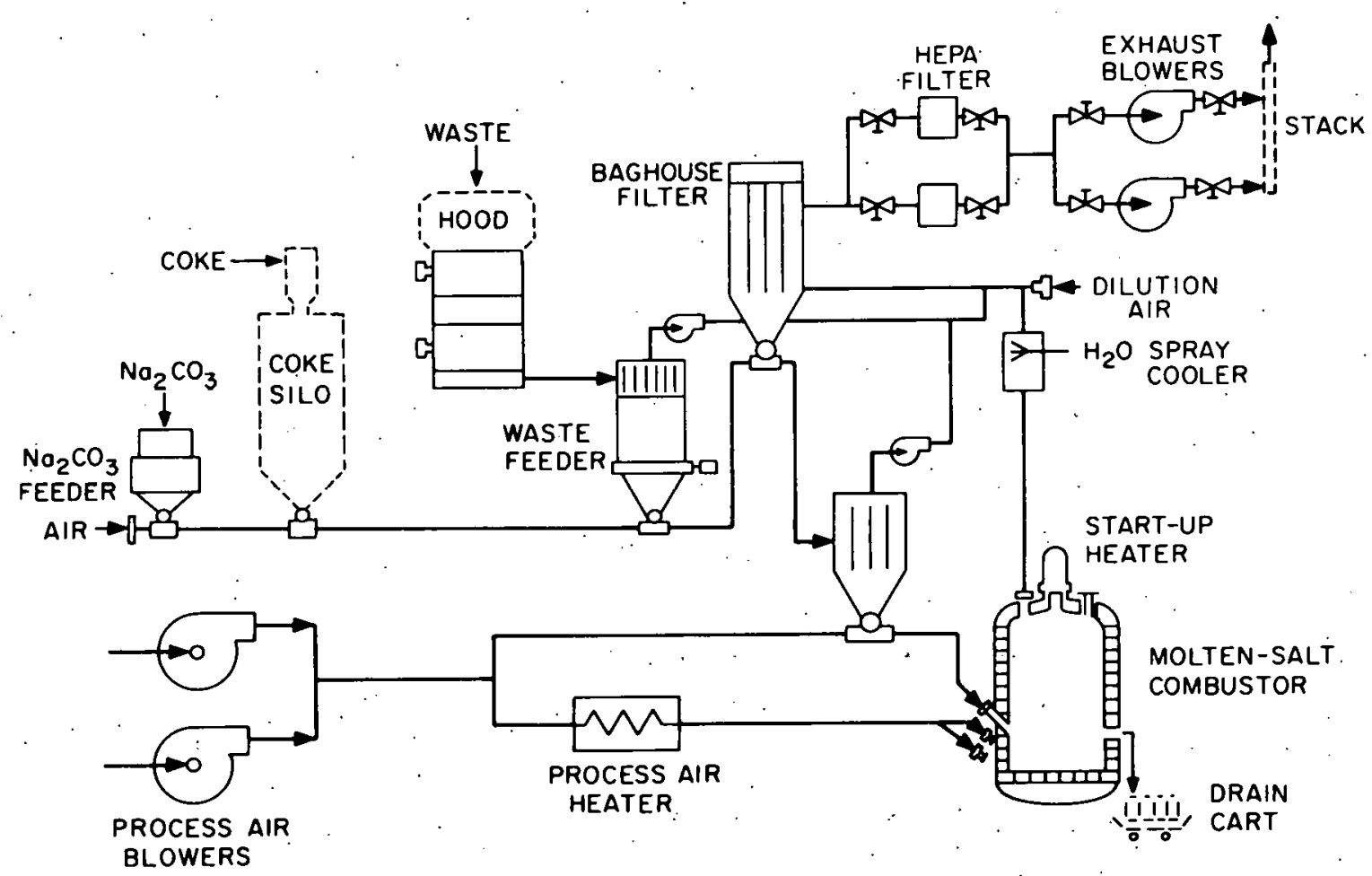

Fig. 3.8, Schematic of the Atomics International molten-salt combustion system. 
roughly approximate the heat of combustion of ordinary municipal waste (i.e., the feedstock will be $47 \%$ TRU waste, 33\% bark, and $20 \%$ high sulfur coal). ${ }^{37}$ The Andco-Torrax unit under consideration for INEL has been demonstrated using municipal refuse. ${ }^{18}$. It receives the waste charge through a large port at the top, as shown in Fig. 3.9. As the waste material is channeled down toward the hearth at the bottom, it passes through three zones: first, drying; second, pyrolyzing; and third, combustion/melting. Stoichiometric or slightly deficient preheated air is introduced at the hearth through nozzles, while the slag is drawn off and quenched in a water tank. The gases formed in the pyrolysis zone are routed to an oxygen-rich secondary chamber (afterburner) for complete combustion. Operating temperatures ${ }^{18}$ in the pyrolysis zone range from 800 to $1400^{\circ} \mathrm{C}$; afterburner temperature is 1200 to $1425^{\circ} \mathrm{C}$. Maximum temperature in the combustion/melting zone is $1650^{\circ} \mathrm{C}$. Wet scrubbing and/or dry off-gas cleanup systems have been used with the SPI in municipal refuse burning, and no significant problems are anticipated in the dry off-gas system proposed for the INEL unit. 30,38 The presence of significant quantities of lead in the waste, however, could cause some deposition problems because of its volatility and low melting point. 30 some preliminary testing of the slagging properties of simulated INEL retrieved waste is being negotiated with the SCK/CEN Nuclear Energy Research Center in Mo1, Belgium. ${ }^{38}$ The slagging incinerator at Mol is of a different design, 39 but the product material shni1d be similar. Further large-scale testing with nonradioactive simulated waste is planned for this year in the Andco-Torrax unit being installed for mun1cipal waste treatment at Disney World. 38 . The Idaho waste processing facility is scheduled for completion in 1989.

\subsubsection{Molten-glass incinerator (electromelter or joule-heated} furnace). Technology for producing high-quality glasses by using the electrical conductivity of the molten glass at elcvated temperatures to maintaln the temperature of the melt (i.e., joule heating) has been well escablished. Production units with capacities as large as 140 tons per day have been operated successfully for many years. ${ }^{25}$ At start-up, a refractory-lined vessel is charged with pieces of glass or glass frit. Either a sacrificial wire mounted between the two electrodes that protrude 


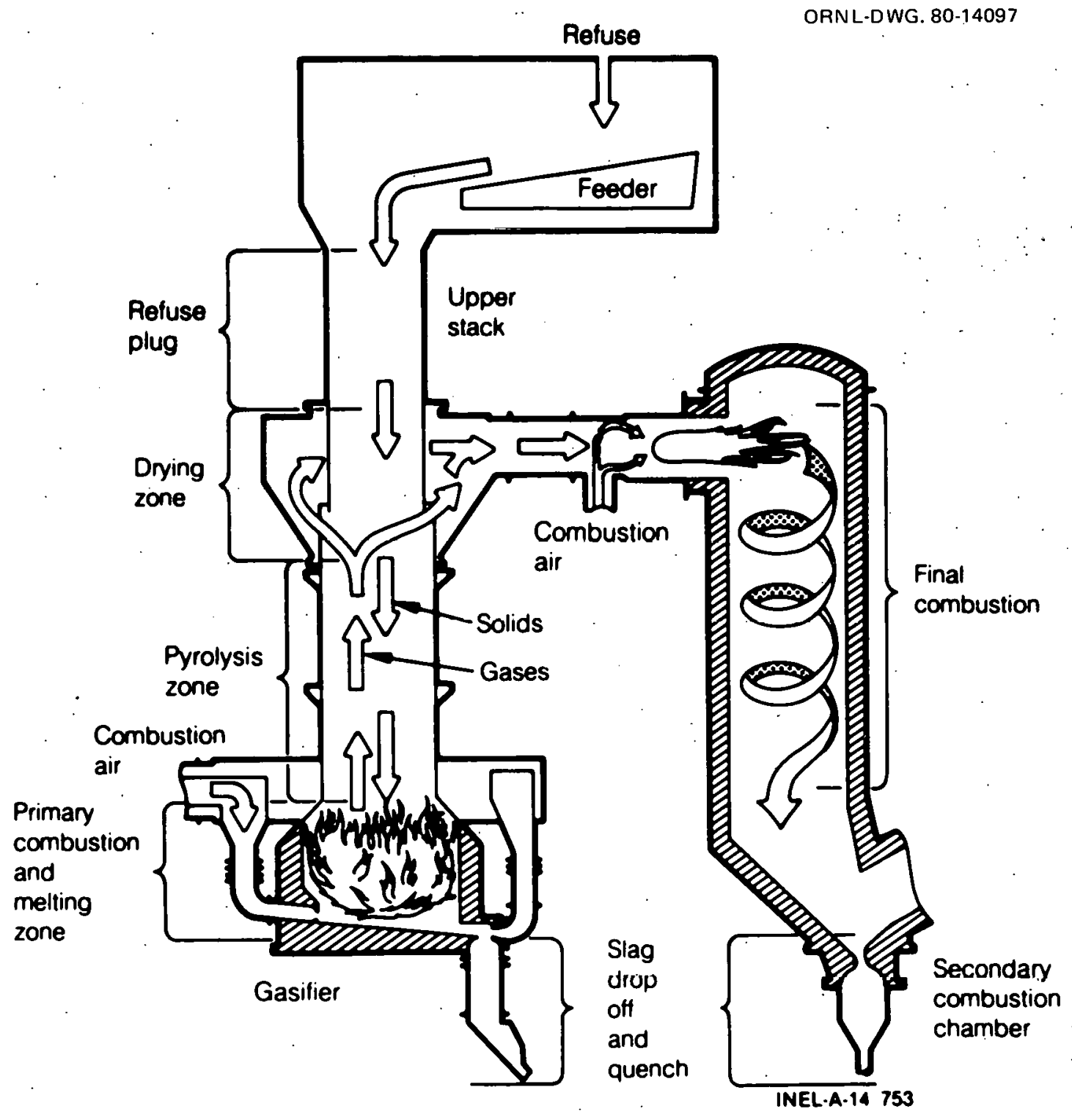

Fig. 3.9. Andco-Torrax slagging-pyrolysis incinerator. 
into the glass layer or a removable resistance heater provides the necessary heat for initiating melting of the glass. The glass charge heats slowly to a temperature at which the melt becomes electrically conducting. At this point, the immersed electrodes alone provide the current necessary to maintain self-sustaining joule heating. The temperature of the bath reaches $\sim 1000$ to $1250^{\circ} \mathrm{C}$ during operation. As material is burned in the melt, most of the ash produced is sorbed into the molten glass, thus gradually increasing the liquid level. The molten glass and waste mixture is removed thrnugh pither a gravity drain or a simple overflow weir into a collection container where it cools and solidifies. A joule-heating furnace has been used at Battelle Pacific Northwest Laboratory (BPNL) to successfully demonstrate the technical feasibility of vitrifying average Hanford defense waste calcine by this method. 40 A similar melter is being used at Savannah Kiver in development studies ${ }^{41}$ on the immobilization of calcined SRP waste sludges. Only recently has there been interest in applying electromelter technology to the disposal of LLW. Some sma11-scale tests have been carried out with materials typically found in LLW (e.g., toluene, paper, wood, concrete, rubber, plastics, scrap glass, and metal). 42 An electromelt incinerator that should be capable of burning up to $\sim 112 \mathrm{~kg}$ of toluene per hour or $225 \mathrm{~kg}$ of cellulosic. wastes per hour is now under construction. 25 . Calculations indicate that a 140 -ton/d glass furnace could accept up to 700 tons of waste feed per ray. ${ }^{25}$ A conceptual flowsheet of a commercial electromelter system that has been proposed $^{42}$ for LLW treatment is shown in Fig. 3.10. Many design parameters for treating LLW in a molten-glass incinerator are still unknown or unavailable (e.g., afterburner and off-gas cleaning requirements and capacity for noncombustibles). Therefore, the design of a complete test luنp willı all the necessary off-gas equipment and monitoring devices for temperatures, pressures, particulate carryover, etc., has not been established. This is needed for determining overall system reliability. Development studies now under way should provide the information needed to evaluate the role of electromelt incineration in LLW treatment. 
ORNL DWG 80-1063

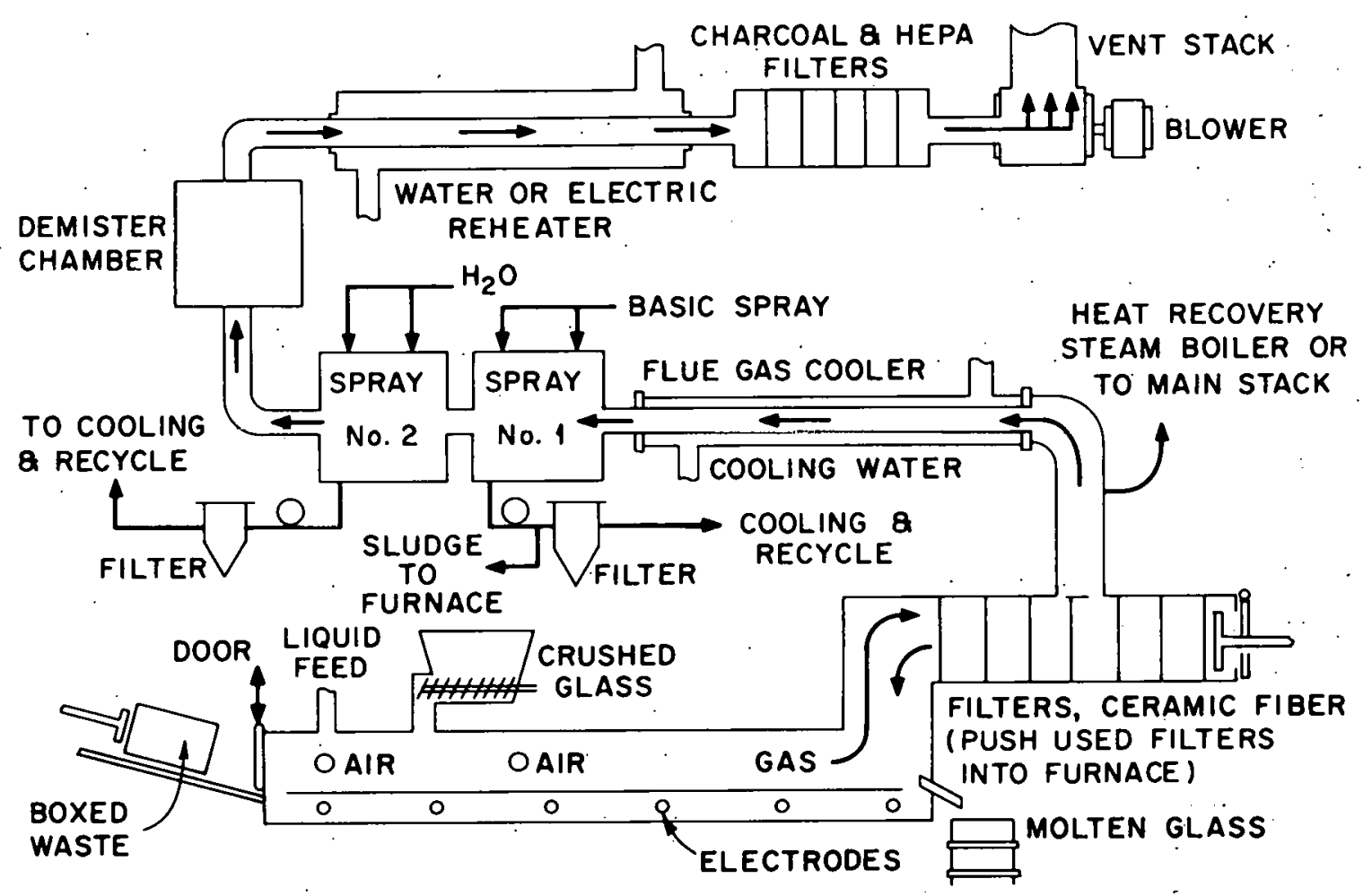

Fig. 3.10. Sketch of the Penberthy molten-glass incinerator (electromelter) system proposed fur treating low-level waste.

(Source: Penberthy Electromelt International, Inc., Seattle, Wash.). 
3.1.2.7 Other incinerators at DOE sites. Even though they have no R\&D program for studying incineration, some DOE sițes usse commercially available incinerators for burning at least a portion of their wastes. An incinerator that incorporated LASL-supplied equipment specifications and operating information is now in operation at Lawrence Livermore Laboratory (LLL). This incinerator is being used for disposal of pathological and other nonradioactive hazardous wastes. ${ }^{25}$ At BNL, a vertical three-stage incinerator with a maximum feed capacity of $0125 \mathrm{~kg} / \mathrm{h}$ was used to burn trash along with scintillation vials containing organics such as $p$-dioxane or toluene. Scintillation fluids and small amounts of other highly flammable, potentially explosive, or toxic waste chemicals have been burned at BNL since 1973.43 Inti:T .Tan. 1, 1980, when the Environmental Protection Agency (EPA) forced shutdown of the incinerator because of lack of proper licensing, $\sim 100 \mathrm{~kg}$ of scintillation vials, constituting $<10 \%$ of the total feedstock, were being burned each week. In the first chamber of the BNL incinerator, which is located near the bottom of the unit, pyrolysis takes place at relatively low temperature in a slightly oxygen-deficient atmosphere. The pyrolysis gases then enter the second chamber immediately above and are burned to rnmpletion at a somewhat higher temperature in the presence of a slight excess of oxygen. The third chamber at the top is only for retention of the offgases just before direct discharge to the atmosphere. The gaseous effluents must meet the New York State Ambient Air Quality Standards, and particulate emission has never been adequately measured. Before shutdown, attempts were being made to eliminate the particulate problem because $1 t$ precluded issuance of a license to burn animal carcasses. When in operation, the glassy ash from the incineration process drops into a collection box at the very bottom of the unit. The ash was being used to fill voids in offste shipments of radioactive waste.

\subsubsection{Fluidized-bed dryer/incinerator. A fluidized-bed dryer/} inclinerator that uses separate vessels for drying and incineration (Fig. 3.11) has been developed by Aerojet Energy Conversion Company. 44 In this system, aqueous waste is sprayed into the dryer vessel containing a starter bed of granular material, such as fine sand, which is fluidized 


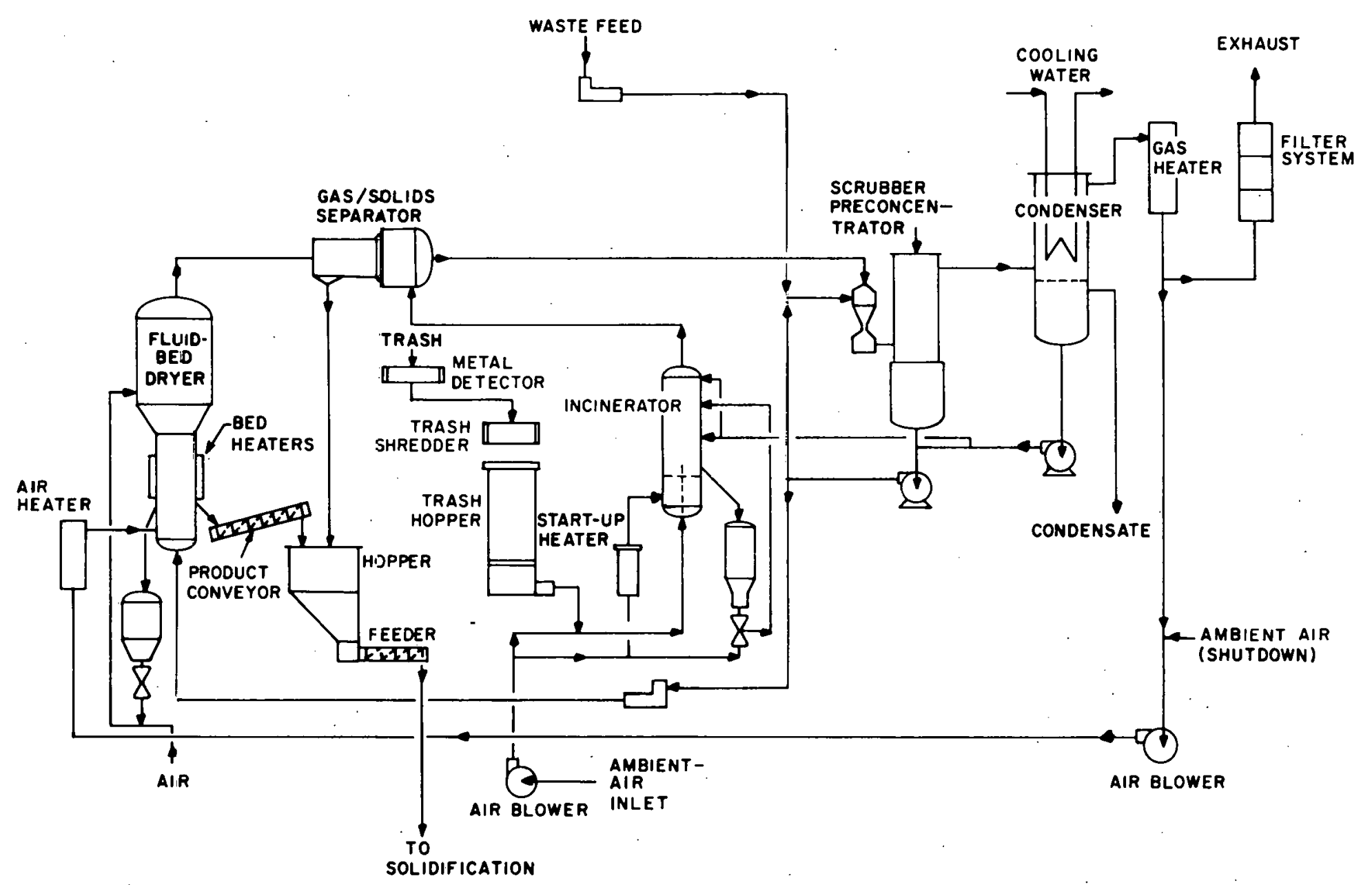

Fig. 3.11. Flow diagram of the fluidized-bed dryer/incinerator system developed by the Aerojet Energy Conversion Company. 
by a stream of preheated air. The bed is further electrically heated to an operating temperature of $\sim 450$ to $480^{\circ} \mathrm{C}$. Water is evaporated, and salts that are unstable at these temperatures are decomposed, leaving anhydrous, free-flowing solids in the bed. The off-gas from the calciner vessel contains steam and other gases as well as fine solid particles. A cyclone separates most of these solids from the gases and drops them into a product storage hopper. To maintain a constant bed depth as more waste is dried, a portion of the bed is periodically removed through a screw conveyor, cooled, and moved to the product storage hopper. Hot gases from the cyclone pass through a wet scrubber/waste preconcentrator, where heat from the gases is used to preconcentrate feed to the dryer up. to $\sim 28$ wt $\%$ solids. At the same time, virtually all remaining particulates are scrubbed from the gases. The off-gas from the preconcentrator then passes through a condenser. Most of the off-gas (air at this point) is routed through a gas heater prior to recompression and recycle to the dryer. A small portion of the exhaust air is continuously bled from the system via a HEPA filter, a charcoal bed, and a final HEPA filter, then monitored for radiation, and discharged to the atmosphere. While aqueous wastes are volume-reduced in the fluidized-bed dryer, dry combustible wastes and contaminated oils are volume-reduced by burning in a separate fluidized-bed incinerator (Fig. 3.11). The bed in the incinerator $1 \mathrm{~s}$, as in the dryer, an inert material such as sand. The bed is preheated to $\sim 540^{\circ} \mathrm{C}$ with hot air. Combustible wastes pass through a metal detector, are shredded, and blown into the incinerator. Combustion takes place at a temperature of $\sim 790^{\circ} \mathrm{C}$. Both solid and gaseous products of combustion are removed as an overhead stream and are treated in the off-gas system described above for the fluidized-bed dryer. Since essentially no material is added to the bed, no removal of bed material during operation is normally required.

A full-scale, prototype fluidized-bed dryer/incinerator has operated successfully for over $3500 \mathrm{~h}$ with nonradioactive aqueous wastes (e.g., solutions of $\mathrm{Na}_{2} \mathrm{SO}_{4}$ and $\mathrm{Na}_{2} \mathrm{~B}_{4} \mathrm{O}_{7}$ ) and for over $500 \mathrm{~h}$ on combustible wastes. 44 This unit can dry aqueous wastes at a rate of 75 to $450 \mathrm{l} / \mathrm{h}$ and burn dry combustible wastes at $2220 \mathrm{~kg} / \mathrm{h}$. Volume reduction factors 
achieved are: 5 for 20 wt $\% \mathrm{Na}_{2} \mathrm{SO}_{4}$ solutions; 10 for 12 wt $\% \mathrm{H}_{3} \mathrm{BO}_{3}$ solutions; and 70 for uncompacted, dry, compressible wastes. The DF for ${ }^{131} \mathrm{I}$ across the dryer and off-gas cleanup system was determined to be $10^{5}$ for all chemical forms of iodine tested. 44 Several units similar to the prototype have been ordered for LWRs, but these will not be operational for 2 to $5 \mathrm{yr}$.

\subsubsection{Fluidized-bed calciner/incinerator. A VR system that is} both a fluidized-bed calciner and incinerator (Fig. 3.12) has been developed by Energy, Incorporated/Newport News Industrial Corporation. 44 Liquid (aqueous and organic) and dry, combustible solid wastes, as well as dewatered resins, have been treated in a prototype unit. The system is similar in principle to the one described in Sect. 3.1.2.8 (Figs. 3.11 and 3.12). However, three major differences do exist: (1) the Newport News unit uses a single vessel as calciner or incinerator; (2) it uses in-bed combustion to heat the bed; and (3) it operates under slight vacuum, whereas the Aerojet unit operates under slight pressure. Kerosene, or a similar fuel, is injected into the bed and burned. By using an excess of fluidizing air, essentially all of the solid products formed during calcination at $2400^{\circ} \mathrm{C}$ or incineration at $21000^{\circ} \mathrm{C}$ are removed from the bed with the off-gas. The bulk of these solids is removed from the off-gas in a dry cyclone and falls into a product storage hopper. Particulate solids remaining in the off-gas stream are removed by a quench tank and wet cyclone/scrubber arrangement. The off-gas passes through a condenser and demister to remove residual moisture before passing through a HEPA filter, an iodine sorber, and a final HEPA filter prior to discharge.

The commercial nuclear power industry has no operating experience with the fluidized-bed calciner/incinerator. Several units have been ordered for installation at LWRs. These units are designed to treat $\sim 90 \mathrm{~kg}$ of dewatered resins per hour; $\sim 65 \mathrm{~kg}$ of shredded, dry combustible wastes per hour; or $\sim 200 \mathrm{~kg}$ of $25 \mathrm{wt} \% \mathrm{Na}_{2} \mathrm{SO}_{4}$ or $12 \mathrm{wt} \%$ neutralized $\mathrm{H}_{3} \mathrm{BO}_{3}$ solutions per hour. Volume reduction factors expected are: 30 to 40 for dewatered resins; 80 for shredded, dry, combustible wastes; and 6 to 8 for 25 wt $\% \mathrm{Na}_{2} \mathrm{SO}_{4}$ and 12 wt $\% \mathrm{H}_{3} \mathrm{BO}_{3}$ solutions. Although no commercial 


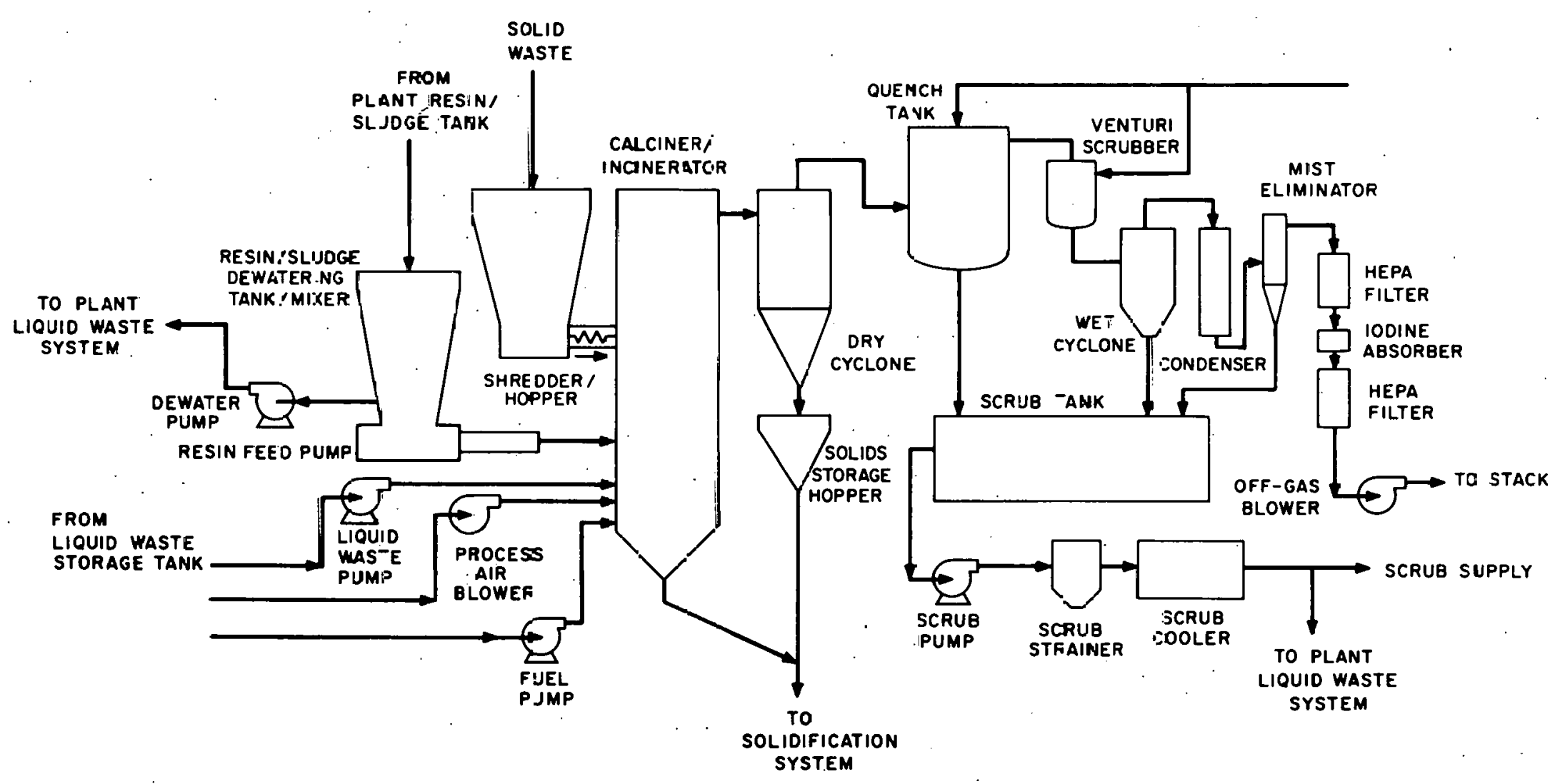

Fig. 3.12. Flow diagram of the fluidized-bed incinerator/calciner system developed by Energy, Inc., and Newpozt-News Industria- Corporation. (Adapted from draing provided by courtesy of Newport-News Industrial Corporation.) 
nuclear power industry experience exists with such units, considerable experience has been gained at INEL where a similar type of calciner is used to treat high-level radioactive aqueous wastes. 45

\subsubsection{Summary of the development status of waste incinerators}

Brief descriptions of several other incinerators that have been or are being used in the United States and abroad for radioactive wastes are listed in Appendix A. The development status of the incinerators described in Sect. 3.1 .2 and that of some other commercially available incinerators are summarized in Table 3.2. Only the moving-grate incinerator has not been applied to treating radioactive wastes. Most of the units listed here have been tested only for TRU contaminated wastes, and further off-gas system studies would probably be needed before they could be used for $\beta-\gamma$ wastes. Units designed for plutonium (or uranium) recovery operate at relatively low temperatures to prevent formation of refractory oxides and may not be suitable for some other applications. Not all incinerators are amenable to treating wet wastes and/or medical wastes that contain organic solids or solvents. Some typical VR factors that can be expected for incinerator units which are suitable for treating radioactive LLW are given in Table 3.3. Volume reduction factors of 20 to 45 are achievable with most compacted dry combustible wastes. Higher VR factors (i.e., 70 to 80 ) have been reported for noncompacted wastes burned in the fluidized-bed incinerators of the types described in Sects. 3.1.2.8 and 3.1.2.9. As noted in the table, volume reduction of some noncombustibles may be realized by melting instead of incineration. Wet solid wastes, when incinerated, will usually be reduced in volume by a factor between 2 and 20, depending on the basic chemical composition of the waste. Aqueous concentrates, which are actually calcined rather than incinerated, have shown that volume reduction factors in the range of 5 to 10 can be readily attained. Oils and other organic liquids normally show volume reduction factors $>100$ when burned. At the present time, only a small fraction of the wet LLW generated in the nuclear industry in the United States is actually incinerated. The current treatment methods used in either storing these wastes or in preparing them for burial are discussed in sect. 3.2. 
Table 3.2. Development status of incinerators used in the United States to reduce the volume of wastes

\begin{tabular}{|c|c|c|}
\hline \multirow{2}{*}{ Incinerator type } & \multicolumn{2}{|c|}{ Development status } \\
\hline & Nonradioactive wastes ${ }^{a}$ & Radioactive wastes \\
\hline Acid digestion. & Not applied & Pilot plant \\
\hline Agitated hearth & Not applied & Under construction $b$ \\
\hline Controlled air & Connercial unit & Demonstration unit \\
\hline Cyc1one drum & Not applied & nemonstration unit \\
\hline Fluidized bed & Commercial unit & Pilot plant \\
\hline Microwave/gas plasma & Laboratory unit & Laboratory unit \\
\hline $\begin{array}{l}\text { Molten glass (joule } \\
\text { heating) }\end{array}$ & Commercial unit & Test unit \\
\hline Molten salt & Commercial unit & Filót plant \\
\hline Moving grate & Commerclal unit & Not applied \\
\hline Multiple hearth & Commercial unit & Not applied \\
\hline $\begin{array}{l}\text { Pyrolysis (controlled } \\
\text { air) }\end{array}$ & Commercial unit & Test unit \\
\hline Rotary kiln & Commercial unit & Under construction $b$ \\
\hline Slagging pyrolysis & Commercial unit & Pilot plant \\
\hline
\end{tabular}

${ }^{a}$ Includes wastes generated in non-nuclear applications. $b_{\text {Full-scale units. }}$ 
Table 3.3. Some volume reduction factors ${ }^{a}$ expected for incinerator units used with low-level radioactive wastes

\begin{tabular}{|c|c|c|c|c|}
\hline Waste type & $\begin{array}{r}\text { Vo } \\
\text { red } \\
\text { fa }\end{array}$ & $\begin{array}{l}\text { lume } \\
\text { luction } \\
\text { actor }\end{array}$ & Waste type & $\begin{array}{l}\text { Volume } \\
\text { reduction } \\
\text { factor }\end{array}$ \\
\hline Combustible/compactible & 20 & to 45 & $\begin{array}{l}\text { Aqueous } \\
\text { concentrates }^{b}\end{array}$ & 5 to 10 \\
\hline Combustible/noncompactible & 20 & to 45 & $\begin{array}{l}\text { Special aqueous } \\
\text { solutions } b\end{array}$ & $\sim 10$ \\
\hline Noncombustible/compactible & & $c$ & Oils & $>100$ \\
\hline Noncombustible/noncompactible & & $c$ & $\begin{array}{l}\text { Other organic } \\
\text { liquids }\end{array}$ & $>100$ \\
\hline Filter cartridges & & $d$ & $\begin{array}{l}\text { Membranes } \\
\left(\mathrm{e} \cdot \mathrm{g} \cdot \mathrm{RO}^{e}\right)\end{array}$ & $d$ \\
\hline Spent resins & 15 & to 20 & Biological & $\sim 20$ \\
\hline Slurries and sludges $b$ & 2 & to 5 & & \\
\hline
\end{tabular}

a Volume reduction factors for incineration step only; solidification of ash is not considered, and secondary wastes from off-gas cleanup are neglected:

$b_{\text {These wastes are not actually incinerated but are calcined to }}$ achieve VR in some units.

$c_{\text {These wastes are not actually incinerated but are melted to }}$ achieve VR in some units.

$d_{\text {Not usually applied to this waste type. }}$

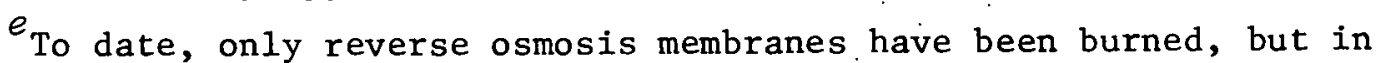
the future, ultrafiltration or electrodialysis membranes may also be Incineraled. 
'ihe granular solids and/or ashes from a dryer, calciner, and/or incinerator may be rendered less mobile by incorporation in a binder or solidification agent. These agents include asphalt, cement, cement/ asphalt, cement/polymers, glass, polyethylene, as well as ureaformaldehyde, unsaturated polyester, and epoxy resins.

\subsection{Wet Wastes}

Wet wastes in this study include emulsions, solutions, slurries, and sludges of both Inorganic and organic materials contaminated with low levels of radioactivity. They arise during the treatment of process or dilute waste streams as nuclear facilities move coward a practice of "maximum recycle or reuse" (of water and other solvents) or "near-zero release" (of radioactivity or other potentially hazardous materials). To be effective, maximum recycle or reuse requires streams that are essen= tially free of impurities which interfere with the process and are low in radioactivity which can increase in-plant personnel exposure. To be achlevable, near-zero release requires effluent streams that have been highly purified (decontaminated) or detoxified. The majority of wet wasles arise when water is decontaminated prior to recycle or discharge to the environment. A generic flowsheet that shows the sources and usual methods for treating wet, radinartive T.LW is presented in Fig. 3.13.

Among the unit operations commonly used in the cleanuf of in-plant process streams and 1iquid LLW wastes are adsorption, biodegradation, clarification, coagulation, evapnration, filtration, flocculation, iun exchange, precipitation, reverse osmosis, sedimentatinn, and ultrafiltration. The small quantities of radinactivity present in the dilute process and waste streams are concentrated in various types of wet sludges and precipitated salts, ion exchange resins, and evaporator concentrates that must be stored and conditioned for disposal. The unit operations also serve to reduce the volume of waste that must be prepared for transport to a burial ground. 


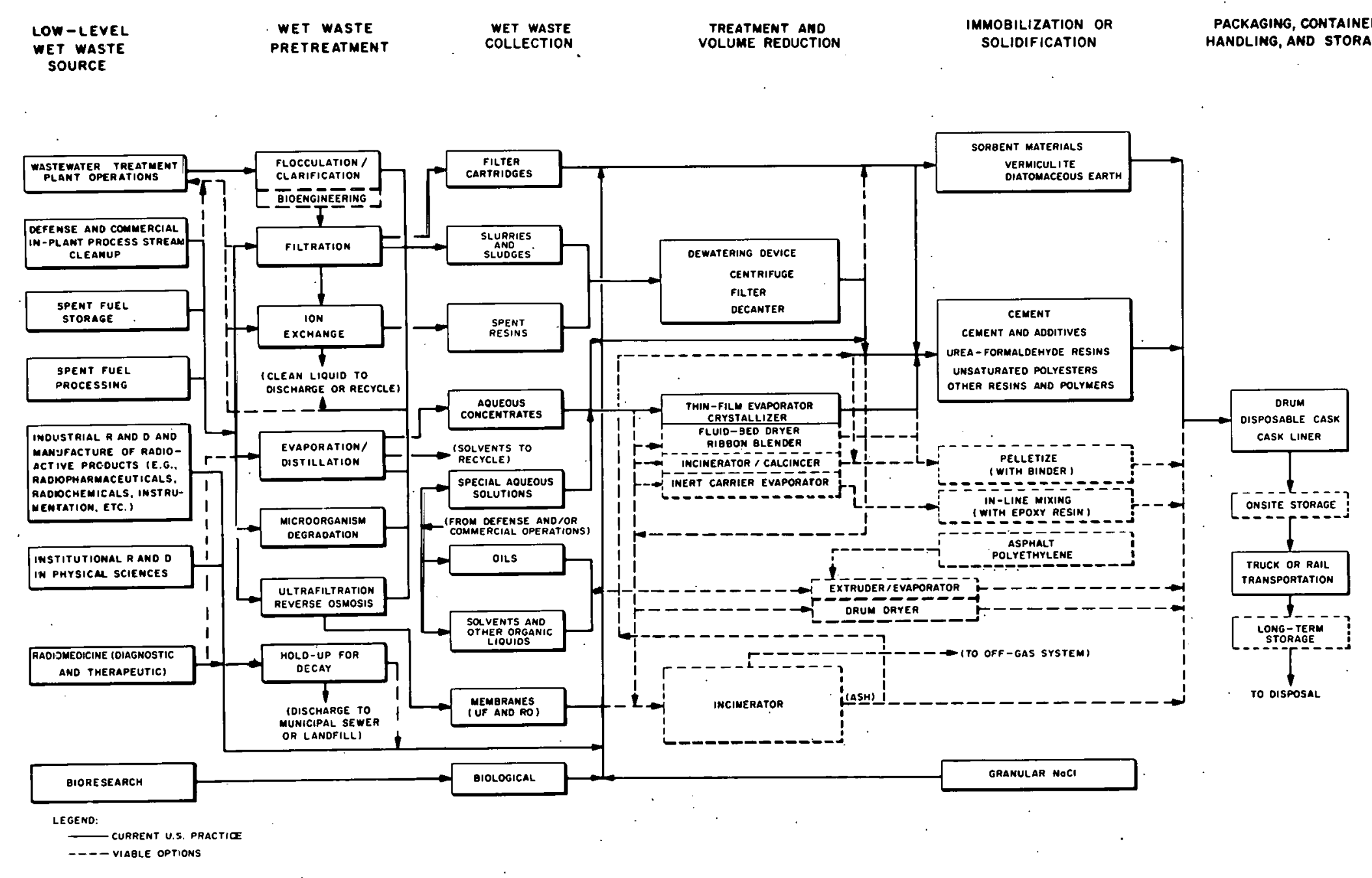

Fig. 3.13. Flow diagram illustrating the management of wet low-level radioactive wastes. 


\subsubsection{Physical treatment methods}

Presently, the most frequently used unit operations that employ physical or mechanical processes for treating liquid LLWs are evaporation and filtration. Used to a lesser extent are centrifugation, freeze/ drying, reverse osmosis, and ultrafiltration.

3.2.1.1 Evaporation. Evaporation is the process by which the volatile and nonvolatile components of a solution or slurry are separated via boiling away the volatile component. It is a unit operation that has wide application at nuclear facilities for reducing both waste volumes and the amount of radioactivity in liquid effluents. Evaporation can be used on solutions or slurries having widely different compositions and concentrations; however, it is most effectively used on radioactive liquids having high concentrations of impurities.

Among the important elements involved in pvapnrator design arc hcat transfer, separation of evolved vapor from residual liquid, volume reduction, prevention of fouling of the heating surface, and conservation of energy. In the design of evaporators for nuclear facilities, vaporliquid separation is the most important factor because decontamination of the liquid is the most important objective. Selection of construction materials is also important since corrosion can be a problem which reduces the iffe of an evaporator. The elements involved in evaporation are described generically in standard chemical engineering texts (e.g., ref. 46), handbouks (e.g., ref. 47), and encyclopedias (e.g., ref. 48). Some of these elements are reviewed with particular application to radioactive liquids in refs. 49 to 51.

An evaporator is a devire designed to tranefor heat to a liquid (solution or slurry) that boils and to separate the vapor thus formed from the boiling liquid. The unit or building block in which heat transfer takes place may be called a calandria, heating element, heat exchanger, heater, or tube bundle. The unit in which vapor-liquid separation takes place may be called a body, flash chamber, or vapor head. The term body is also used to denote the minimum basic units needed to form an evaporator, that is, one heater and one flash chamber. The concentrated solution or slurry removed from the evaporator is variously called 
bottoms, concentrate, discharge, strong liquor, or thick liquor. Evaporators that are used or proposed for use at nuclear facilities employ tubular heating surfaces. Tubes may be long or short, straight or bent, and may have uniform or tapered cross sections. The heattransfer medium or fluid (usually steam) may be inside or outside the tubes. The flash chamber and heater may be an integrated unit (integral or internal heater), or they may be separate units (separate or external heater). The heater may be horizontal or vertical. The movement of liquid past the heating surface may be induced either by gravity or the density variations brought on by boiling (natural circulation) or by mechanical means such as a pump or propeller (forced circulation). Evaporators may be operated as once-through or as circulation units. In once-through operation, the feed liquor passes through the tubes only once. In this single pass, it releases vapor and leaves the unit as thick liquor. In circulation operation, the feed mixes with liquid that has passed through the tubes one or more times, and the mixture passes through the tubes. In this mode of operation, only part of the total evaporation occurs in a single pass. Evaporator accessories include devices such as condensers, entrainment separators, feed preheaters, gas strippers, vent systems for noncondensable gases, and appropriate instrumentation.

Evaporators may be categorized in a number of ways, depending usually upon the classifier's interest. Since a measure of evaporator performance, as judged by the DF achieved, is the prime interest with radioactive liquids, a division that seems to bring out this point has been selected. The types of evaporators that are used or proposed for use at nuclear facilities have been rough1y divided into four main categories: natural circulation, forced circulation, spray film, and submerged U-tube. Examples of these types are illustrated in Figs. 3.14 to 3.17. Evaporators of the types illustrated in Figs. 3.14 to 3.17 are expected to yield concentrates rnntaining 20 to 25 wt \% solids. The solids content of the concentrate can be at least doubled by using a wiped-film evaporator or an evaporator/crystallizer. 44

The wiped-film evaporator (Fig, 3,18) is considered to be a forcedcirculation type since it uses mechanical energy to improve heat transfer. 
ORNL OWG 72-1395R3

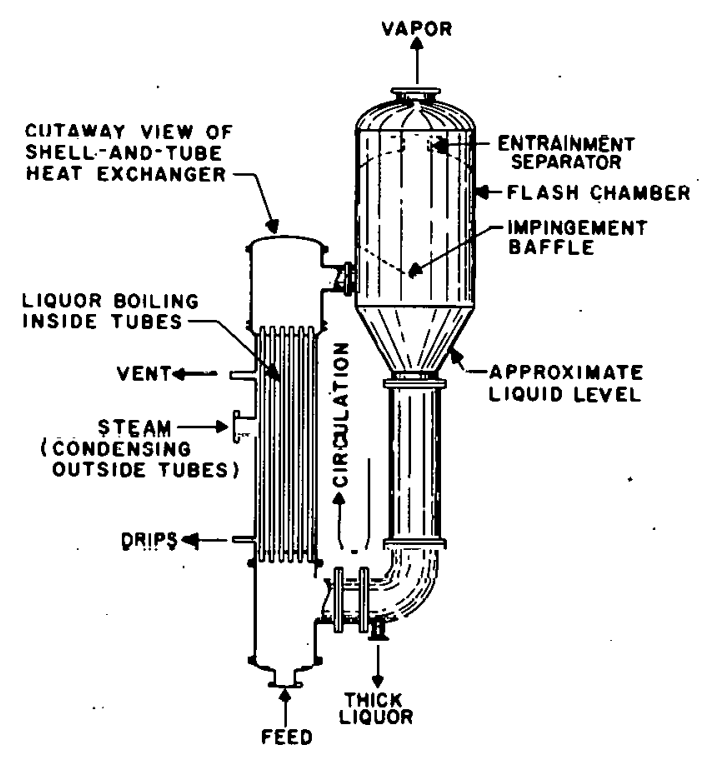

fig. 3.14. Natural-circulation, rising-film, long-tube vertical evaporator with an external heater.

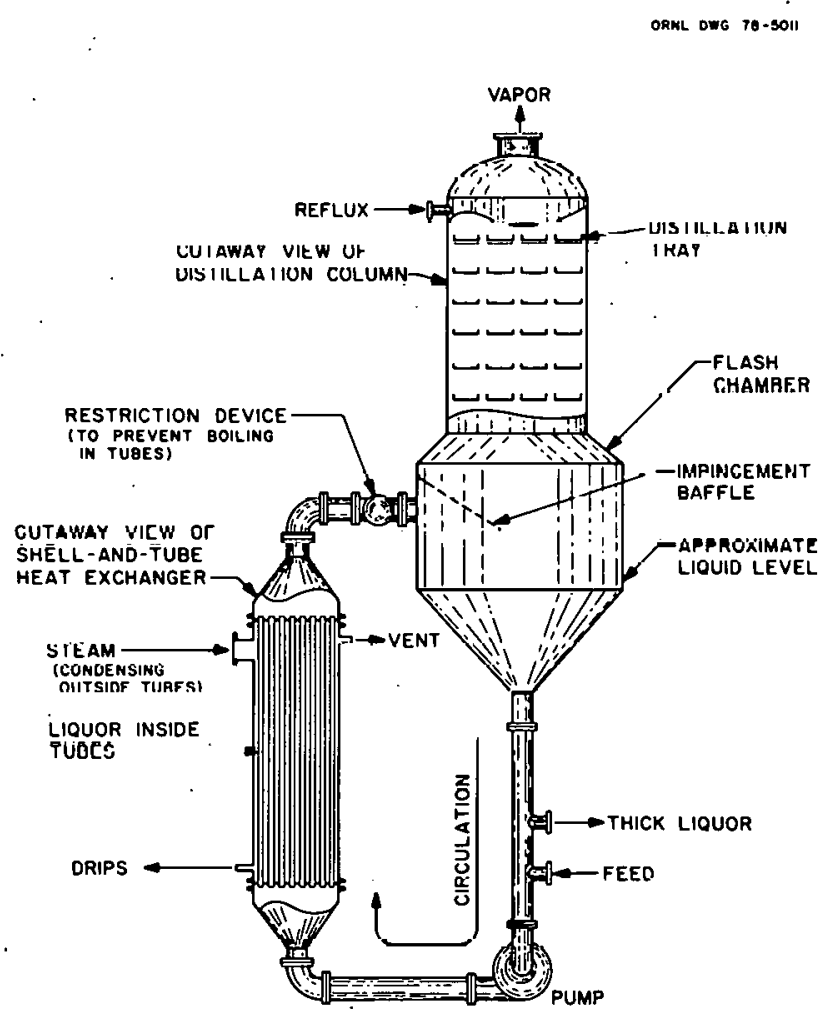

Fig. 3.15. Forced-circulation evaporator with an external, vertical, single-pass heater and restriction device to prevent boiling in tubes. 
ORNL DWG $78-5018 R$

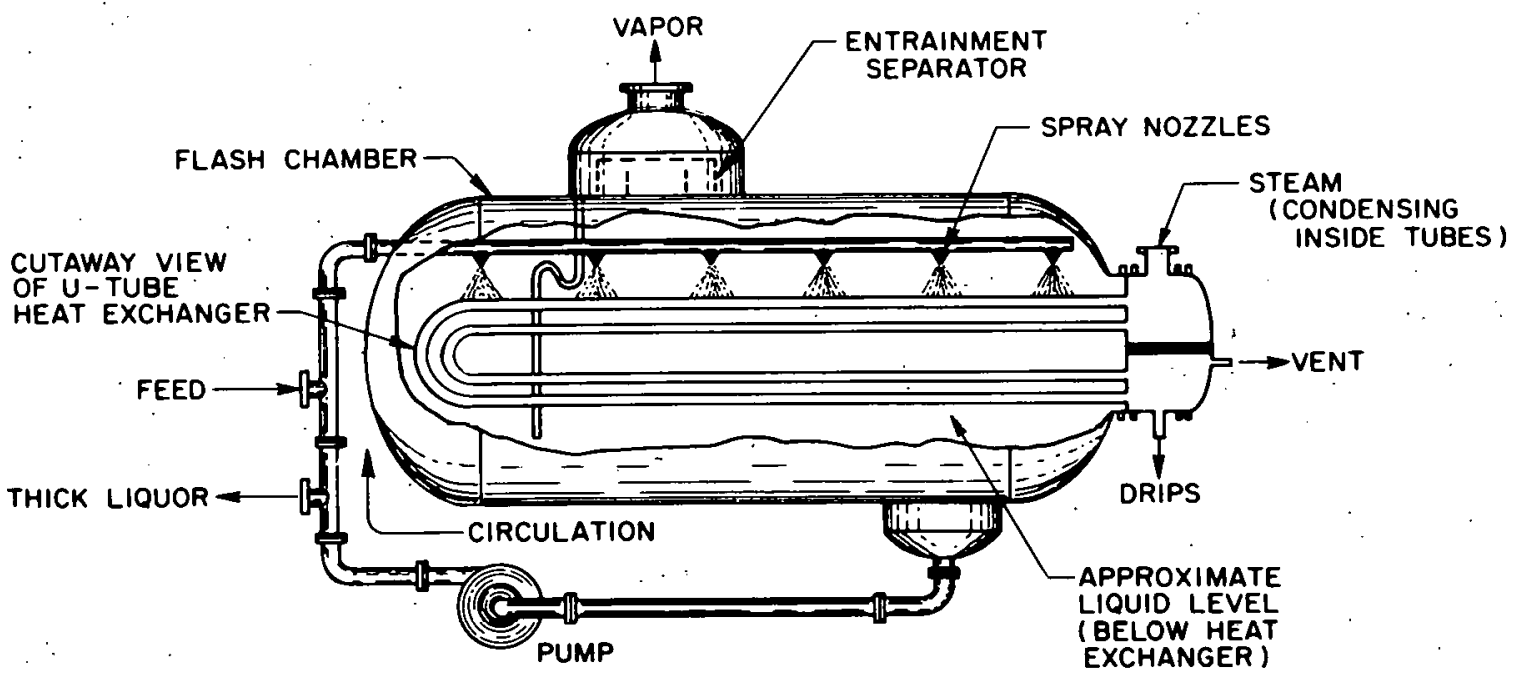

Fig. 3.16. Spray-film evaporator with horizontal U-tube heater.

ORNL DWG 78-5019R

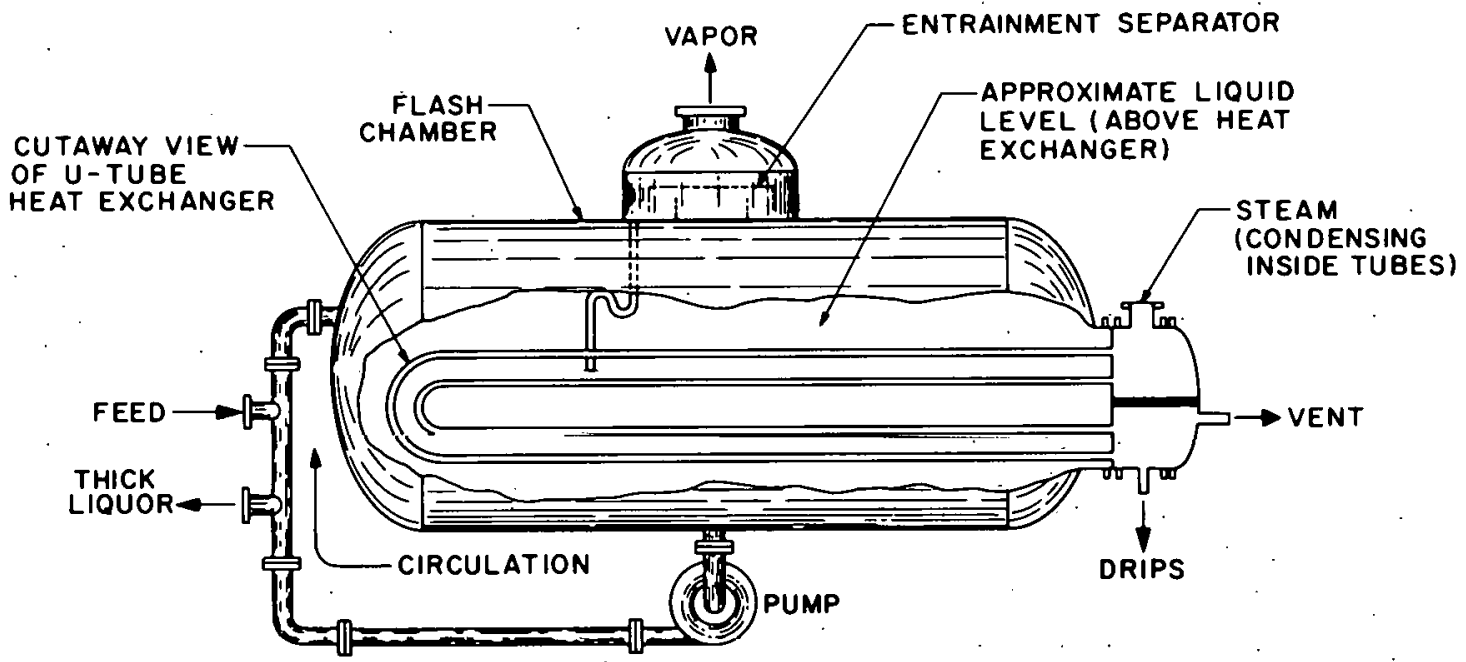

Fig. 3.1.7. Submerged U-tube evaporator. 


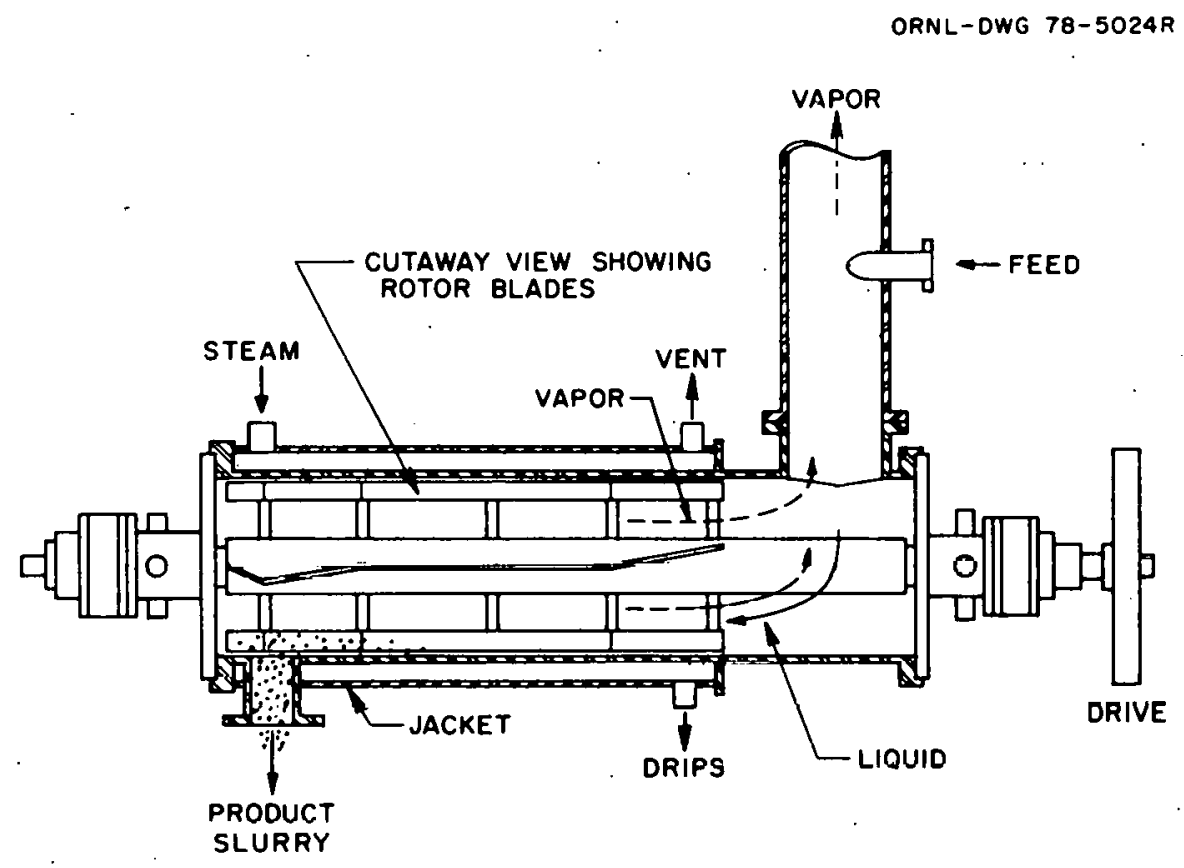

Fig. 3.18. Wiped film evaporator.

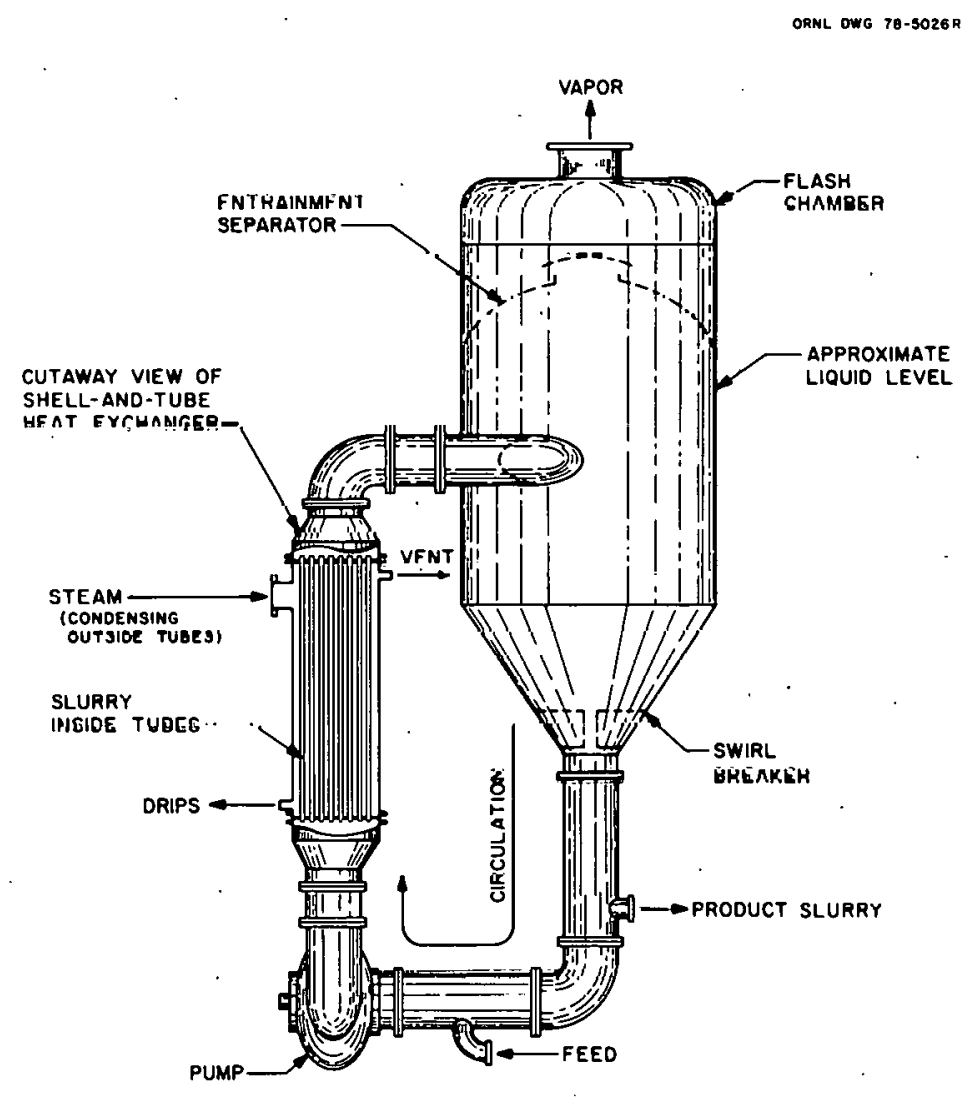

Fig. 3.19. Evaporator/crystallizer. 
These machines are also called agitated-, scraped-, thin-, and turbulentfilm evaporators. The heating surface consists of a single, largediameter, cylindrical or tapered tube. The liquid being concentrated is spread out into a thin, highly turbulent film by the blades of the rotor. Wiped-film evaporators are usually operated in a once-through mode. They are available in either horizontal or vertical models. They have been studied extensively at Savannah River for reducing the volume of the high-level aqueous waste stored there. Since 1951, roughly 50 units have been used to treat radioactive liquids. 52

Evaporation techniques for the crystallization of salts have been used for centuries. Forced-circulation evaporators are well suited to concentrating salting liquors and hence function as evaporating crystallizers (or crystallizing evaporators). In this study, such a unit is referred to as an evaporator/crystallizer; whether it is an evaporator or a crystallizer depends largely on the shape of the solubility curve of the material on which it operates. An evaporator/crystallizer is illustrated in Fig. 3.19 (see also Fig. 3.15). Evaporator/crystallizers have been used since 1974 to reduce the volume of high-level aqueous waste at Hanford. Several have been purchased recently for treating radioactive liquid wastes in LWRs. 49

\subsubsection{Filtration. Liquid filtration refers to a process in} which undissolved particulate solids suspended or carried by a liquid are separated from the liquid by forcing it through a porous body. The mixture of solids and liquid to be separated is often called the feed, feed slurry, influent, or prefilt. The solids to be separated are sometimes termed contaminant, crud, dirt, or suspended solids. The liquid passing through the porous body is generally called the effluent or filtrate. The porous body is variously named the filter medium, medium, or membrane. The term septum is used sometimes to mean the filter medium. However, septum is also used frequently to mean the support for the filter medium or the partition between the prefilt and filtrate. The solid particles can be trapped within the pores of the filter medium and/or can build up a layer on the surface of the medium. 'This layer is called filter cake, or simply cake, and is composed of a bulky mass 
of irregularly shaped particles separated by many small, tortuous passages through which liquid can flow. As implied above, not all filters form a cake. If the solids are stopped at the surface of the filter medium and pile upon one another to form a cake of increasing thickness, the process is called "cake filtration." If the solids are trapped within the pores of the medium, the process is called "filter-medium filtration." Obvious1y, filter-medium filtration may precede the onset of cake filtration. The assemblage of equipment that provides housing for the filter medium, room for cake accumulation (if needed), holdup space for the feed and filtrate, drainage channels for the filtrate, means for the supply and removal of appropriate streams, control devices and instruments, etc., is called a filter. More detailed discussions of llquid tiltration and filters are given in refs. 53 and 54. The use of filtration at LWRs is described in ref. 55.

Filters of variouo types are widely used lhroughour the different systems of nuclear facilities to remove suspended solids from liquid streams that are to be recirculated (recycled) within the plant or discharged to the environment. The need for removal of these solids may stem from requirements for low radioactivity level or freedom from unwanted (interfering and abrasive) materials. For example, radioactive suspended solids may be removed from a stream to reduce the level of personnel exposure during maintenance or reactor refueling operatinns, or to avoid unnecessary wear on equipment such as pump seals. Occasionally, the suspended solid represents a material of value whose recovery is desirable (e.g., resin slurries), but most often, suspended solids are removed because they can interfere with a subsequent operation or process (e.g., ion exchange or evaporation). Frequently, they are removed to prevent their abrasive attack on sensitive instrumentation located downstream.

Filtration and filters may be categorized in a number of ways, several examples of which are given in ref. 55, depending usually on the point of interest. Since the characteristics and amounts of wet wastes generated by filters are among the prime interests of this study, a division that seems to bring out these details has been selected. The many types 
of filters that have been used for liquids in nuclear facilities have been roughly divided into two main categories: disposable and reusable. Under each of these main categories, several types of filters are included. Most of the types that are in use or are proposed for use in nuclear facilities are listed in Table 3.4. A typical disposable type (cartridge) is shown in Fig. 3.20 and reusable type (pressure precoat) in Fig. 3.21.

3.2.1.3 Centrifugation. Like filtration, centrifugation is another unit operation used to remove suspended solids from radioactive liquid streams. Centrifuges are mechanically driven rotating devices that employ centrifugal forces to separate solids from liquids. By taking into account the centrifugal force developed, the range of throughputs normally obtained, and the solids concentration that can be handled, three main types can be identified, 56 namely, tubular- and disk-bow1 centrifuges, and the solid-bowl centrifugal (i.e., centrifugal filter). Examples of this last type are depicted in Fig. 3.22. In the United States, centrifuges have been installed at several LWR plants (e.g.,. Millstone 1, Montice11o, and Vermont Yankee) to dewater resins and/or filter sludges. The defense high-level waste solidification process under development at Savannah River uses a centrifuge to separate the sludge and salt slurry from the waste tanks into a salt solution and sludge.

3.2.1.4 Reverse osmosis. The phenomenon of osmosis may be defined as the spontaneous passage of liquid from a dilute to a more concentrated solution across a semipermeable membrane which allows the passage of the solvent but not the dissolved solids. This transfer continues until the pressure, defined as the osmotic pressure, is large enough to prevent any net transfer of the solvent to the more concentrated solution. If a pressure [ 2 to $10 \mathrm{MPa}$ (300 to $\left.1500 \mathrm{lb} / \mathrm{in} .{ }^{2}\right)$ ] that exceeds the osmotic pressure, is applied on the concentrated side, the phenomenon of reverse osmosis (RO) takes place, wherein the solvent flows from the concentrated side to the more dilute side. The semipermeable membrane normally used today is a modified cellulose acetate $\mathrm{film}$. The membranes have pore sizes $<0.001 \mu \mathrm{m}$ and thus are effective in removing solutes and particles 
Table 3.4. Filters for liquids in nuclear facilities

\begin{tabular}{ll}
\hline $\begin{array}{l}\text { Disposable } \\
\text { Pleated paper cartridge } \\
\text { Pleated wire screen }\end{array}$ & $\begin{array}{l}\text { Reusable without precoat } \\
\text { Pound cartridge }\end{array}$ \\
Woven mesh bag & Porous ceramic \\
Reusable deep bed & Stacked etched disc \\
Crushed coal & Reusable with precoat \\
Ground walnut shells & Backflushable tubular bundle \\
Sand & Centrifugal discharge \\
Reusable magnetic & Clamshell \\
Magnetite bed & Flat bed \\
Elcctromagnctic & Pressure leaf \\
\hline
\end{tabular}




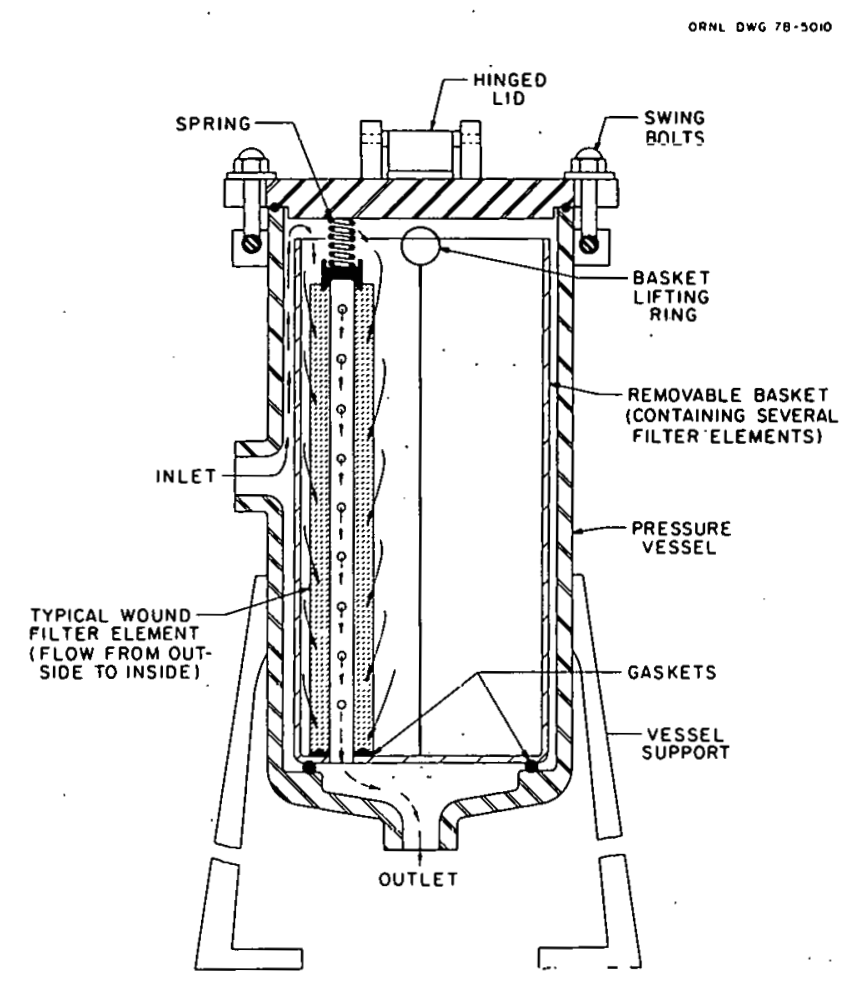

Fig. 3.20. Typical disposable-cartridge filter illustrating liquid flow from outside to inside of element.

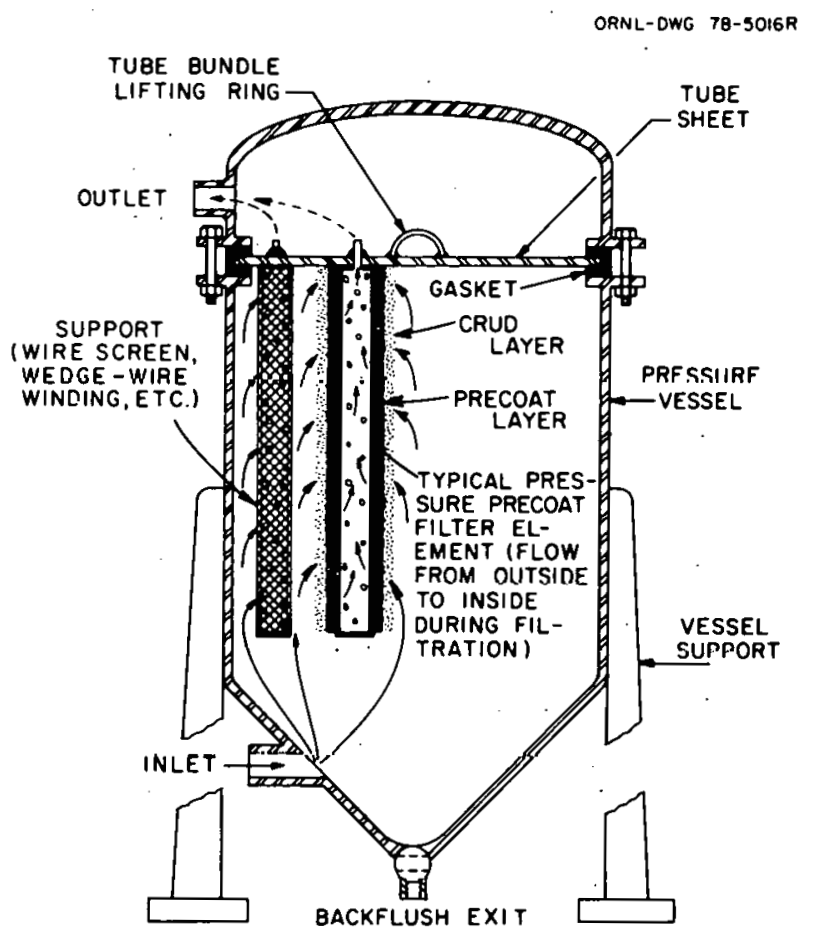

Fig. 3.21. Typical tubular-support pressure-precoat filter. 


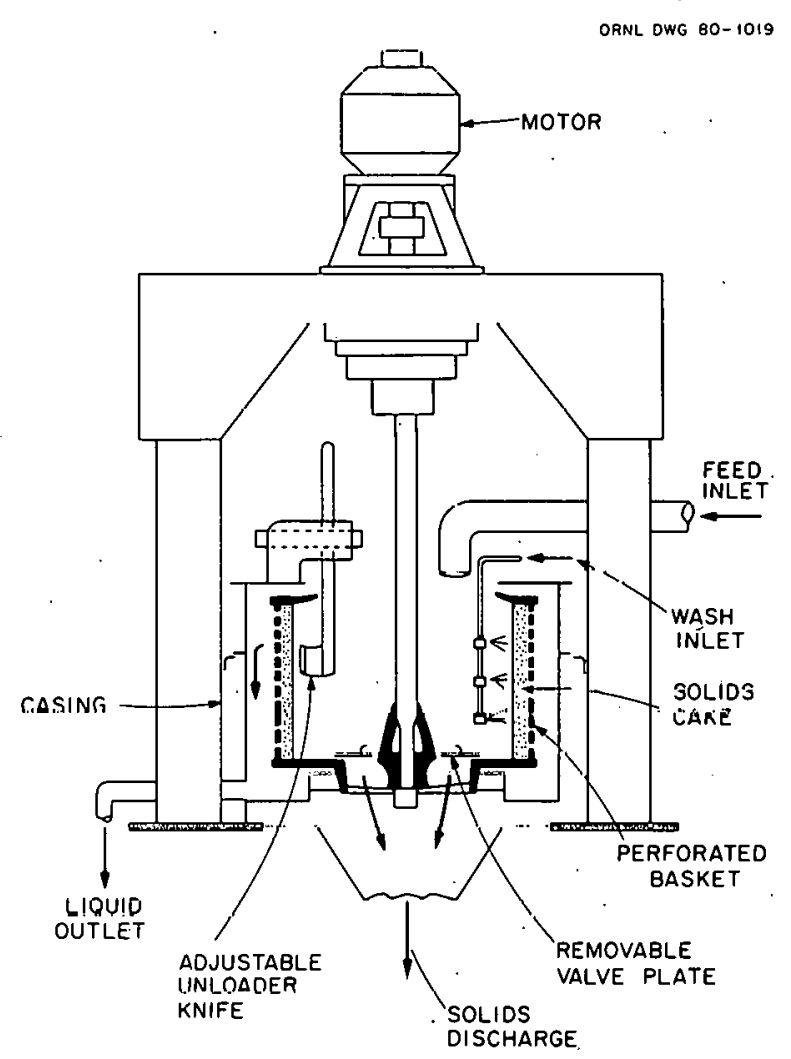

(a)

ORNL OWG 80-1042

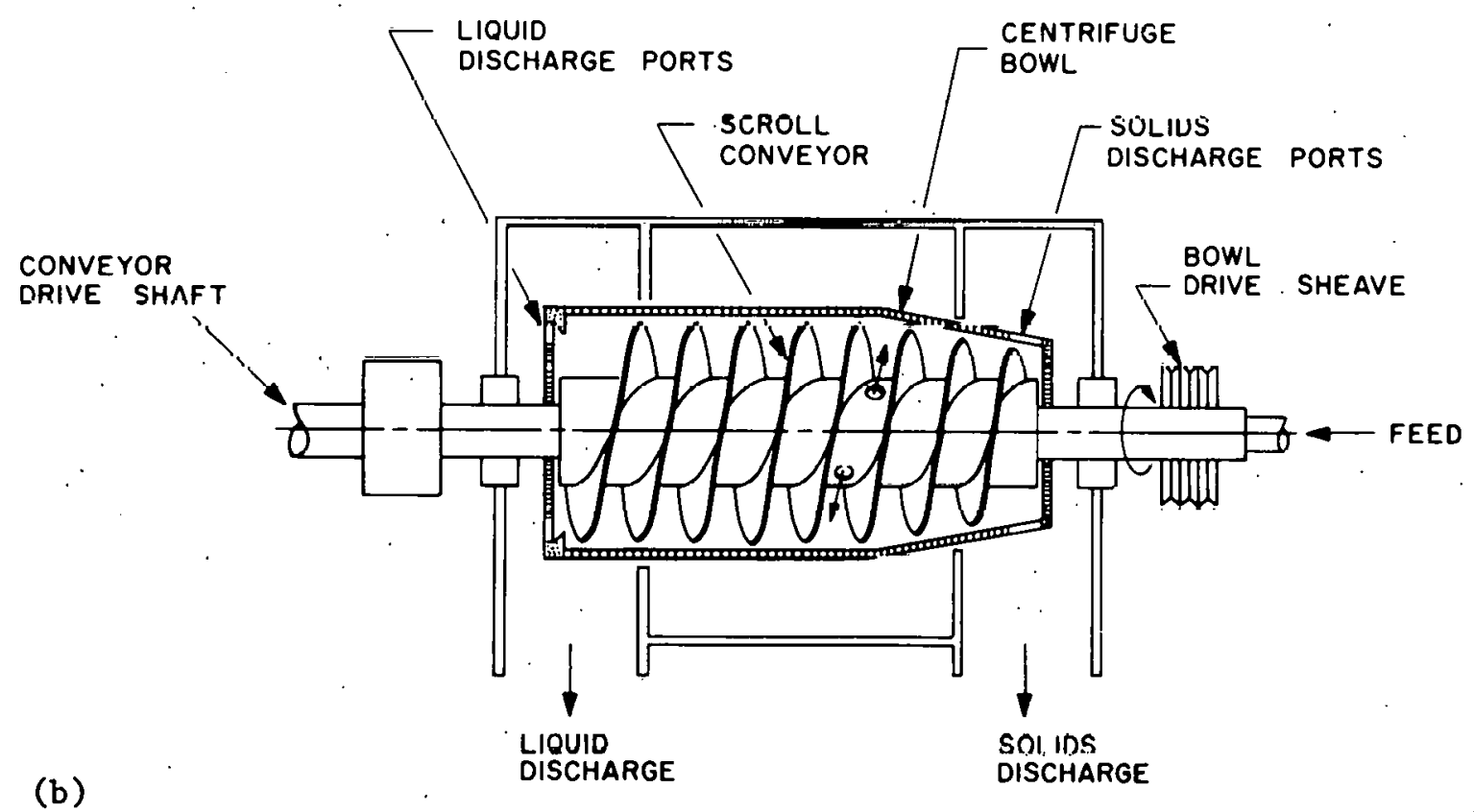

Fig. 3.22. Typical centrifuge types: (a) top-suspended perforatedbasket centrifugal, and (b) helical-conveyor solid-bowl centrifugal. 
in the size range of $\sim 4 \times 10^{-4}$ to $6 \times 10^{-2} \mu \mathrm{m}$. Various types of RO units with varying degrees of prefiltration requirements for acceptable operation are on the market today. There are spiral-wound, hollowfiber, and tubular designs (Fig. 3.23) with feed pretreatment for suspended solids ranging from prestraining to filtering out 5- $\mu \mathrm{m}$ particles to prevent fouling. Reverse osmosis units are usually composed of a number of stages so that the permeate (solution that passes through the membrane) from one stage is the feed to the next stage. That portion of the feed which is rejected by the membrane is called blowdown, brine, or concentrate. To prevent hydrolysis (which causes deterioration) of the membrane, the temperature of the feed should be relatively low $\left(<50^{\circ} \mathrm{C}\right)$, and the $\mathrm{pH}$ should be neutral or slightly acidic ( 4 to 7 ). Application of RO units to radioactive liquids is reviewed in ref. 57.

In the United States, RO is used or has been evaluated by several LWR plants. At the R. E. Ginna Nuclear Power Plant, a $0.13-\ell / \mathrm{s}$ (2-gpm) unit is used on laundry waste. A $0.13-l / s$ (2-gpm) pilot-plant unit tested at H. B. Robinson, Unit 2, led to the installation of a $3.2-l / \mathrm{s}$ (50-gpm) full-scale unit at Brunswick Steam Electric Plant (both plants belong to Carolina Power \& Light) for treating floor-drain waste. This unit has seen limited operation: A number of RO units are on order by LWR plants now under construction (e.g., Comanche Peak, LaSalle, and Zimmer). The Idaho Chemical Processing Plant (ICPP at INEL) has, in the past, used a $1.6-\ell / \mathrm{s}$ (25-gpm) unit to remove suspended solids from the fuel-storage-pool water. To recover water from sanitary sewage for recycle to cooling towers, the RFP also evaluated RO. The results obtained with the $1.3-l / s(20-\mathrm{gpm})$, two-unit (brine from the first is fed to the second) pilot plant led to the construction of a full-scale plant, which is now undergoing shakedown. The plant has three parallel Iines and is designed to operate at 9.5 , 19, or $28 \mathrm{l} / \mathrm{s}(150,300$, or $450 \mathrm{gpm})$.

3.2.1.5 U1trafiltration. The process of ultrafiltration is related to $R O$ in that contaminated water is forced through the membrane under pressure. The ultrafiltration membrane, however, is considerably more porous than the Ro membrane. As a result, most soluble species pass 


\section{SPIRAL - WOUND}
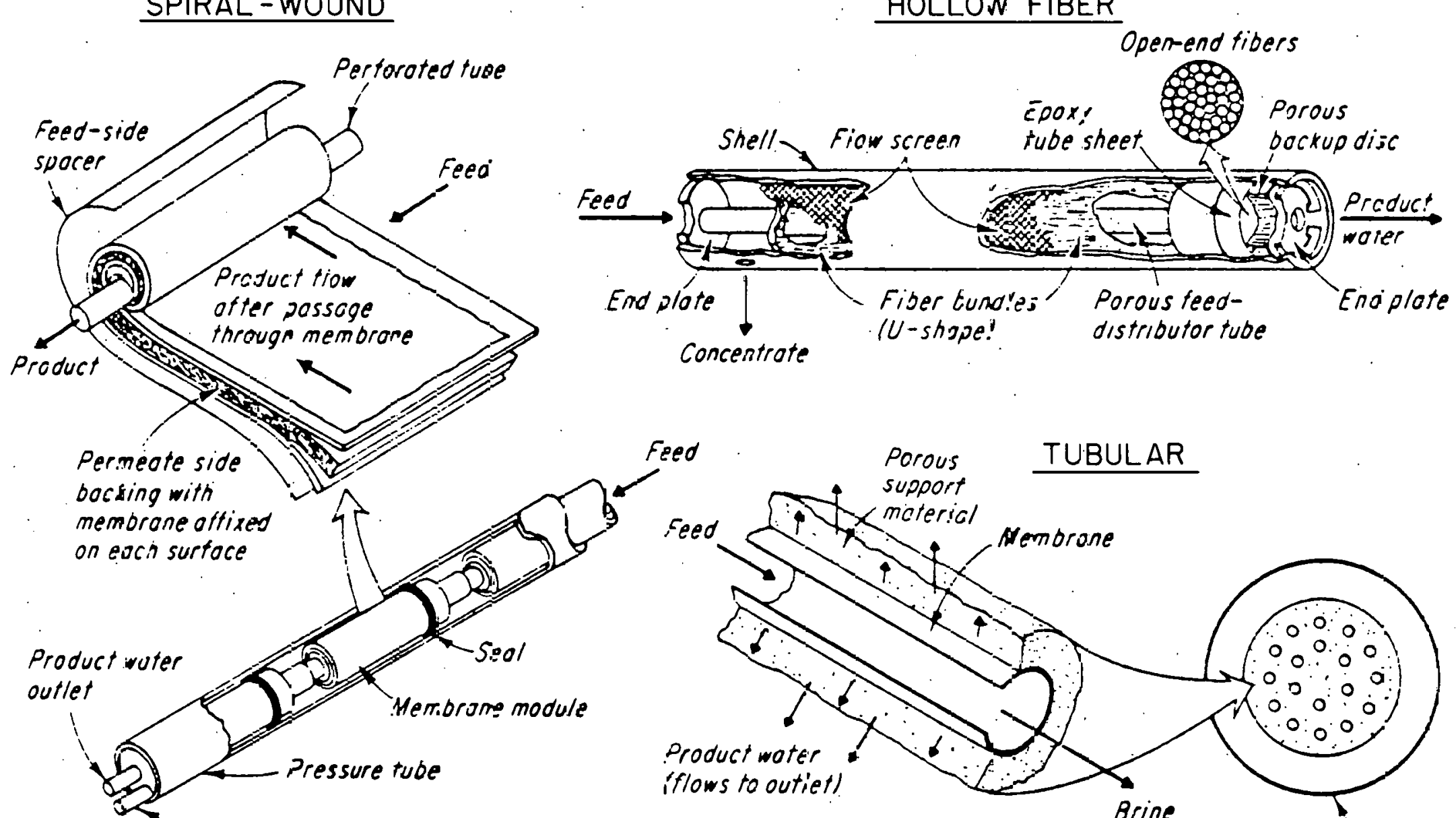

concentiote outlet

Fig. 3.23. Drawings of several commercially available reverse-osmosis designs. 
through the membrane with the water, but colloids, suspended solids, and high-molecular-weight organic molecules $\left(\sim 2 \times 10^{-3}\right.$ to $10 \mu \mathrm{m}$ in size) do not. The porous nature of the ultrafiltration membrane allows the process to be operated with high fluxes at relatively low pressures [ 0.2 to $1.4 \mathrm{MPa}$ (25 to $2001 \mathrm{~b} / \mathrm{in}^{2}$ )], in contrast to the high pressures required by RO. This advantage stems from the fact that the osmotic pressures of colloids and high-molecular-weight organics are extremely low. Mound Laboratory has evaluated ultrafiltration using a $\sim 1.9-\ell / \mathrm{s}(30-\mathrm{gpm})$ pilot plant and has a program which would lead to the demonstration of a 1iquid-waste treatment system utilizing ultrafiltration, RO, and adsorbents. The data collected would be used to design a full-scale waste treatment facility utilizing these three unit operations, either in combination or separately. A pilot-plant ultrafiltration unit has been installed at Tsuruga. Nuclear Power Plant (Japan) for testing on actual in-plant streams.

\subsubsection{Chemical treatment methods}

Present1y, the most frequently used unit operations that employ chemical processes for treating low-level radioactive liquids are coagulation/flocculation and ion exchange. Used to a lesser extent in the United States is incineration. Since coagulation/flocculation is always followed by sedimentation, a discussion of it is deferred to Sect. 3.2.3 on combined methods.

3.2.2.1 Ion exchange. Ion exchange refers to a process in which a reversible interchange of ions of the same sign (+ or -) takes place in a stoichiometrically equivalent proportion between an electrolyte solution and a solid phase (ion exchanger) in contact with the solution. A multitude of natural and synthetic materials have ion exchange properties. Some typical examples are slightly soluble ionic crystals, slightly soluble inorganic polymers such as aluminosilicates (zeolites), organic polymers of a carbohydrate type such as cellulose, or of a polypeptide type such as protein, and synthetic organic polymers such as sulfonated cross-linked polystyrene. Of these, the important commercial ion exchangers are the natural and synthetic zeolites and the synthetic organic polymers. The ion exchange process may be carried out 
as a bațch or column operation. Column operation is essentially a large number of batch operations in series and is the system used in treating radioactive liquid wastes. Column operation has many variations, and these include the following: $58^{\circ}$

1. Single column, fixed bed

- Cation exchange only

- Anion exchange only

- Mixed bed (monobed)

2. Series columns, fixed bed

- Cation exchange columns in series

- Anion exchange colunus in series

- Mixed-bed columns in series

3. Dual columns, fixed bed

- Cation exchange column followed by anion exchange cólumn

- Series of allernaring cation exchange and anion exchange columns

4. Moving-bed, continuous, countercurrent exchanger, or pulsed-bed contactor

- Cation exchange columns

- Anion exchange columns

The moving-bed system apparently has not been used to treat radioactive 11quid wastes.

The ion exchange system most frequently employed in liquid LLW treatment is the mixed-bed system, which consists of a stationary bed containing mixed anion and cation resins (Fig. 3.24). The liquid stream is fed to the top of the bed and percolates downward through the resin bed, thus effecting the ion exchange process. When ionic contaminants begin to appear in the effluent in significant quantities (breakthrough), the bed is considered to be exhausted or loaded, and the feed is discontinued. The bed is then regenerated with appropriate solutions (followed by rinsing with deionized water), or the spent bed is discarded and replaced with fresh resins. These beds contain resins with a particle size range of 0.4 to $0.7 \mathrm{mn}$. For removal of both cation and anion contaminants from liquid waste, two separate ion exchange beds in series - a cation bed ahead of an anion bed - are sometimes used instead of a 


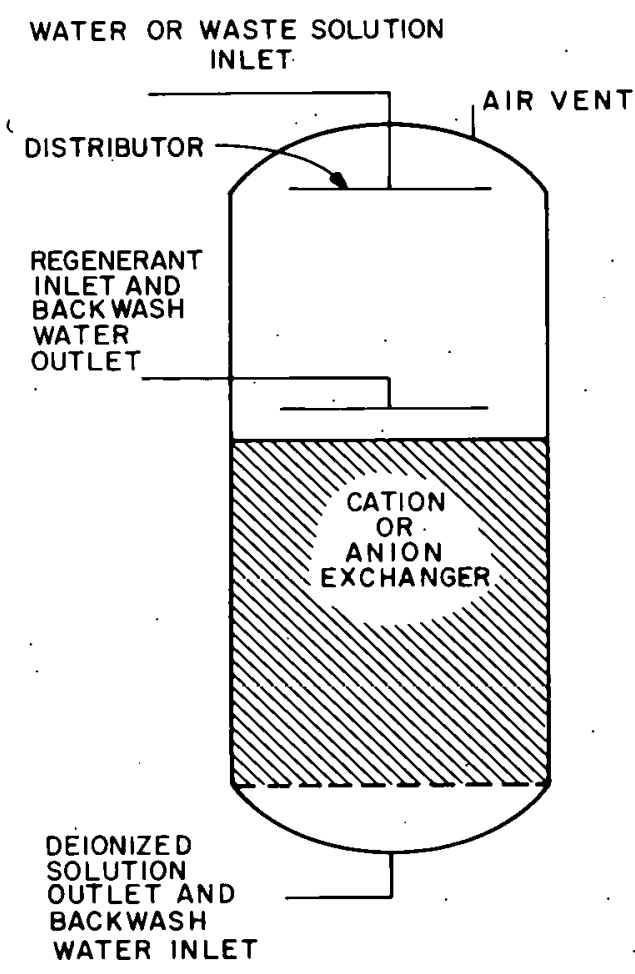

(a) SEPARATE BED SYSTEM

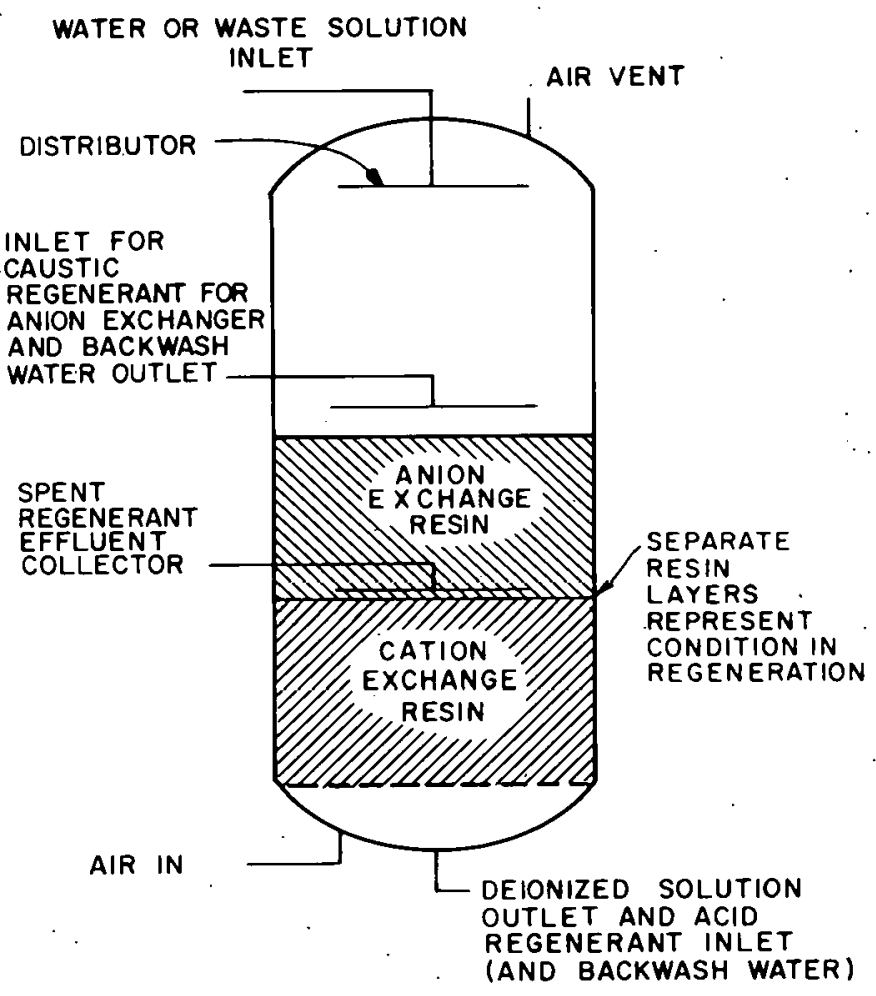

(b) MIXED-BED SYSTEM

Fig. 3.24. Schematic diagram of mixed-bed and separate-bed ion exchange systems. 
mixed-bed system. The separate-bed arrangement (Fig. 3.24) may be preferred for the purpose of removing specific radionuclides. Regeneration is much simpler with a separate-bed unit than with a mixed-bed unit. Inorganic ion exchangers are rarely regenerated. Decontamination factors achieved in ion exchange treatment of radioactive waste liquids vary in accordance with the type and composition of the stream, the radionuclides in the liquid, type of exchanger, regeneration methods, and operational procedures. With synthetic organic resins, DFs have been reported as $10 \mathrm{w}$ as 2 and as high as $10^{5}$. However, average DFs are usuaily in the $10^{2}$ to $10^{3}$ order of magnitude. Some of the myriad uses of ion exchange at nuclear facilities are reviewed in rets. 38 to $6 U$.

\subsubsection{Incineration. All the types of incinerators described in} Sect. 3.1.2 either have or, with proper changes, could burn combustible liquids. A modification of the feed system, or an additional one, may be required for liquid incineration. At the SRP, pilot-plant studies showed that quiescent, open-pan burning in a two-chamber unit can be an effective method for treating contaminated solvents. At the ICPP. (INEL), low-level contaminated solvent from the solvent extrartinn process is sieam d1sc1lled to remove most of the contamination, then burned in a solvent bushes.

\subsubsection{Biological treatment. Reported experience with the bio-} logical treatment of nuclear facility liquid wastes has been very limited; although the technology is well developed. It is widely applied in municipal water treatment plants and in various industrial facilities. Such biological treatment methods as activated sludge, aerated lagoons, anaerobic digestion; and trickling filters are used routinely in municipal sewage treatment and in the canning, dairy, iron and steel, oil refining, petrochemical, paper, and many other industries.

In the biodegradation process, microorganisms chemically alter the composition of waste products and convert them to innocuous forms. Microorganisms can be broadly placed into three classifications: aerobic, which require oxygen to oxidize organic carbon compounds; anaerobic, which live in an oxygen-free environment; and facultative bacteria, which 
can survive with or without oxygen. Aerobic bacteria are commonly found in fertile soils and are the type usually used in activated-sludge processes.

The growth rate of microorganisms depends upon many factors, including the availability of water-soluble organic carbon compounds; the presence of trace elements such as phosphorous, sulfur, sodium, calcium, magnesium, potassium, and iron (i.e., nutrients); and proper control of the environment. An excess of organic carbon and nutrients with proper environmental control yields the maximum growth rate. This growth displays four distinct phases: (1) the lag phase while the microorganisms become acclimated to the environment but do not reproduce; (2) the growth phase in which the population expands exponentially; (3) the stationary phase in which new cell growth is equal to the final (1ysis) phase where (4) death occurs. Death can be caused by lack of carbon or nutrients, environmental changes, or by addition of a toxic agent to the activated sludge.

At the Oak Ridge Y-12 Plant, biodegradation of waste machining coolant by using activated sludge in a stirred-tank bioreactor system has been used for several years. ${ }^{62}$ At ORNL, research on biodenitrification, biological removal of organics, and biosorption, using a fluidized-bed bioreactor system, is being conducted. 63

\subsubsection{Combined methods}

While coagulation/flocculation, precipitation, and sedimentation are individual processes, they are interrelated and are often carried out in a single vessel. Although an ion exchange column filled with $20.5-\mathrm{mm}$ bead resins does some filtering, filtration is not its intended function. However, when these resins are finely ground $(>90 \%,<0.03 \mathrm{~mm})$, they can function as both filter media and ion exchangers in a single vessel. Such operations, in which chemical and physical processes take place more or less simultaneously in the same vessel, are referred to as combined methods in this study.

3.2.3.1 Coagulation/flocculation/sedimentation. There are basically three stages in coagulation/flocculation. First, coagulating 
chemicals (e.g., alum, sodium aluminate, and ferrous or ferric salts) are added to the liquid. To ensure that the chemicals are distributed evenly and promptly throughout the liquid, rapid agitation or mixing must occur. This prevents localized high concentrations of chemicals that can produce reactions other than those intended. Second, coagulation (a series of complex chemical reactions and physicochemical changes) occurs and leads to the formation of finely divided precipitating solids. Third, through gentle agitation of the liquid, flocculation takes place; that is, the finely divided particles contact, adhere to one another, and form progressively larger floc. The insoluble flocculent precipitate settles out, carrying with it the collodial materials present in the 11quid (sedimentation). Coagulation/flocculation/sedimentation (C/F/S) can be carried out as either a batch or continuous operation. In a batch operation, agitation of the liquid is stopped after coagulation and flocculation, and the floc is allowed to settle out. In a continuous operation, the use of suspended-solids contact devices or sludge-blanket clarifiers permits the stages to be performed in a single vessel with continuous feed addition and sludge withdrawal.

Although $\mathrm{C} / \mathrm{F} / \mathrm{S}$ is widely used at nuclear research and production facilities, it is not used at U.S. LWR plants. In Appendix B, several examples of such use are presented. A review of $\mathrm{C} / \mathrm{F} / \mathrm{S}$, as applied to radioactive wastes, is given in ref. 64 .

3.2.3.2 Filtration/demineralization. Consideration of the improved kinetics in ion exchange with small particle sizes has led to the development of finely powdered ion exchange resins. Since the particles are so small $(>90 \%,<0.03 \mathrm{~mm}$ ), the powders can also serve as filter media (see also Sects. 3.2.2.1 and 3.2.3). Use of such powdered resins involves coating the elements of a standard tubular-support, pressure-precoat filter (shown previously in Fig. 3.21) with thin layers ( $/ 3$ to $12 \mathrm{um}$ ). of the resin. In this arrangement, the resin functions both as a filter and as an ion exchanger. Such units are used extensively at LWR plants for cleaning in-plant streams that have lnw suspended solids loadings and low ionic strengths (e.g., coolant water). 55,59,60. The spent powdered resins are not regenerated. 


\subsubsection{Solidification methods}

The radionuclides that are removed from process and waste streams at DOE and commercial nuclear facilities and some research institutions (e.g., universities) collect in the waste concentrates and residues that must be prepared for storage and/or disposal. The types of wet waste, their.sources, and the treatment options for each were presented in Table 2.2 and Fig. 3.13. The long-term confinement of the radioactivity. contained in these wastes, especially ${ }^{90} \mathrm{Sr}, 134,137 \mathrm{Cs},{ }^{60} \mathrm{Co},{ }^{3} \mathrm{H},{ }^{14} \mathrm{C}$, and any other long-lived radionuclides, must be ensured in the interest of protecting the environment. Immobilization of the activity by incorporation of the contaminated liquids and wet solids into a nondispersible form can be accomplished in any of several ways. The matrix materials and the various methods for using them to treat radioactive wastes are discussed below.

\subsubsection{Sorbents. For many years, high-surface-area granular} materials have been used for immobilizing radioactive liquid wastes. In an IAEA review of the uses of natural minerals in the treatment of radioactive wastes, 65 many of these sorbent materials are described. There are also several synthetic minerals that have been used for this purpose. Vermiculites are naturally occurring micaceous minerals (hydrous silicates) that are highly water-sorbent. They, and synthetic calcium silicates, have been widely used in the United States for sorbing radioactive 1iquids (e.g., evaporator concentrates, solvents, and oils) in preparation for burial. Vermiculite is sometimes added to packages of dewatered spent resins and/or filter sludges to ensure that any free residual water will be immobilized in transit. Although this type of sorption process continues to be routine at several government installations and within the institutional community (e.g., hospitals), the practice is becoming less prevalent at nuclear power plants. This latter tendency is due to the more restrictive attitudes toward waste solidification in the NRC, EPA, the Department of Transportation (DOT), and state agencies. Many of these inorganic sorbent materials (e.g., clays or shales) exhibit some ion exchange properties and, when used as additives to other solidification agents (e.g., cement), can serve to inhibit the leaching of radionuclides. 66 
Another class of compounds that has been receiving some attention as sorbents for radioactive liquids is hydrolyzed starch-polyacrylonitrile graft copolymers. 67 These organic "super slurpers" can absorb several hundred times their weight of water or dilute ionic solutions. Their use in control of radioactive liquid spills has been suggested, 68 even though the absorbed water will eventually evaporate on continued exposure to air. A mixture of super slurper, cement, and attapulgite was used to solidify tritium LLW, with a resultant volume reduction of $20 \%$ in the solidified product when compared to products made with mixtures of cement and attapulgite alone. 69

An organic sorbent for organic liquids (e.g., coolants, solvente, or oils) is being investigated at the Paducah Gaseous Diffusion Plant for containment of in-plant spills of potentially radioactive polychlorinated biphenyls (PCBs). 70 The "imbiber beads" are constructed of crosslinked polymers of alkylstyrene designed to exclude water while sorbing a wide range of solvents, including gasoline. Chlorinated, as well as some aromatic, solvents and fuel oils are also sorbed. ${ }^{70}$ Preliminary testing to determine the capacity of the beads to sorb PCBs indicates that they could be useful in spill control. The organic-impregnated beads can be immobilized by incorporation into a polyester resin matrix.

\subsubsection{Cements. In the United States, cement has been used as a} solidification agent for radioactive wastes since the inception of the nuclear industry. Several U.S. rnmpanies are vending wasto colidification systems that use cement. These include Chem-Nuclear Systems, Inc., General Electric Company, Hittman Nuclear Development Corporation, Stock Equipment Company, and UNC Nuclear Industries, Inc. In the past, Westinghouse Electric Corporation also sold solidification systems using cement, but they are no longer being offered. Hittman and one other vendor, Delaware Custom Mater1el, Inc., provide radioactive nuclear waste cementing service on a contract basis; using mobile systems.

Cement and waste can be combined either by in-the-drum (or other container) or in-line mixing. Both methods (examples shown, respectively, in Figs. 3.25 and 3.26) are used for radioactive waste cementation. The in-drum mixing methods sometimes use vermiculite in the cement mix to aid 
ORNL DWG 74-10919

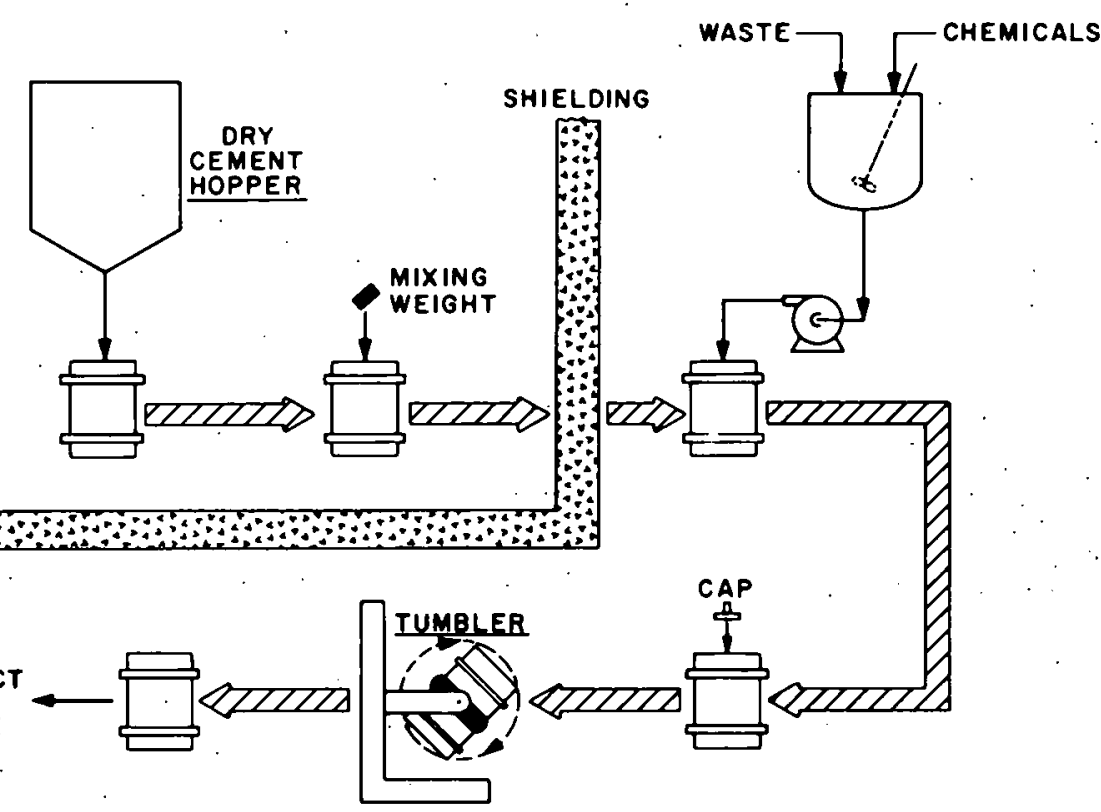

Fig. 3.25. An in-drum method for mixing radioactive waste with cement.

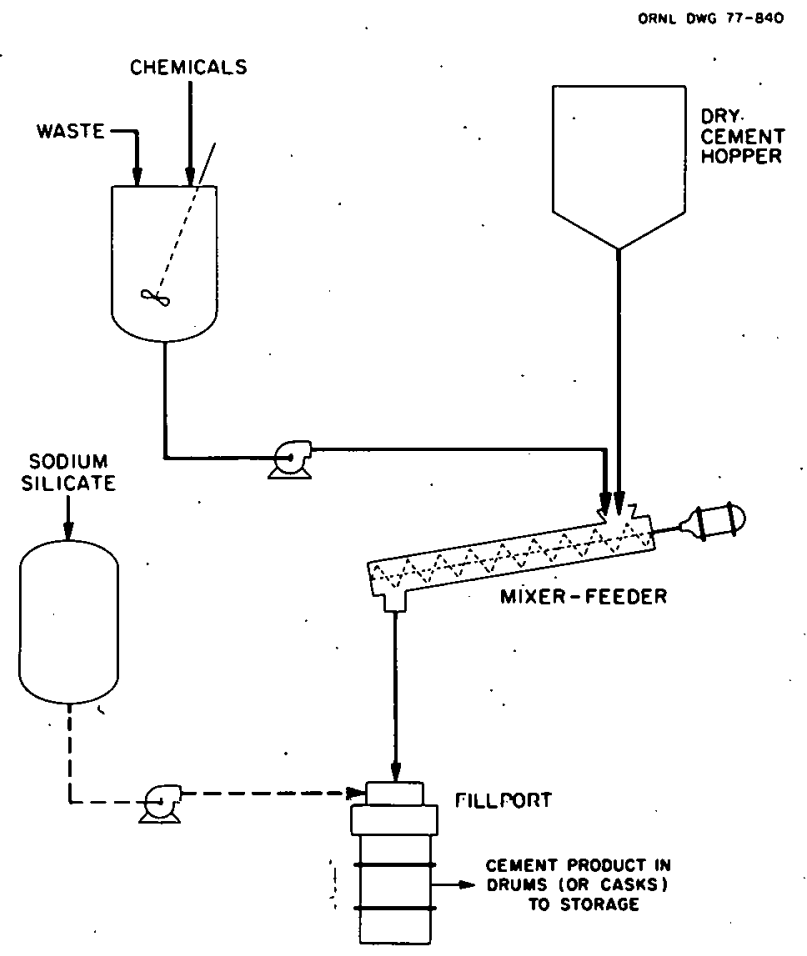

Fig. 3.26. An in-line method for mixing radioactive waste with cement. 
in dispersing the liquid uniformly. The in-line mixing methods frequently use some form of sodium silicate as an additive to increase fluidity and control setting time. Two interesting examples of in-line mixing cementation methods are the pug mill at LASL $^{71}$ and the hydrofracture facility at ORNL $^{13}$ which are shown in Fig. 3.27.

Cementation has shown promise as an immobilizing agent for radioactive incinerator ashes. ${ }^{72}$ In some instances, fly ash can be added as an inexpensive extender in mixtures of cement and waste. Cement can also be impregnated with organic materials (e.g., styrene) to enhance its mechanical properties, improve its resistance to chemical attack, and render it less leachable. ${ }^{72}$ Portland cement Types I, II, and III are the cements most commonly used for solidifying radioactive liquids. ${ }^{33,14}$

3.2.4.3 Asphalts. For nearly 2 decades, asphalts (which behave like thermoplastic resins) have been used extensively in Europe for immobilizing the radionuclides in liquid LLWs. Oxidized (or air-blown) asphalts that have softening points in the range of 70 to $140^{\circ} \mathrm{C}$ are usually used. Operating temperatures at which the wastes are processed range from $\sim 150^{\circ} \mathrm{C}$ for wet resins to slightly $>200^{\circ} \mathrm{C}$ for dilute aqueous wastes. The flash points for oxidized asphalts are usually between $250^{\circ} \mathrm{C}$ and $300^{\circ} \mathrm{C}$. Straight-run distillation and cracked asphalts have also been used successfully. In general, these two types of asphalt have lower softening temperatures (i.e., 35 to $85^{\circ} \mathrm{C}$ ) and lower flash points (i.e., 230 to $290^{\circ} \mathrm{C}$ ) than the oxidized variety. Asphalt emulsifier with surface active agents (e.g., alkaline soaps or amine salts) is still another type that has been used to immobilize radioactive wastes. At the operating temperature of any asphalt solidification process, the wastewater is evaporated off, leaving behind the dry solid particles which become coated with the asphalt binder.

The earliest processes for incorporating radioactive waste in asphalt ${ }^{75}$ used stirred-batch, electrically heated evaporators. The long residence times and high surface temperatures in these processes caused hardening of the asphalt and distillation of light oils and tars, which make off-gas purification difficult. The processes or systems that have 
ORNL. OWG $80-1044$

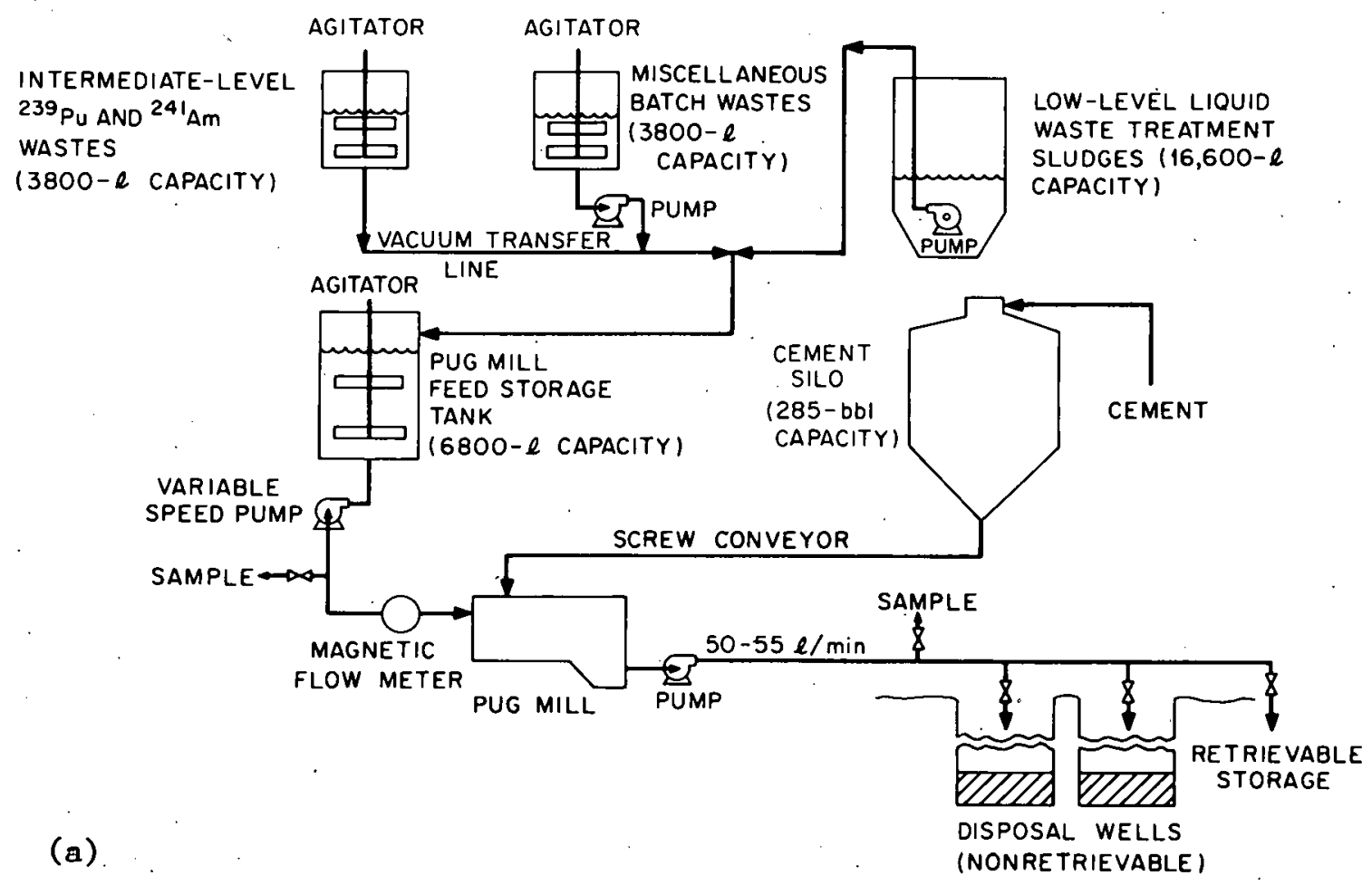

ORNL DWG 73-3976RI

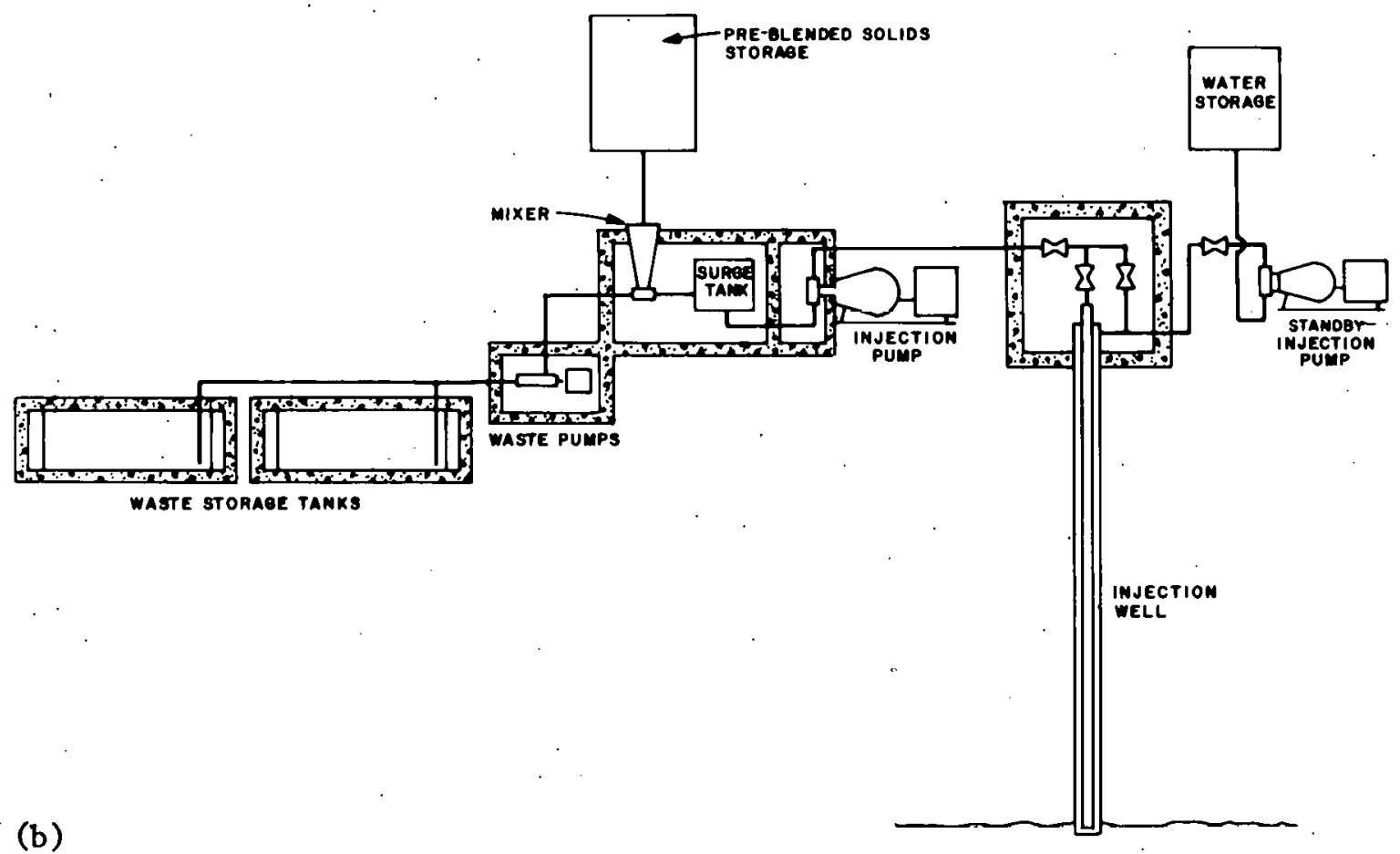

Fig. 3.27. Processes for continuous in-line mixing of radioactive wastes with cement; (a) pug mill system used at Los Alamos Scientific Laboratory and (b) hydrofrarture facility at Oak Ridge National Laboratory. 
gained favor are those which use a fluid heat-transfer medium (e.g., steam) and devices with low holdup volume, for example, an extruder/ evaporator (Fig. 3.28) or a thin-film evaporator.

The extruder/evaporator manufactured by Werner \& Pfleiderer Corporation has been ordered for installation in four U.S. nuclear power plants. Both the extruder and the thin-film evaporator have been used with asphalt for solidifying wet radioactive wastes in Europe. A system that uses a vertical thin-film evaporator (Fig. C.l, Appendix C) is marketed in the United States by Associated Technologies, Inc. Since 1973, a drum-mixer version of the asphalt waste solidification process has been in operation in Japan. The drum mixer developed by Japan Gasoline Company (JGC) is now marketed in the United States by Nuclear Power Services, Inc. Teledyne Energy Systems also offers a volumereduction system that couples a ribbon blender to a mixer/evaporator. The drum mixer and the ribbon blender systems are shown in Appendix $C$ in Figs. C. 2 and C.3, respectively. A1though they are apparently not being studied in this country, mixtures of asphalt and cement are being given some serious attention in France.

3.2.4.4 Thermosetting organic polymers, A rather new development in the solidification of radioactive wastes is the use of thermosetting organic polymers as binding agents. These compounds require heat (or a catalyst) to promote hardening, which is irreversible. The unsaturated polyester, epoxy, and urea-formaldehyde resins are among the polymers that are used or are proposed for use in waste solidification.

The chemistry of unsaturated polyester resins is well known and can be found in standard texts. ${ }^{76}$ After a polyester is formed by the condensation of a glycol with a dibasic acid, it is dissolved in a monomer (e.g., styrene) to form a liquid mixture. Radioactive waste solutions, slurrics, or powders can be dispersed uniformly as small partieulates throughout the organic liquid with a high-speed mixer. The gelling or hardening of the continuous organic phase is initiated by addition of a suitable catalyst (prior to emulsification) that promotes polymerization of the monomer. The polymeric resin thus formed does not combine chemically with the waste, but merely encapsulates it within small pores 


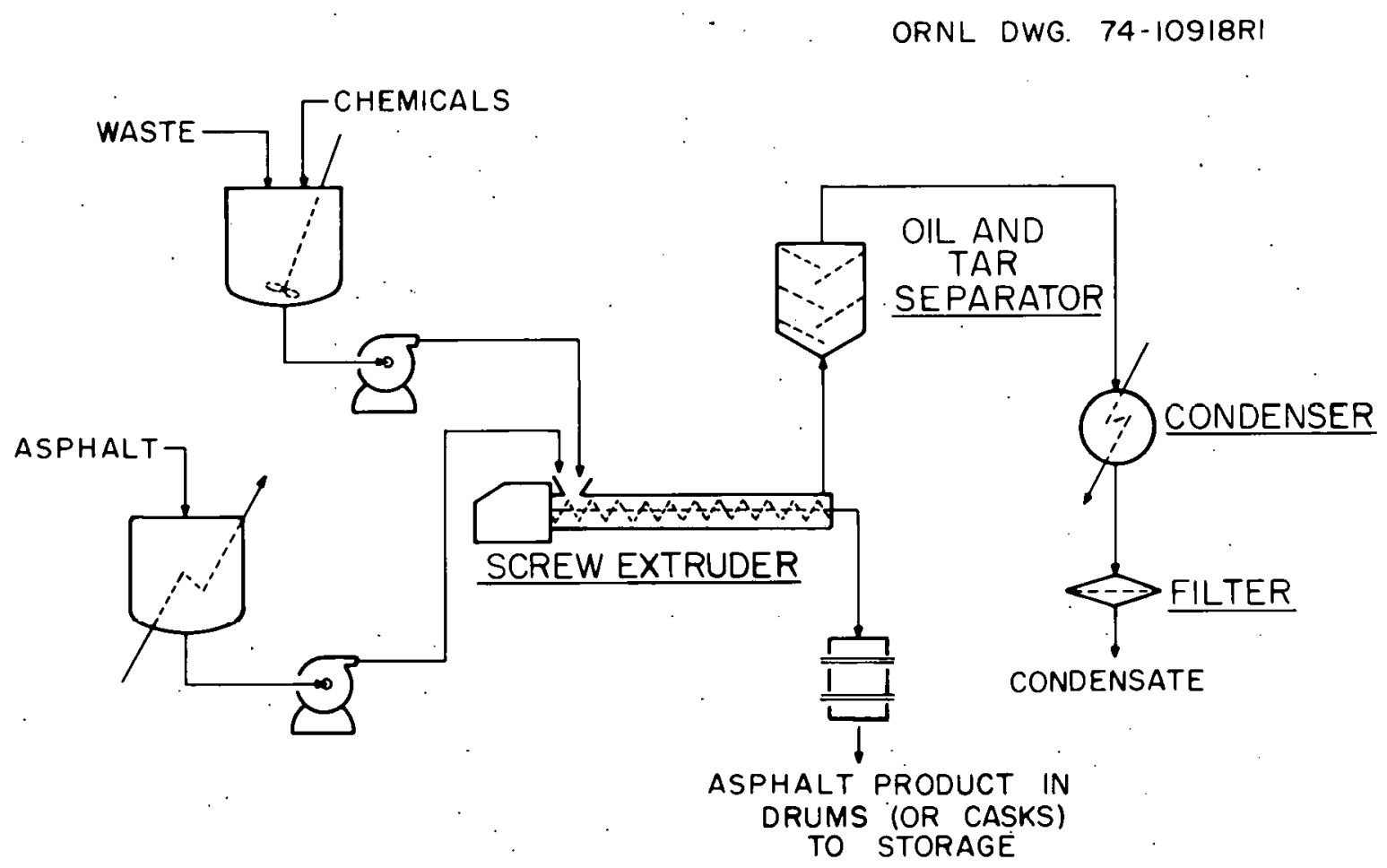

Fig. 3.28. Werner \& Pfleiderer extruder/evaporator process for volume reduction and solidification in asphalt. 
throughout the solid matrix. Much basic research on the encapsulation of simulated radioactive wastes in unsaturated polyesters has been done at the University of Washington. 77-79 However, only one such process (based on a modified vinyl ester resin) 80 is being offered commercially in the United States. It was developed by Dow Chemical Company primarily as a means of solidifying aqueous decontamination wastes at the Dresden-1 reactor. ${ }^{81,82}$. The Dow material has been used by Chem-Nuclear Systems, Inc., to solidify wastes at Three Mile Island, Unit 2, using mobile solidification equipment. The polyester resins appear to be good solidification agents for spent ion exchange resins.

Urea-formaldehyde resins were, for a while, the most popular binders for solidifying radioactive wastes at nuclear power plants in the United States. A solidification process based on urea-formaldehyde resin was the first all liquid-reagent, low-temperature system developed for this purpose. A partially polymerized liquid mixture of urea and formaldehyde condensation products is mixed with the waste along with an acid (or acid salt, e.g., $\mathrm{NaHSO}_{4}$ ) catalyst, which promotes the polymerization to completion with the formation of water as one end product. It soon became evident that the "solidified" products continued to exude water evèn after being sealed. Waste packages containing free (unbound) liquid are not acceptable at commercial burial grounds, and since no entirely dependable remedy has been found, utility companies have become disenchanted with urea-formaldehyde resins as solidification agents. Chem-Nuclear Systems, Inc., and Hittman Nuclear and Development Corporation have made some modifications in the urea-formaldehyde reoin process and continue to use it in their mobile solidification units when requested. Probably the newest polymers being developed for use with radioactive wastes are the epoxy resins. Epoxy resins have been used with simulated wet LWR power plant wastes in pilot-scale demonstration of the Inert Carrier Radwaste Process (ICRP) shown in Fig. 3.29. The demonstration unit ( $1 / 10$ scale) is providing design data for a full-scale unit that is expected to process 227 to $454 \mathrm{l} / \mathrm{h}(60$ to $120 \mathrm{gal} / \mathrm{h})$ of 1 iquid waste or 114 to $228 \mathrm{~kg} / \mathrm{h}$ (250 to $500 \mathrm{lb} / \mathrm{h}$ ) of wet solid wastes (i.e., resins and sludges). The process is being developed jointly by United Technologies, Inc., and the General Electric Company. ${ }^{83}$ In the ICRP, 
ORNL DWG 80-1041

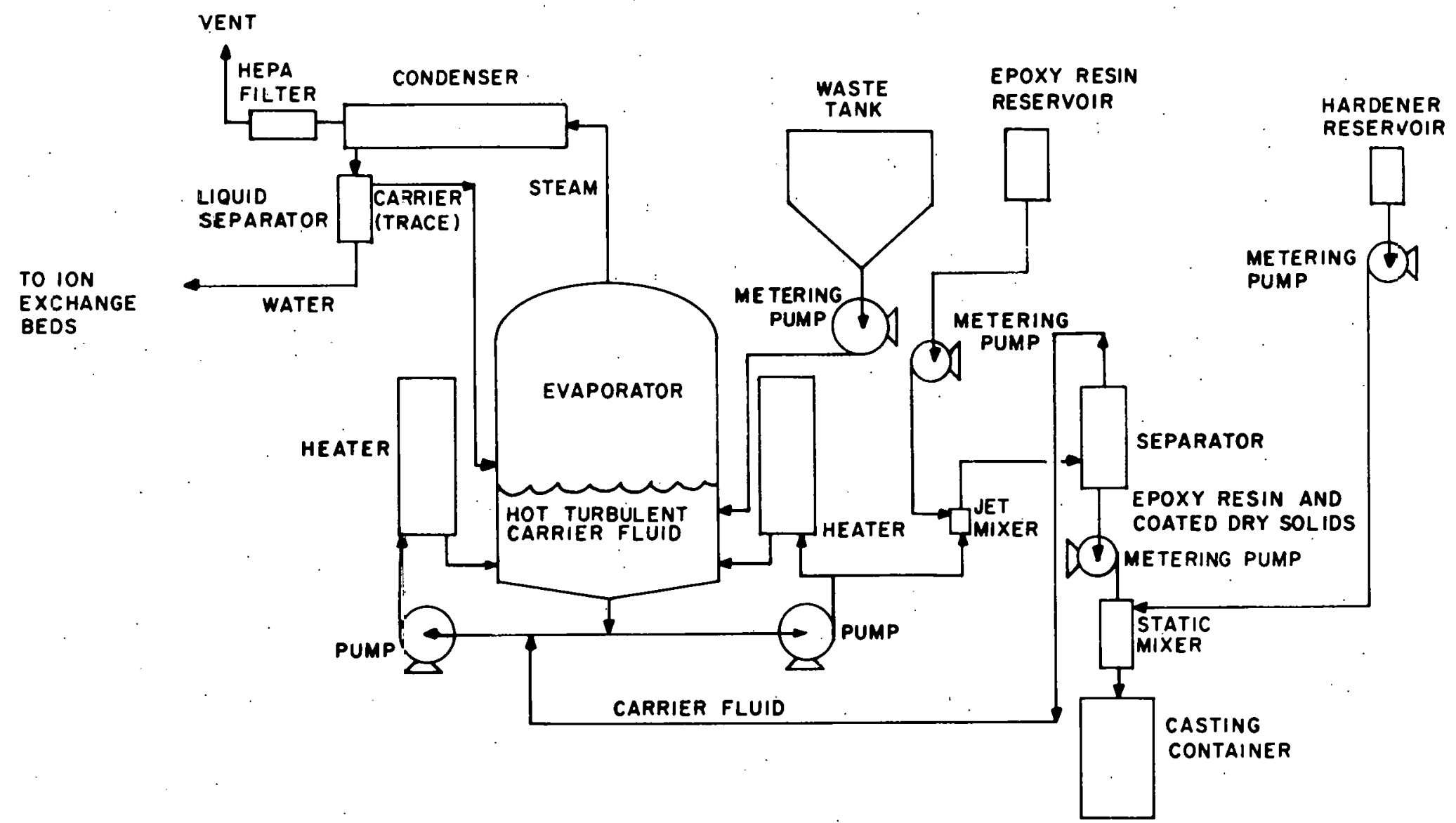

Fig. 3.29. Inert-Carrier Radwaste Process (ICRP) being developed by United Technologies, Inc., and General Electric Company. 
wet radioactive wastes are evaporated or dried by introducing them into a hot $\left(\sim 300^{\circ} \mathrm{C}\right)$, turbulent silicone oil bath where the water and other volatiles are flashed off for discharge or recycle. The dry solid residue is separated from the oil carrier by coating the suspended particles with epoxy resin as a bleed stream is passed through a jet mixer. The resin-coated suspension is then routed to a separate column for phase separation by gravity. The solids are drawn off the bottom of the column and mixed with hardener in an in-line mixer which discharges to a drum for solidification. Epoxy resins for solidifying radioactive wastes are being studied in Europe (e.g., France and England), and CIBA/Geigy (Switzerland) has developed an epoxy resin that reputedly can accommodate wastes containing 220 to 30 wt \% water.

The properties of solidified LLW usually considered to be of primary importance in the safety and economics of waste management are radiation rcsistance, leachability, mechanical ruggedness, long-teru chemical stability, thermal stability, compatibility with container, water content, final volume, and overall cost.

There are differences of opinion concerning the relative importance of these properties. However, the requirements or constraints imposed by the storage facility and disposal site can influence the choice of product type and composition. A knowledge of many physical, chemical, physicochemical, and radiological properties of the solid is required for understanding and controlling the solidification process as well as for optimizing the packaging, transport, storage, and disposal of the product. A consideration of these is beyond the scope of this study.

\subsubsection{Conditioning wet waste residues for shipment/disposal}

The DOE and fuel-cycle (other than power plant) wct waste residues or concentrates are largely sludges of various types (e.g., CaO, $\mathrm{CaF}_{2}$, $\mathrm{NaNO}_{3}, \mathrm{Fe}_{2} \mathrm{O}_{3} \cdot \mathrm{xH}_{2} \mathrm{O}$, and other metallic oxides and nitrates) collected in settling ponds or storage tanks and concentrated nitrate solutions or slurries (Appendix B). The BWR wet waste residues are mostly sludges composed of filter precoat materials such as diatomaceous earth, cellulosic filter aids, and powdered or bead ion exchange resins, and 
evaporator concentrates containing 20 to 25 wt $\% \mathrm{Na}_{2} \mathrm{SO}_{4}$ from resin regeneration. The PWRs generate less sludge than BWRs because they have tended to use disposable-cartridge filters rather than precoat filters in stream cleanup. The evaporator concentrates from PWRs are mostly neutralized 8 to 12 wt $\% \mathrm{H}_{3} \mathrm{BO}_{3}$, but since more of these plants are beginning to regenerate bead resins, more $\mathrm{Na}_{2} \mathrm{SO}_{4}$ wastes can be expected in the future. As mentioned earlier, several power plants are planning to use RO for cleanup of laundry and/or floor-drain wastes, thus more spent membranes and Ro sludges can also be expected as part of the wet waste residues. The DOE and fuel cycle installations generate some waste organic salt solutions, organic solvents or other liquid organic compounds [e.g., polychlorinated biphenyls (PCBs)], and oils that require disposal. The majority of the wet wastes from pharmaceutical, medical, and biological research applications are also organic. The wet pharmaceutical wastes have not been well defined at this point; however, a large fraction of them are probably derived from "tagging" organic compounds with radioactive atoms. If the product yields in such tagging reactions are low, the wet waste residues can be expected to be among the more radioactive wastes generated in the health-related industry. The single largest fraction of the wet waste... generated in medical applications and requiring offsite shipment is accounted for by scintillation vials or "cocktails" composed of solvents (e.g., xylene or toluene) containing scintillation fluids and some water. The dilute aqueous wastes generated at hospitals and clinics are often stored onsite until the short-lived ieotopee (usually ueed in diagnoetic or therapeutic practices) decay to a level that permits discharge to the municipal sewage system. Only the low-level medical and biological research wet wastes that are routinely shipped to burial grounds are considered here. Besides scintillation vials, these include surplus radiopharmaceuticals, tissues, cultures, and animal carcasses. The conditioning (preparation for transport, storage, and/or burial) of these wet waste residues or concentrates is described in the following sections. Generally, this conditioning includes additional VR where possible and immobilization/ solidification (Fig. 3.13). 
3.2.5.1 Filter cartridges. Some DOE sites and almost all commercial nuclear power plants use cartridge filters for liquid stream cleanup at some point in the plant. For example, they are used frequently for filtering fuel pool and reactor coolant waters circulating within the plant and for laundry wastes prior to discharge. The activity level associated with spent filter cartridges varies widely, depending on their particular service in a plant. In many cases, changeout and discard operations require biological shielding. Spent cartridges are sometimes collected onsite in a shielded container until a sufficient number has been accumulated. Then, sorbent material or a solidification agent is introduced into the container prior to offsite shipment or burial. Power plants that use large shipping casks or cask liners to dispose of other plant LLW sometimes include spent filter cartridges with spent resins or evaporator concentrates that are also immobilized or solidified in preparat.inn for disposal.

\subsubsection{Spent resins. Until recently, the practices for disposing} of spent resins at most DOE sites and in the commercial power industry involved merely reducing the water content of the resin slurry to $\sim 50$ to 80 wt $\%^{84}$ and placing the dewatered resins in drums (snmetimes with absorbent material such as vermiculite) and shipping them to a burial ground. In the last few years, however, more stringent regulations are being imposed on the commercial generators of LLW, and immobilization of the spent resins in a solid matrix will probably be required. ${ }^{85}$ The incorporation of spent resins into a solidification agent can present complex problems. For example, if cement is chosen as the solidification agent, a careful balance between water, resin, and cement must be maintained in order to obtain a product with good mechanical strength. 86 Incorporation of resins into asphalt is possible, but a certain amount of cauliun is required to prevent resin decomposition at the elevated process temperature. The presence of spent ion exchange resins can effect the hardening of organic binders such as urea-formaldehyde and unsaturated polyester resins because the polymerization is sensitive to $\mathrm{pH}$ changes that the resins can initiate. Another alternative treatment for spent resins that is currently receiving attention is incineration with subsequent solidification of the ash by pelletization with a 
proprietary binder 87 or incorporation in cement, asphalt, or polyester resin. Small amounts of resins have been incinerated in the fluid-bed incinerator at the RFP and in the acid-digestion test unit at HEDL.

3.2.5.3 Slurries and sludges. Slurries and sludges are generated at DOE installations and at commercial fuel cycle facilities. Disposal of the sludges that have gradually accumulated and settled out in old 1iquid-waste storage tanks at some DOE sites are now under study. 88,89 At BNL, $\sim 100 \mathrm{~m}^{3}\left(3500 \mathrm{ft}^{3}\right)$ of old diatomaceous-earth sludge was collected in storage tanks during the time that their graphite reactor was functioning. The sludge is contaminated with $\sim 10 \mathrm{Ci}$ of plutonium, $1.5 \mathrm{Ci}$ of ${ }^{235} \mathrm{U}$, and $21000 \mathrm{Ci}$ of mixed fission products. Removal of the sludge from the tanks will probably be a difficult operation. Incorporation of the sludge into a cement-silicate mixture is being contemplated. A possible alternative that is being considered is transfer to a shipping container by a nuclear services contractor, with subsequent shipment to a DOE burial ground.

The type of LIW sludges that have accumulated in outdoor settling ponds at wet process $\mathrm{UF}_{6}$ production and fuel fabrication plants are, for the most part, nitrates and some extremely insoluble $\mathrm{CaF}_{2}$ contaminated with traces of naturally occurring uranium isotopes and their decay daughters. They are being impounded at the plant sites, pending selection of the method to be used for removing and permanently disposing of them. On the other hand, the neutralized waste sludges from plutonium recovery operations at the RFP that have been allowed to collect in an outdoor storage basin are being removed, mixed with fly ash, and packaged for shipment to the Nevada Test Site (NTS) for disposal. Once this storage basin is cleaned, it will be used to collect Ro brine arising from cleanup of tertiary wastewater on the site. ${ }^{57}$. Retention pond sludges at the Oak Ridge Gaseous Diffusion Plant (ORGDP) are composed mostly of lime contaminated with traces of radioactivity (uranium $=17.1 \mu \mathrm{g} / \mathrm{ml}$ ) and sma1l amounts (ppm) of $\mathrm{Cr}, \mathrm{Cu}, \mathrm{Ni}, \mathrm{Zn}, \mathrm{Mn}, \mathrm{Pb}$, and other metals. No final decision on the method of disposal has yet been made, but laboratory and pilot-plant evaluations of fixation methods to determine drying requirements and solid strengths are planned. 90. 
Fuel-storagc-pool sludges at the ICPP at INEL were removed from the floor and walls of the pool and transferred to a waste storage tank by vacuum. From there, the sludge was transferred into portable concrete vaults for solidification with urea-formaldehyde resin prior to shipment to the Radioactive Waste Management Complex at INEL for disposal.91 The fuel-storage-pool sludges at the Morris (Illinois) operation are mostly precoat filter materials contaminated with tramp activity washed from the surface of the spent fuel cladding since no disassembly activity has taken place to date. All the sludges generated since start-up in 1973 are stored onsite in the low activity waste (LAW) vault. 9.2 Al1 sludges generated from spent fuel storage at the Nuclear Fuel Services (NFS) Fuel Reprocessing Plant at West Valley, New York, are collected in an LAW vault similar to the one at Morris. The sludges from the NFS wastewater treatment plant are dewatered by centrifugation, drummed, and then stored or disposed of onsite. 93

The LLWs normally referred to as sludges from nuclear power plants are filter sludges generated in in-plant stream cleanup. When precoat filters are used, the sludges may contain diatomaceous earth, cellulosic filter aids, and/or powdered resins. In the past, these sludges have merely been dewatered and drummed with sorbent materials in preparation for offsite shipment. Just as with spent resin disposal, newer regulations will require that these sludges also be incorporated into a solidified matrix for burial.

\subsubsection{Aqueous concentrates. Most DOE installations and many} commercial nuclear power plants (about three-fourths) use evaporators to clean up process streams and to concentrate dilute aqueous wastes. The condensates are usually purified by ion exchange and discharged to the environment or recycled within the plant. The composition of the aqueous waste concentrate is dependent on its source. The LLW concentrates from most DOE defense and R\&D operations are largely $\mathrm{NaNO}_{3}$ solutions, those from BWRs are high in $\mathrm{Na}_{2} \mathrm{SO}_{4}$, and those from PWRs are high in neutralized $\mathrm{H}_{3} \mathrm{BO}_{3}$. Additionally, at many facilities there are miscellaneous wastes that are collected in a common tank, neutralized, and evaporated prior to disposal. Such miscellaneous wastes have wide variations in their 
compositions, even at a single site. This lack of uniformity poses problems when formulating mixtures with solidification agents. Several DOE installations merely sorb such evaporator concentrates on vermiculite placed in drums, while other sites incorporate the concentrates into various cements or grout mixtures prior to disposal. Such cementitious grout mixtures are used for disposing of concentrated ORNL liquid wastes by injection into shale beds at the onsite hydrofracture facility.12,13 At nuclear power plants, evaporator concentrates have been solidified with Portland cement, cement with additives such as lime and/or sodium silicate, or with urea-formaldehyde resins. In Europe, Japan, and Canada, aspha1t (or polyethylene) has been widely used as the solidification agent for aqueous concentrates, but it has not been used in the United States up to the present. However, at least four U.S. nuclear power plants have ordered Werner \& Pfleiderer Company equipment for incorporating evaporator concentrates into asphalt, indicating that this method will probably be used here in the near future. Several U.S. nuclear power plants have ordered the Dow Chemical Company process for incorporating LLWs, including evaporator concentrates, into a solid matrix using an unsaturated polyester resin. As mentioned in Sect. 3.2.4, mobile units can be supplied by private vendors for incorporating aqueous concentrates into various cement systems and urea-formaldehyde or unsaturated polyester resins. Other options for treating aqueous concentrates include such VR methods as thin-film evaporation, crystallization, drying, calcination, or incineration by any of the previously described methods prior to immobilization in a solidification agent.

3.2.5.5 Special aqueous solutions. Decontamination, etching, electropolishing, and pickling, solutions are examples of the special aqueous solutions denoted here. They may be strong oxidants or reductants, have extremely corrosive properties, or be highly toxic in nature. These types of LLWs are usually given individual attention, and if the amount of such waste is large, an $R \& D$ program may be required to determine the safest and most effective method of treatment and disposal (see Sect. 4). For example, the extensive R\&D program that has accompanied the decontamination of Dresden-1 reactor ${ }^{94}$ includes provision for disposal of the spent decontamination solutions. 81 
3.2.5.6 0ils. The organic liquid wastes at nuclear installations include lubricating, vacuum pump, and cutting oils. As pointed out in Sect. 3.2.2.2, several DOE sites have incinerators that are capable, or potentially capable, of burning waste oils. In several cases, however, additional R\&D would be required to optimize performance. For example, the incinerators at Savannah River and Los Alamos are not designed to accommodate liquids, and therefore would require modification for burning oils. At some DOE sites, oils are currently being stored onsite, pending a decision on the method to be used for disposing of all types of organic liquids. Other DOE sites sorb waste oils on vermiculite or other sorbent materials placed in drums for disposal. Such wastes would not be acceptable at the commercial Barnwell burial ground since the state of South Carolina has imposed an upper limit of 1 vol \% on oil in packages shipped to the site. 95 The ruling has created a problem for nuclear power plants that had been incorporating waste oils into their regular solidification agents. The ORGDP transports its waste oils to the Y-12 Plant where a simple, but interesting, form of biodegradation is used. The oils are spread out over soil, plowed under, and fertilized. Gradual1y, the microorganisms in the soil break down the organic waste macer1a1s. 'the method has seasonal drawbacks in that rain, which is heavy in the region, interferes with the process, and it cannot be employed in the winter. Thus, another means of disposing of these waste oils is being sought.

3.2.5.7 Other organic 1iquids. Although the biodegradation of oils dispersed in soil is not an entirely satisfactory nperation at the Y-12 Plant, microorganisms in a stirred-tank bioreactor are used routinely to decompose the water-soluble organic coolants which are used at that plant (Sect. 3.2.2.3). As mentioned earlier, the use of microorganisms to degrade various organic contaminants in nuclear facilities is being studied under the ORNL bioengineering program.

At some DOE installations where chemical processing of spent fuel is performed, waste solvents are being stored in underground tanks until a decision is made on a satisfactory disposal method. Incineration in. an explosion-proof incinerator was the option chosen for the Barnwell 
Nuclear Fuel Plant, and presumably some form of incineration for waste solvent disposal is still a viable choice. At Hanford, Rockwell International has initiated a research program to study the utilization of microwaves in an oxygen plasma to decompose 2120,000 \& of old hexone wastes that are now stored onsite. The method is based on a similar microwave technique that has been developed by Lockheed (under contract to EPA) for destroying hazardous organic wastes, including such compounds as Malathion, methyl bromide, PCBs, phenylmercuric acetate, and Kepone. Successful detoxification of these substances on a pilot scale (i.e., $\sim 2.5$ to $3.5 \mathrm{~kg} / \mathrm{h}$ ) indicates that with development, a scale-up to $50 \mathrm{~kg} / \mathrm{h}$ is feasible. 96 . Another method that has been considered for disposing of waste solvents is oxidation by the HEDL acid-digestion process. Preliminary small-scale experiments with hexone and TBP have apparently shown promising results.

Other solvents (e.g., xylene or toluene in scintillation fluids) and various other organic liquids have been burned successfully in the cyclone incinerator at Mound Facility. Inctneration of numerous organic liquids has also been demonstrated with the fluidized-bed unit at the RFP (Sect. 3.1.2.2). The rotary-kiln incinerator being built at the RFP site is also designed to burn liquid wastes.

of special. concern among the organic liquid wastes generated at nuclear installations (especially the gaseous diffusion plants) are the PCBs which are used as insulator fluids in transformers and capacitors. The EPA has designated in the Toxic Substances Control Act (40 CFR 761) that high-temperature incineration is required for disposal of all PCB liquids, and that materials contaminated by PCBs are required to be disposed of either by incineration or in a chemical-waste 1 andfill. 70

\subsubsection{Other wet solid wastes. Two types of wet, solid LLW} rçidues that have been menlloned previously, but the conditioning of which has not been discussed, are reverse osmosis and ultrafiltration membranes and biological wastes. Incineration of both these types of wastes would of course be desirable. At the RFP, RO membranes have been shredded and successfully burned in the fluidized-bed demonstration unit. ${ }^{3}$ The treatment and disposal methods used or to be used for Ro and 
ultrafiltration membranes at other DOE sites and commercial nuclear power plants do not seem to have been specifically reported. None of the nuclear power plants that use RO membranes now have incinerators, thus the possibility of burning them onsite is precluded for the present.

The various institutions that use radioisotopes for bioresearch occasionally use incineration as a means of disposing of contaminated biological specimens. 97 In usual practice, however, most research institutions merely drum animal carcasses with sorbent materials or a solidification agent and ship them for burial at a licensed disposal site. Recent1y, BNL was required to pack such animal carcasses in dry salt to meet the acceptance criteria at the Barnwell commercial burial ground. The salt acts as a preservative that helps prevent the buildup of gaseous decomposition products in the container, thus aileviating the potential for explosion. Use of liquid preservatives (e.g., formaldehyde) is not recommended because. they may enhance chemical or radionuclide migration. 98 A few large institutions have onsite burial grounds for disposing of some biological wastes.

\subsection{References for Section 3}

1. C. R. Cooley and D. E. Clark, "Treatment Technologies for Non-HighLevel Wastes (U.S.A.)," In Proceedings of the International symposium on the Management of Wastes from the LWR Fuel Cycle, July 11-16, 1976, Denver, Colo., sponsored by U.S. ERDA, CONF-76-0701.

2. D. E. Clark and R. E. Lerch, "Volume Reduction Options for Management of Low-Level Radioactive Wastes," in Management of Low-Level Radioactive Waste, vol. 1, M. W. Carter, A. A. Moghissi, and B. Kahn, eds., Pergamon, New York, 1979.

3. L. C. Witbeck and R. M. Fryer, Waste Production and Management at EBR-II, ANL 79-14 (April 1979).

4. E. B. Moore, Jr., et al., Facilitation of Decommissioning Light Water Reactors, NUREG/CR-0569 (December 1979). 
5. K. J. Schneider, C. E. Jenkins, and R. E. Rhoades, Technology, Safety, and Costs of Decomissioning a Reference Nuclear Fuel Reprocessing Plant, NUREG-0278 (October 1977).

6. R. J. Smith, G. J. Konzek, and W. E. Kennedy, Jr., Technology, Safety, and Costs of Decommissioning a Reference Pressurized Water Reactor Power Station, NUREG/CR-0130 (June 1978).

7. C. E. Jenkins, E. S. Murphy, and K. J. Schneider, Technology, Safety, and Costs of Decommissioning a Reference Smalz Mixed Oxide Fuel Fabrication Plant, NUREG/CR-0129. (February 1979).

8. E. S. Murphy and G. M. Holter, Technology, Safety, and Costs of Decommissioning a Reference Low-Level Waste Burial Ground, NUREG/CR-0570 (June 1980).

9. S. L. She11, "The Disposal of Solid Waste at the Paducah Gaseous Diffusion Plant," in Compization of Papers Presented at the 1979 UCC-ND Waste Management Seminar, March 6-9, 1979, K/C-1347,

M. E. Mitchell, compiler, ORGDP (March 1979).

10. A. H. Kibbey, "A Brief Survey of Solid Radwaste Management at ERDA Installations," ORNL/CF-76/129 (April 1976). Released under the Freedom of Information Act in May 1977.

11. A. H. Kibbey, H. W. Godbee, and E. L. Compere, A Review of Solid Radioactive Waste Practices in Light-Water-Cooled.Nuclear Reactor Power Plants, NUREG/CR-0144, ORNL/NUREG-43 (October 1978).

12. U.S. Energy Research and Development Administration; Management of Intermediate Level Radioactive Waste, ERDA-1553 (September 1977).

13. H. O. Weeren, J. G. Moore, and E. W. McDaniel, "Waste Disposal by Shale. Fracturing at ORNL," in Scientific Basis for Nuclear Waste Management, vol. 1, G. J. McCarthy, ed., Plenum, New York, 1979.

14. B. L. Perkins, Incineration Facilities for Treatment of Radioactive Wastes: A Review, LA-6252 (July 1976). 
15. J. Phillips et a1., A Waste Inventory Report for Reactor and Fuel Fabrication Facility Wastes, ONWI-20, NUS 3314, prepared by NUS Corporation for the Office of Nuclear Waste Isolation, BattelleColumbus (March 1979).

16. R. L. Andersen, T. J. Beck, L. R. Cooley, and C. S. Strauss, Institutional Radioactive Wastes, NUREG/CR-0028, University of Maryland (March 1978).

17. L. Roche-Farmer, Study of Altemative Methods for the Management of Liquid Scintiliation Counting Wastes, NUREG-0656 (February 1980).

18. FMC Corporation, Engineered Systems Division, Selection of Waste Troatmont. Procass for Ratribubd TRU Waste at Idaho National. Engineering Laboratory, Final Report, Contract K-1010, FMC Document No. R-3689, prepared for EG\&G, Idaho (Nov. 10, 1977).

19. S. S. Freeman, L. M. Klingler, D. F. Luthy, and J. E. Todd, "The Mound Laboratory Cyclone Incinerator for Radioactive Waste,".in Management of Low-Level Radioactive Waste, vo1. 1, M. W. Carter, A. A. Moghissi, and B. Kahn, eds., Pergamon, New York, 1979.

20. L. M. Klingler, D. H. Batchelder, and E. L. Lewis, TRU Waste Cyclone Drum Incinerator and Treatment System: April - June 197.8, MLM-2541 (Ju1 $1 \bar{y} 28,1978)$.

21. L. M. Klingler, D. H. Batchelder, and E. L. Lewis, TRU Waste Cyclone Drum Incinerator and Treatment System: July - September 1978, MLM-2575 (Nov. 30, 1978).

22. L. M. Klingler, Defense Waste Cyclone Incinerator Demonstration Program: October - March 1979, MLM-2618 (May 22, 1979).

23. L. M. Klingler, Defence Waste Cyctone Incinerator Demonstration Program: Apriz - September 1979, MLM-2672 (Dec. 14, 1979).

24. L. M. Klingler, B. M. Alexander, and J. E. Todd, Mound Cyclone Inoinoraton Froliminary Dasign Critaria - Datoh Moda Oporation, MLM-2646 (Sept. 28, 1979). 
25. L. C. Borduin and A. L. Taboas, "USDOE Radioactive Waste Incineration Technology: Status Review," LA-UR-80-692, a paper presented at Waste Management ' 80 , sponsored by the University of Arizona, Tucson, Ariz., Mar. 10-14, 1980; proceedings in preparation.

26. M. D. Boersma, H. E. Hootman, and P. H. Permar, "Development of an Integrated Facility for Processing TRU Wastes at the Savannah River Plant," in Treatment, Conditioning, and Storage of Solid AlphaBearing Waste and Cladding Hulls, ISBN 92-64-01747-X, OECD, 1978; presented at the NEA-IAEA Technical Seminar on the Treatment, Conditioning, and Storage of Solid Alpha-Bearing Wastes and Cladding Hul1s, Paris, Dec. 5-7, 1977.

27. H. E. Hootman, D. J. Trapp, and J. H. Warren, "Operation of a Pilot Incinerator for Solid Waste," DP-MS-78-97, a paper presented at the 1979 Annual Meeting of the American Nuclear Society, Atlanta, Ga., June 3-8, 1979.

28. J. H. Warren, Design of an Experimental Incinerator for Alpha Waste, DP-1521 (August 1979).

29. H. E. Hootman, SRL, personal communication to A. H. Kibbey and H. W. Godbee, July 2, 1979, on work under the direction of Dr. David I. Orloff at the University of South Carolina.

30. J. D. Christian, B. E. Kirstein, and D. T. Pence, R\&D for an offGas Treatment System for a Slagging Pyrolysis Radioactive Waste Incinerator - Final Report for Phase I, SAI 178-747-LJ, prepared for EG\&G, Idaho, by Science Applications, Inc., San Diego, Calif. (June 1978).

31. A. J. Johnson, S. C. Burkhardt, J. A. Ledford, and P. M. Williams, Status Report: Waste Incineration and Imobilization for Nuclear Facilities (October 1977 - March 1978), RFP-2863 (May 1979).

32. D. L: Anderson, F. G. Meyer, and P. K. Feng, Fluidized Bed Incineration System for U.S. Department of Energy Defense Waste, JuZy December 1977, RFP-2734 (October 1978). 
33. P. M. Williams, A. J. Johnson, and J. A. Ledford, "Vitrification of TRU Wastes at Rocky Flats Plant," in Proceedings of Waste Management '79, Feb. 26 to Mar. 1, 1979, Tucson, Ariz., R. G. Post, ed., University of Arizona, 1979.

34. R. E. Lerch and C. R. Allen, Division of Waste Management Programs Progress Report, January - June 1978, HEDL-TME 78-73 (December 1978).

35. D. E. McKenzie, L. F. Grantham, and R. B. Paulson, "Volume Reduction of Waste Contaminated by Fission Product Elements and Plutonium Using Molten Salt Combustion," in Management of Low-Level Radioactive Waste, vol. 1, M. W. Carter, A. A. Moghissi, and B. Kahn, eds., Pergamon, New York, 1979.

36. A Comparison of Slagging Pyrolysis and Molten Salt Incinerators for Treating TRU Waste at the INEL, TID-29095, 77-92 RE (November 1977).

37. G. J. Shea, TRU Waste Analysis and Preliminary Operating Parameters for a Radioactive Waste Slagging Pyrolysis Incinerator, TID-29096, a report prepared for EG\&G, Idaho (March 1978).

38. T. G. Hedah1 and M. D. McCormack, Research and DeveZopment PZan for the Slagaing Pyrolysis Incinerator, TREE-1309 (January 1979).

39. R. Kohout, "Incineration of Radioactive Waste from Nuclear Power Reactors," a lecture given at the ASME Course on Radioactive Waste Management for Nuclear Power Reactors, Alexandria, Va., May 21-25, 1979.

40. C. C. Chapman et al., Vitrification of Hanford Wastes in a JouleHeated Ceramic Melter and Evaluation of Resultant Canisterized Product, PNL-2904 (August 1979).

41. M. J. Plodinec and P. H. Chrismar, SmaZZ-Scale, Joule-Heated Melting of Savannah River Plant Waste Glass. I. Factors Affecting LargeScale Vitrification Tests, DP-1535 (October 1979).

42. L, Penberthy, Penberthy Electromelt International, Inc., talk presented at the Volume Reduction Workshop, Waste Management ' 80 , Tucson, Ariz., Mar. 10-14, 1980. 
43. U.S. Energy Research and Development Administration, Final Environmental Impact Statement, Brookhaven National Laboratory, Upton, New York, ERDA-1540 (July 1977).

44. Gilbert/Commonwealth Companies, State of the Art Review of Radioactive Waste Volume Reduction Techniques for Commercial Nuclear Power Plants, ORNL/SUB-79/13837/2 (April 1980).

45. Billy R. Dickey, "Long-Term Management of High-Level Defense Wastes at the Idaho Chemical Processing Plant," pp. 93-99 in Nuclear Engineering Questions: Power, Reprocessing Waste, Decontamination, Fusion, R. D. Walton, Jr., ed., AIChE Symposium Series, vo1. 75, No. 191 (1979).

46. W. L. McCabe and J. C. Smith, "Evaporation," pp. 427-463, Chap. 16, in Unit Operations of Chemical Engineering, 3rd ed., McGraw-Hill, New York; 1976.

47. R. H. Perry and C. H. Chilton, eds., "Evaporators," Pp. 11-27 to 11-38 in Chemical Engineer's' Handbook, 5th ed., McGraw-Hill, New York, 1973.

48. F. C. Standiford, "Evaporation," pp. 559-580 in Kirk-Othmer Encyclopedia of Chemical Technology, 2nd ed., vo1. 8, Wiley, New York, 1965.

49. H. W. Godbee and A. H. Kibbey, The Use of Evaporation to Treat Radioactive Liquids in Light-Water-Cooled Nuclear Reactor Power plante, NUREG/CR 0142, ORNL/NUREG-42 (SejLember 1978).

50. H. W. Godbee, Use of Evaporation for the Treatment of Liquids in the Nuclear Industry, ORNL-4790 (September 1973).

51. Y. Yamomoto, N. Mitsuishi, and S. Kadoya, compilers, Design and Operation of Evaporators for Radioactive Wastes, Technical Report Series No. 87, International Atomic Energy Agency, Vienna, 1.968.

52. H. L. Freese and W. T. Gregory III, "Volume Reduction of Liquid Radioactive Wastes Using Mechanically Agitated Thin-Film Evaporators," a paper presented at the 85 th National Meeting of American Institute of Chemical Engineers, Philadelphia, Pa., Junc 1978. 
53. D. B. Purchas, Industrial Fiztration of Liquids, 2nd ed., CRC Press, The Chemcial Rubber Co., Cleveland, Ohio, 1971.

54. W. L. McCabe and J. C. Smith, Unit Operations of Chemical Engineering, pp. 922-53, Chap. 30, 3rd ed., McGraw-Hill, New York, 1976.

55. A. H. Kibbey and H. W. Godbee, The Use of Filtration to Treat Radioactive Liquids in Light-Water-Cooled Nuclear Reactor Power Plants, NUREG/CR-0141, ORNL/NUREG-41 (September 1978).

56. A. S. Foust et al., Principles of Unit Operations, pp. 458-65, Chap. 22, Wiley, New York, 1960.

57. J. Markind and I'. V. Tran; A Study of Reverse Osmosis Applicubizily to Light Water Reactor Radwaste Proceseing, NUREG/CR-0724 (April 1979).

58. International Atomic Energy Agency, Operation and Control of Ion Exchange Processes for Treatment of Radioactive Wastes, Technical Report Series No. 78, IAEA, Vienna, 1967.

59. K. H. Lin, Use of Ion Exchange for the Treatment of Liquids in Nuclear Power Plants, ORNL-4792 (December 1973).

60. W. E. Clark, The Use of Ion Exchange to Treat Radioactive Liquids in Light-Water-Cooled Nuclear Reactor Power. Plants, NURFG/CR-014.3, ORNL/NUREG/TM-204 (August 1978).

61. U.S. Energy Research and Development Administration, Final Environmental Impact Statement, Waste Management Operations, Idaho National Engineering Laboratory, Idaho, p. II-62, ERDA-1536 (September 1977).

62. R. M. Davis, Biodegradation of Waste, Organic Mackining Coolants, Y-2192, Y-12. P1ant, Oak Ridge, Tenn. (November 1979).

63. W. W. Pitt, C. W. Hancher, B. D. Patton, and S. E. Shumate II, "Advanced Biological Treatment of Aqueous Effluent from the Nuclear Fuel Cycle," in Compitation of Papers Presented at the 1979 UCC-ND Waste Management Seminar, March 6-7, 1979, K/C-1347, M. E. Mitche11, compiler, ORGDP (March 1979). 
64. International Atomic Energy Agency, Chemical Treatment of Radioactive Wastes, Technical Report Series No. 89, IAEA, Vienna, 1968.

65. International Atomic Energy Agency, Use of Local Minerals in the Treatment of Radioactive Waste, Technical Report Series No. 136, IAEA, Vienna, 1972.

66. R. W. Granlund and J. F. Hayes, "Solidification of Low-Level Radioactive Liquid Waste Using a Cement-Silicate Process," in the Proceedings of the Health Physics Society 12 th Midyear Symposium on Low-Level Radioactive Waste Management, Feb. 11-15, 1979, Williamsburg, Va., EPA 520/3-79-002 (May 1979).

67. M. O. Weaver, G. F. Fanta, and W. M. Doane, "Highly Absorbent Starch-Based Polymer," a paper presented at the International NonWovens and Disposables Association, Washington, D.C., Mar. 5-6, 1974; paper available from Northern Regional Research Laboratory, Agricultural Research Service, U.S. Department of Agriculture, Peoria, Ill.

68. J. F. Pritchard and R. R. Komrow, "A Method for Treating Liquid Radioactive Wastes," in Management of Low-Level Radioactive Waste, vol. 1, M. W. Carter, A. A. Moghissi, and B. Kahn, eds., Pergamon, New York, 1979.

69. M. A. Condron and S. S. Freeman, Volume Reduction of Tritiated Liquid Wastes with Super SZurper; MLM-2452 (Oct. 14, 1977).

70. S. F. Seltzer, "PCB Containment at the Paducah Gaseous Diffusion Plant," in Compization of Papers Presented at the 1979 UCC-ND Waste Management Seminar, March 6-7, 1979, K/C-1347, M. E. Mitchell, compiler, ORGDP (March 1979).

71. L..A. Emelity, J. R. Buchholz, and P. E. McGinnis, "Review of Radioactive Liquid Waste Management at Los Alamos," LA-UR-77-1195, in Management of Low-Level Radioactive Waste, vol. 1, M. W. Carter, A. A. Moghissi, and B. Kahn, eds., Pergamon, New York, 1979. 
72. R. M. Neilson, Jr., and P. Colombo, Solidification of Simulated Transuranic Contaminated Incinerator Ash Wastes IJing Portland. I'ype I C'ement, BNL-50854 (May 1978).

73. W. F. Holcomb, A Sumey of the Available Methods of Solidification for Radioactive Wastes, Technical Note ORP/TAD-78-2 (November 1978).

74. P. Colombo and R. M. Neilson, Jr., Properties of Radioactive Wastes and Waste Containers, First Topical Report, NUREG/CR-0619, BNL-NUREG50957 (August 1979).

75. International Atomic Energy Agency, Bituminization of Radioactive Wastes, Technical keport Series No. 116, IAEA, Vịenna, 1.970.

76. B. Golding, Polymers and Resins, Their Chemistry and Chemical Engineering, pp. 264-276, D. Van Nostrand, Princeton, N.J., 1959.

77. R. V. Subramanian and R. A. V. Raff, "Immobilization of Low Level Radioactive Wastes," AIChE Symposium Series 72(154), 62-64 (1976).

78. R. Mahalingam, R. V. Subramanian, M. Juloori, and Wen-Pao Wu, "Pilot Plant Studies on the Polyester Encapsulation Process for Hazardous Wastes," presented at the National Conference on Treatment and Disposal of Industrial Waste Waters and Residues, Houston, Tex., Apr. 26-28, 1977; available from Washington State University, Pullman, Wash.

79. R. V. Subramanian, R. Mahalingam, Wen-Pao Wu, and M. Iu1nori, "Polyester Encapsulation of Hazardous Industrial Wastes," presented at the National Conference on Treatment and Disposal of Industrial Waste Waters and Residues, Houston, Tex., Apr. 26-28, 1977; available from Washington State University, Pullman, Wash.

80. H. E. Filter and K. Roberson, "Solidification of Low-Level Radioactive Wastes from Nuclear Power Plants" in Management of Low-Level Radioactive Waste, vol. 1, M. W. Carter, A. A. Moghissi, and B. Kahn, eds., Pergamon, New York, 1979.

81. J. S. Graves, "The Chemical Cleaning of Dresden Unit 1," in Trans. Am. Nuc1. Soc. 28, 131 (June 1978). 
82. D. E. Harmer and O. U. Anders, "A Prototype Operation for the Dresden-1 Decontamination," Trans. Am. Nucl. Soc. 28 131-32 (June 1978).

83. T. A. Green and R. D. Sheeline, "Inert-Carrier Radwaste Volume Reduction and Solidification System," Trans. Am. Nucl. Soc. $\underline{32}$, 696-97 (June 1979).

84. L. C. Oyen and A. H. Kibbey, "Volume Reduction, Solidification, and Packaging of Wastes from Nuclear Power Plants," Chap. 7 in Nuclear Power. Waste Technology, A. A. Moghissi, H. W. Godbee, M. S. Ozker, and M.W. Carter, eds., ASME Monograph G00132, American Society of Mechanical Engineers, New York, 1978.

85. U.S. Nuclear Regulatory Commission, "Design Guidance for Solid Radioactive Waste Management. Systems Installed in Light-Water-Cooled Nuclear Reactor Power Plants," NUREG-75/087, Standard Review Plan, USNRC, Office of Nuclear Reactor Regulation, Sect. 11.4, Effluent Treatment Systems Branch Technical Positions, BTP ETSB 11-3 (Nov. 24, 1975).

86. R. E. Lerch and C. R. Allen, compilers, Division of Waste Management Programs Progress Report, JuZy-December 1977, HEDL-TME 78-48 (July 1978).

87. J. R. May, "Volume Reduction of Liquid and Solid Radioactive Wastes Using a Fluidized Bed Calciner/Incinerator," presented at the Fifth International Fair and Technical Meetings of Nuclear Industries, Basel, Switzerland, Oct. 3-8, 1978.

88. H. O. Weeren and T. S. Mackey, Waste Sludge Resuspension and Transfer - DeveZopment Program, ORNL/TM-7125 (February 1980).

89. M. J. Plodinec, "Development of Glass Compositions for Immobilization of Savannah River Plant Waste," in Scientific Basis for Nuclear Waste Management, G. J. McCarthy, ed., vol. 1, Plenum, New York, 1979.

90. C. P. McGinnis, "Solid Waste Disposal," in Compization of Papers Presented at the 1979 UCC-ND Waste Management Seminar, March 6-7, 1979, K/C-1347, M. E. Mitchell, compiler, ORGDP (March 1979). 
91. G. W. Hoech and D. W. Rhodes, Removal and Disposal of Radioactive Sludge from the Fuel Storage Basin at the Idaho Chemical Frocessing Plant, ICP-1195 (June 1979).

92. K. J. Eger and G. E. Zima, Commentary on Spent Euel Storage at Morri.s Operation, NUREG/CR-0956, PNL-3065 (July 1979).

93. Nuclear Fuel Services, Inc., Safety Analysis Report, NFS' Reprocessing Plant, West Valley, New York, Docket No. 50-201, Sect. V-8, vol. I (1973).

94. R. A. Shaw and D. L. Uh1, "EPRI Programs in Radiation Control at Nuclear Power Plants," presented at the International Water Conference, Oct. 26-28, 1976, Pittsburgh, Pa.

95. H. G. Shealy, "Regulatory Aspects of Low-Leve1 Waste Disposal" in the Proceedings of the Health Physics Society 12th Midyear Symposium on Low-Level Radioactive Waste Management, Feb. 11-15, 1979, Williamsburg, Va., EPA 520/3-79-002 (May. 1979).

96. L. J. Bailin and B. L. Hertzler, Development of Microwave Plasma Detoxification Process for Hazardous Wastes, Phase I, Final Report, PB-268526, prepared for the U.S. Enyironmental Protection Agency by Lockheed Research Laboratory, Palo Alto, Calif. (April 1977).

97. T. Beck, L. Cooley, M. McCampbe11, and R. Andersen, Institutional Radioactive Waste - 1977, NUREG/CR-1137, University of Maryland (October 1979).

98. G. A. Benda, "Non-fuel Cycle Waste," in Proceedings of Waste Management '79, Feb. 26 to Mar. 1, 1979, Tucson, Ariz., R. G. Post, ed., University of Arizona, 1979. 


\section{RECOMMENDED RESEARCH, DEVELOPMENT, AND DEMONSTRATION}

There are several areas in the treatment of radioactive LLW that could benefit from more intensive study. Among them are VR methods, organic 1iquid and waste metals treatment, and waste solidification techniques. The unit operations used in waste treatment and the methods used in waste solidification systems. should be improved.

\subsection{Volume Reduction of Waste After Generation}

The amount of radioactive LLW being generated in the United States is expected to continue to increase despite efforts to minimize its generation. The many variables involved in any VR process need to be defined (i.e., a data base needs to be built) and their interrelationships evaluated (i.e., systems analyses carried out) if optimization of VR is to be realized. Too of ten in the past, secondary wastes that arise from the treatment of primary wastes have been ignored. Also, the trade-offs between smaller volume and increased radioactivity level have often been neglected in the assessment of VR processes for LLW. For a correct perspective, unbiased studies should include any immobilization techniques that may be applied to the residues from a VR process. In the following discussion, the recommended $R \& D$ of treatment methods for dry wastes is again considered separately from that of wet wastes.

\subsubsection{Dry wastes}

The dry, combustible and/or compactible radioactive wastes generated in government and commercial activities are similar in that they all contain such things as cloth, rubber, plastics, paper, and wood. Both sectors also generate combustible l1quid wastes (e.g., solvents or oils) and noncombustibles such as metals or glass. The proportions of these wastes vary widely, depending on the activity being conducted at a facility, and because a treatment procedure that may be suitable in one case may not necessarily be applicable in another. However, more conscientious segregation of the dry wastes would be beneficial in all instances because it simplifies the choice of a treatment method. 
4.1.1.1 Physical methods. Compaction, shredding, chopping, cutting, and other size reduction methods need refinement an/or development to improve their versatility, especially in remote operations. The problem of airborne radioactive particulates associated with such operations often remains unresolved. Future decommissioning of nuclear facilities will increase the need for improved size reduction methods, as well as the demand for trained crews to perform the operations.

4.1.1.2 Chemical methods. In the United States, there has been only limited experience with the incineration of dry, low-level $\beta-\gamma$ contaminated wastes. The practice was tried and abandoned in the early days of operation at Shippingport Nuclear Power Plant, and, after lessthan-satisfactory performance with contaminated wastes, the old incinerator at the Yankee Rowe Nuclear Power Plant has been restricted to burning essentially nonradioactive trash. The licensing of incinerators for commercially generated radioactive wastes is under the jurisdiction of the NRC. The volatility of some fission and activation products (e.g., $129,131 \mathrm{I},{ }^{106} \mathrm{Ru},{ }^{14} \mathrm{C}$, and ${ }^{3} \mathrm{H}$ ) could pose problems in meeting release requirements if an off-gas system is not properly designed and installed. Not enough is known about the composition of the off-gases that can be expected from the combustion of the various types of commercial LLWs which have been previously described in this survey. A study should be made on the effects of eliminating the use of problematic materials (e.g., PVCs) whenever possible and should include other possible ways tn accomplish off-gas cleanup (e.g., more efficient scrubbing and the use of catalysts or surbents).

Although incineration technology has advanced significantly in recent years, the treatment of the off-gases from the combustion of $\beta-\gamma$ contaminated wastes needs thorough demonstration. An evaluation should be made of the secondary wastes that are generated in achieving sufficient off-gas cleanup. Up to now, the data pertinent to the design and performance of off-gas systems for use in $\beta-\gamma$ waste combustion have been gathered primarily by private vendors of incineration equipment and are therefore not readily available. Independent studies are needed on off-gas treatment systems so that licensing procedures could be simplified. 
The trade-offs involved in selecting an incineration process for $\beta-\gamma$ contaminated wastes from all sources need precise identification. An evaluation of the abilities and limitations of available incinerator systems in accommodating a wide range of anticipated LLWs should be made. Furthermore, a study to determine the advantages and disadvantages of large centrally or regionally located incinerators vs smaller onsite units to process commercially generated radioactive wastes would be useful. The desirability of having more than one type of incinerator (e.g., one for dry trash and one for liquid wastes) at a single site and defining the many parameters involved in making such decisions would be of value. A paper study of the incineration and/or other processes used throughout the world for successfully treating power plant, medical, bioresearch, and other $\beta-\gamma$ LLWs derived from institutional and industrial applications of radioisotopes could be a valuable guide.

A recurring problem that is closely associated with drying and incineration processes is the difficulty frequently encountered in transferring dry powders or ashes (e.g., hoppers clog, screw conveyors jam, and moving belts slip). The development of reliable remote methods for achieving quantitative transfers would be a substantial contribution to present waste-treatment practices.

\subsubsection{Wet wastes}

The variety and complexity of the wet LLWs preclude easy solutions to the many problems that their treatment presents. An attempt is made here to group them in ways such that common treatment methods can be applied.

4.1.2.1 Physical methods. The VR of wet, solid LLW (e.g., spent resins, zeolites, and diatomaceous-earth filter sludges) is usually accomplished by physical means (e.g., filtration or centrifugation) that remove associated water. The presence of abrasives (e.g., diatomaceous earth) in wet wastes can cause undue wear on the metal surfaces they contact during a dewatering process. Choice of properly designed equipment (e.g., case-hardened steel for centrifugal bowls) to match the properties of the solids being dewatered can improve performance and minimize 
maintenance, which in turn reduces the volume of secondary wastes. Filtration remains more of an art than a science. A study of the uses of filtration in the nuclear industry, with special attention to performance (e.g., can the amount of precoat used be reduced or can cartridge filter changeouts be minimized), would be helpful in reducing wet waste volumes and personnel exposures. Studies directed toward finding better ways of drying wet, solid radioactive wastes should be pursued. These might include a physiochemical process such as microwave drying.

As pointed out above, proper equipment design and the proper choice of a process for treating a wet waste can reduce the volume of waste to be disposed of. This also applies to the evaporation of dilute aqueous wastes in nuclear facilities. A high equipment DF ensures greater possibility of water recycle with minimal secondary waste generation (e.g., spent resins from condensate cleanup). Since the use of evaporators is so widespread in the nuclear industry, an evaluation of the performance of the various types being employed would be an aid in reducing waste volumes. Evaporators and crystallizers are used routinely to reduce the volume of liquid LLWs. Operating experience shows that evaporators and crystallizers routinely give DFs (feed-to-condensate ratio) equal to $10^{2}$ to $10^{4}$. Theoretical considerations indicate that these DFs should exceed $10^{6}$. Experiments are needed to determine the reasons for these low DFs and to find ways to increase them. Engineering correlations are needed to describe mist formation vs physical properties and operating conditions. With knowledge of how mists form, designs could be chosen to minimize mist formation. Experimental studies are needed to determine the factors limiting demister performance. If the phenomena that limit demister performance are understood, improved designs can be found. More studies are needed on multiple-effect evaporaLurs [1.e., sevcral evaporators (or effects) connected so that the vapor from one effect serves as the heating medium for the next] to determine whether they can give improved (higher) DFs and better energy utilization. Operating experience also shows that an evaluation is sorely needed of the factors (e.g., corrosion, maintenance, controls, etc.) that influence the availability and reliability of evaporators and crystallizers used to treat wastes. 
The possibility of recycling scintillation fluids after purification by evaporation or distillation and the separation of such fluids from crushed or pulverized vials are two other areas that deserve some consideration.

4.1.2.2 Chemical methods. The oxidation of wet, radioactive organic wastes (solid and liquid) has not been adequately studied in the United States. Thse materials can be greatly volume-reduced by some form of incineration (Sect. 3.1), but again, proper choice of process and equipment is essential to maximize overall VR. Incineration is already being used in certain limited cases (e.g., for animal carcasses and scintillation fluids at some institutions). However, the rigid specifications imposed on the releases of radioactivity and particulates in the off-gas make licensing a difficult process, which discourages wider application of this technique.

The problems associated with burning all types of low-level wet wastes should be carefully examined with regard to combustion characteristics and off-gas composition. For example, the recent NRC study ${ }^{1}$ on disposal of scintillation fluids could be extended to include more combustible wet wastes (e.g., ion exchange resins, lubricating oils, and organic coolants). As mentioned several times before, a particularly hazardous organic liquid waste that has caused some concern at DOE installations (especially, the Gaseous Diffusion Plants) is the PCB used in transformers and capacitors. The EPA has specified that, where possible, PCBs (Iiquids and contaminated solids) must be destroyed by hlyh-temperature incineration. The DOE study now in progress for determining its needs for such incinerators should be continued. The disposal of noncombustible solids that are contaminated with PCB is a separate problem that needs attention. The availability of the proper type of incinerator and landfill for disposal of the potentially radioactive PCBs from nuclear facilities is an area that should receive more study. Waste solvents from the chemical processing of spent nuclear fuels have accumulated at some DOE sites because a satisfactory method for their disposal has not yet been developed. Preliminary scouting experiments at HEDL have indicated that oxidation by the acid-digestion process 
may be one way of safely destroying these liquids (and spent ion exchange resins). As described before, Rockwell (at Hanford) has recently initiated a research program in which a plasma/microwave technique is being tested for detoxification of old hexone wastes. These and other techniques (e.g., biodegradation) for decomposing or otherwise disposing of waste solvents should continue to be investigated. Imbiber beads might also find application as an intermediate treatment step in the incineration or immobilization and disposal of organic liquids. The possibility of applying such methods to other organic liquids (e.g., scintillation fluids, various oils, and PCBs) should also be evaluated. Incineration may prove to be the most viable alternative for treating organic, wet LLW if the unit is suitably designed and adequate off-gas treatment can be achieved. However, some incineration processes may be more amenable to treating these wastes than others, and an unbiased assessment is essential. Some additional study along these lines would benefit not only the power and health industries but government installations as well.

\subsection{Metallic Waste Treatment}

The metals in some wastes are of sufficient purity that recovery becomes a feasible alternative to disposal. Not only the cost and abundance of the metal, but also its hazard potential, must be considered in making such a decision.

\subsubsection{Hazardous metals}

The contaminated elemental sodium wastes that are being stored at ANL-West are peculiar to that site. The disposal of these with wastes having a high chemical reactivity will require the development of a facility for treating them. Apparently, criteria must also be developed for acceptance of the treated sodium wastes (sodium alcoholates and/or oxides are a possibility) at the INEL Radioactive Waste Management Complex.

Other hazardous metallic LLW (e.g., cadmium and mercury) that are generated in DOE operations should be inventoried and a study conducted to determine the adequacy of present treatment and disposal methods. 


\subsubsection{Potentially reusable metals}

In general, LLW metals can be separated into two categories - those having only surface contamination and those that have activation products distributed throughout the structure. Different methods are necessary for treating each of these types of contaminated metals, and a need for R\&D work exists in both cases.

4.2.2.1 Surface contaminated metals. The development and testing of more effective cleaning reagents (e.g., complexing agents, detergents, and solvents) for removing radioactive contamination from metal surfaces should continue to be pursued. The need for such compounds or formulations will increase as the decommissioning of all types of nuclear facilities increases. Methods for effective application of cleaning reagents by remote operation may need to be developed. Improvement of decontamination techniques could possibly result in greater recovery and reuse of materials or lower disposal costs. The generation of secondary wastes in decontamination operations must always be considered. The need for developing solidification agents for special decontaminating reagents may be necessary.

4.2.2.2 Irradiated metals. An inventory should be made of the highly purified, but slightly radioactive, waste metals from sources such as reactors and particle accelerators that have accumulated at DOE sites. The value of such metals could then be estimated, and the treatment options could be evaluated. If recovery and reuse are deemed appropriate, emelting techniqucc could bc aclccted or developed. If discard is decided upon, the adequacy of the present method of outdoor aboveground storage should be examined. The development of melting techniques to accomplish VR may be desirable. It may be worthwhile to include universities and colleges with research reactors and accelerators in the survey.

\subsection{Upgrading Solidification Systems for Low-Level Wastes}

The solidification systems currently in operation in the United States use cement (with or without additives) and urea-formaldehyde or 
modified vinyl ester resins. Asphalt is also expected to be used in the near future. Experience with these solidification agents has pointed up their limitations, as well as their advantages. Speaking broadly, no one solidification agent can be used equally well for all types of LLWs. The present practice at some government installations of sorbing liquid LLWs on vermiculite alone is contrary to the NRC Regulatory Guides for commercially generated liquid wastes. They are required to be solidified into a freestanding monolith. Improvements in the utilization of existing systems and a search for new and better ones should be an ongoing endeavor.

\subsubsection{Limitations of currently used solidification agents}

Cement solidification can be retarded or prevented by the presence of some organic compounds (e.g., sugar) or by too high a concentration of borate as it occurs in PWR wastes. On the other hand, urea-formaldehyde resin polymerization is adversely affected by too high a concentration of $\mathrm{Na}_{2} \mathrm{SO}_{4}$ in BWR wastes. Neither of these solidification agents can tolerate the presence of much oil or detergent, and no definitive studies have been made on the presence of antifoaming agents (e.g., those that accumulate in evaporator bottoms) in these systems. Presently, the limitations of unsaturated polyester resins in incorporating oils and other organics are not well known.

Perhaps the most troublesome wet-waste solidification problem is the immobilization of spent ion exchange resins. The technology for resin solidification in various matrix materials is not developed to the point that a satisfactory solidified waste product can always be ensured. The parameters effecting spent resin solidification processes (e.g., water content, $\mathrm{pH}$, reaction with the matrix material, and other physicochemical properties) need investigation. On the basis of such studies, the boundary conditions for obtaining products with specified characteristics could then be established. Methods for producing consistent resin feed materials for solidification processes may need to be developed. For instance, swelling and shrinking behaviour, which is strongly dependent on water content, can reduce the mechanical strength of the final 
solidified product. Therefore, methods for drying spent resins as a pretreatment to solidification would be of interest. Microwave drying should be considered in this application.

Outlined above are areas requiring future study that could lead to improved solidified products. The European, Japanese, and Canadian experience with asphalt and/or polyethylene should be. studied and evaluated in view of the anticipated use of asphalt for waste solidification at some U.S. nuclear power plants.

\subsubsection{Exploration for new solidification methods}

Many of the low-melting ceramics and glasses are not considered suitable for high-level wastes because of thermal effects (e.g., phase changes and/or devitrification), radiation effects (e.g., radiolytic gas generation and/or metamictization), and poor bulk properties (e.g., low thermal. conductivity and compressive strength). In general, these effects or disadvantages do not apply if LLW, instead of high-level waste, is incorporated into a given binding agent. This suggests that an experimental program should be carried out to demonstrate the applicability of these agents to LLW. Hot-pressed and polymer-impregnated cements are other possible candidates for incorporating LLW. Also, advanced, new, or nontraditional binding agents are being developed and used to advantage in chemical processing and other industries. A survey should be made to evaluate existing information on the characteristics of binding agents used with LLW and with comparable (with respect to nonradioactive constituents) wastes in other industries. In particular, attention should be given to prospective, untried agents that might be considered for LLW. Such a study would embrace new agents and should be unhampered by ties to conventional solidification agents and processes. Agents that have proven valuable in at least one other application (i.e., practical experience with them exists) should be tested for application in LLW treatment. Any that show the promise of making improved solidified waste products should be chosen for process development and pilot-scale demonstration. 


\subsubsection{Maximizing the amount of waste incorporated per unit volume of solidified product}

By carefully choosing compatible VR and solidification methods, the amount of waste incorporated into the final product can be maximized. Often this ratio is loosely referred to as "packaging efficiency." It is sometimes expressed on the basis of the volume ratio of the waste to the binder, and sometimes as the volume or mass of the waste incorporated per unit volume of final solidified product. Unless the exact basis of measurement is specified, valid comparisons among solidified waste products are difficult, if not impossible. The nonradioactive bulk solids are usually the factor that limits the packaging efficiency for solidified LLWs. For aqueous solutions and solid wet wastes, the dry weight of total waste solids incorporated per unit volume of solidified product is the more meaningful value. The solids loading must not exceed a limit beyond which undesirable phystcal properties become manifest (e.g., retarded setting of cement or urea-formaldehyde resins, crumbly cement products, or abrasion of equipment while forming asphalt products). For oils and other organic liquids, there is almost no data available for any of the commonly used solidification agents that would indicate the amounts (volume/final solidified volume) that might be deemed acceptable at a burial ground. In view of this lack of information, the state of South Carolina requires that the oil content in solidified wastes accepted for burial at Barnwell not exceed 1 vol \%. Studies to determine the maximum loadings of the various LLWs that can be tolerated in a given matrix material are needed.

\subsubsection{Detection of free (unbound) liquid in sealed waste packages}

The presence of free liquid in solidified LLW packages is undesirable for ac lcast two reasuns: first, a package that might leak in transit to a burial ground could disperse radioactivity in the public domain; and second, it is likely that any free water would contain acids or bases which could accelerate container corrosion. Though no, credit is assigned to the container after burial, the longer it can remain intact, the more time there is for radioactive decay inside the extra barrier, thus 
ensuring added protection against nuclide migration. Although free liquid may appear in all the common solidification systems (with the exception of asphalt which boils the water away), the solidification agent that most frequently suffers from the free-water problem is urea-formaldehyde resin. The formation of water is inherent in the urea-formaldehyde polymerization reaction, which may continue after a container is sealed or after a hardened layer forms across the top. The formation of such a layer prevents visual perception of free water in the bottom of the container. Attempts to detect free liquid by inserting a rod or pole through the hardened layer are not always successful, especially if the layer is too thick. Another method that has been tried with less-than-adequate performance is periodic drainage of free water from the bottom of the container. The method currently being used by a vendor of solidification service entails use of a sacrificial tube that reaches down to the bottom of the container through which any liquid that forms or remains after $24 \mathrm{~h}$ can be removed by pumping. The fact that no more water is formed after $24 \mathrm{~h}$ apparently remains unverified. Also, the bumping and jarring that occurs in transit to burial can, in some cases, cause release of encapsulated water from the urea-formaldehyde matrix. The problems encountered with solidification processes have a variety of causes and are not the same for all solidification agents. Where free water is obviously present, some waste generators have added sorbents (e.g., vermiculite or Portland cement) to the waste packages to alleviate the condition. Prevention of the occurrence of free water by controlling the solidification process within predetermined parameters is considered to be the best way of dealing with the problem.

Until a few months ago, no method for reliably detecting free water in sealed containers of solidified liquid wastes had been suggested. Now, at HEDL, an external method, using infrared scanning or a thermal transducer to sense the differences in the thermal properties of solids and liquids within the container, ${ }^{2}$ is showing promise. More development work is needed to expand the versatility and applicability of this method and to demonstrate its usefulness as a mobile instrument. 


\subsubsection{Determination of leaching properties}

Leach rate is generally conceded to be the most important property in the evaluation of solid waste products generated by the nuclear industry and to be the most difficult to measure and interpret. Standardized, evaluated leach rate data are needed by developers of waste solid forms, producers of large-scale solid products, and those concerned with the interim storage, transportation, and disposal of these solids. Mathematical models being applied to nuclear waste disposal systems require leach rate data on the solid products. There is a present need for solidification system vendors and nuclear waste generators (e.g., nuclear power plant operators) to be able to compare the efficacy of their processing on a common hasis. There is also a need to present common-basis leaching information to regulatory agencies. Ultimately, the attainment of a certain leach rate will probably be required for acceptance of solidified wastes at burial sites.

Although the importance of leaching has long been recognized, the situation remains complex for several reasons: (1) leaching itself is quite complex, consisting of several concurrent reactions and/or mechanisms, the relative importance of which changes with time, temperature, impuritics in the water, radioisotope of interest, matrix material, and other variables; (2) the actual leaching conditions that a solidified waste form may encounter during its lifetime cannot be known precisely, with postulated conditions varying widely; and (3) each investigator of waste forms has tended to use a leach test procedure unique to his or her study, making intercomparisons difficult. As a first step toward rectifying the latter situation, the IAEA published a suggested standard leach test in $1970 .{ }^{3}$ The suggested test has generally been agreed to in principle, but has not always been followed exactly in practice. Instead, many tests now being used are described as "modified" IAEA tests. The "modifications" are unique to individual laboratories, so standardization is still lacking.

Other efforts directed toward adoption of uniform lcach-test standards are now under way. A working group (ISO/TC 85/SC 5/WG 5) of the International Standards Organization (ISO) is addressing the problem, as is a 
working group (ANS-16.1) of the American Nuclear Society (ANS). Recently, DOE's Materials Characterization Center (MCC), for which Battelle Pacific Northwest Laboratory is the lead laboratory, has been charged with screening and selecting, as well as developing test procedures for and data on nuclear waste forms. Foremost among these concerns is leach rate. More attention needs to be given to coordinating the efforts and results of the many diverse organizations that are writing standards and generating data. In this way, evaluated data sets on leach rate for all types of waste products could be available when required.

\subsection{References for Section 4}

1. L. Roche-Farmer, Study of Altemative Methods for the Management of Liquid Scintizlation Counting Wastes, NUREG-0656 (February 1980).

2. W. O. Greenhalgh and D. R. Green, Detection of Free Liquid in Sealed Containers Simulating Dmoms of Solidified Radioactive Liquid Wastes, HEDL-SA-1602 (September 1978).

3. International Atomic Energy Agency, "Leach Testing of Immobilized Radioactive Waste Solids, A Proposal for a Standard Method," edited by E. D. Hespe, At. Energy Rev. $\underline{9}(1)$, 195-207 (1971). 
THIS PAGE

WAS INTENTIONALLY

LEFT BLANK 
Appendix A

OTHER INCINERATORS IN RADIOACTIVE SERVICE

\section{Tables}

Page

A.1 Other U.S. incinerators used for treating radioactive wastes ..................... 118

A. 2 Some incinerators used outside the United States for treatment of radioactive wastes . . . . . . . . . 119 
Table A.1. Other U.S. Encinerators used for treating radioactive. wastes ${ }^{a}$

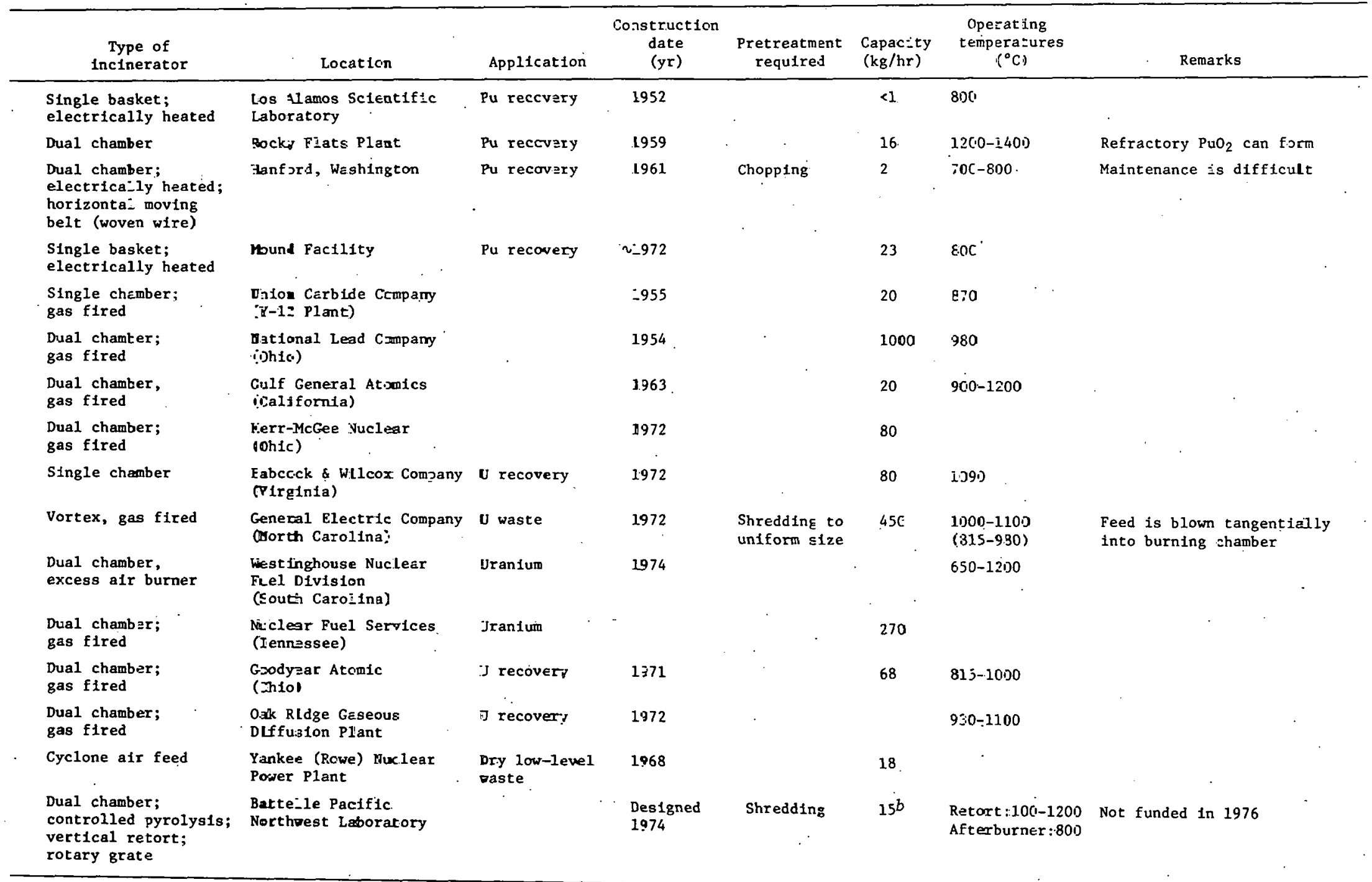

a Not described in Sect. 3.1 .

$b$ Tested only on nonrodfoactive materfals. 
Table A.2. Some incinerators used outside the United States for treatment of radioactive wastes

\begin{tabular}{|c|c|c|c|c|c|c|c|c|}
\hline $\begin{array}{c}\text { Type of } \\
\text { Incinerator }\end{array}$ & Location & & Application & $\begin{array}{l}\text { Construction } \\
\text { date } \\
\text { (yr) }\end{array}$ & $\begin{array}{l}\text { Pretreatment } \\
\text { requfred }\end{array}$ & $\begin{array}{r}\text { Capacity } \\
(\mathrm{kg} / \mathrm{hr})\end{array}$ & $\begin{array}{l}\text { Operating } \\
\text { Temperature } \\
\left({ }^{\circ} \mathrm{C}\right)\end{array}$ & Remarks \\
\hline $\begin{array}{l}\text { Continuous slagging } \\
\text { pyrolysis; movable } \\
\text { paddles }\end{array}$ & Belgium & & $\begin{array}{c}\text { Solid waste } \\
\text {. }\end{array}$ & 1975 & $\begin{array}{l}\text { Sorting and } \\
\text { mixing }\end{array}$ & 100 & $1400-1600$ & $\begin{array}{l}\text { Off-gas passes through } \\
\text { sand filters before } \\
\text { HEPA }\end{array}$ \\
\hline $\begin{array}{l}\text { Dual chamber, } \\
\text { batch pyrolysis; } \\
\text { movable grate }\end{array}$ & $\begin{array}{l}\text { w. Germany } \\
\text { (Jue11ch) }\end{array}$ & & Solid waste & 1977 & Hand sorting & 100 & 1000 & . \\
\hline \multirow{5}{*}{$\begin{array}{l}\text { Vertical retort; } \\
\text { afterburning in hot } \\
\text { ceramic candle } \\
\text { f1lters; Inftial } \\
\text { gas blast-300 to } \\
850^{\circ} \mathrm{C}\end{array}$} & $\begin{array}{l}\text { W. Germany } \\
\text { (Karlsruhe) }\end{array}$ & $\cdot$ & $\begin{array}{l}\text { Dry low-level } \\
\text { waste }\end{array}$ & 1970 & Sorting & 60 & $1000-1100$ & \\
\hline & $\begin{array}{l}\text { Switzerland } \\
\text { (EIR-Wueren11ngen) }\end{array}$ & & $\begin{array}{l}\text { Dry low-level } \\
\text { waste }\end{array}$ & & Sorting & $25-30$ & 1000 & · \\
\hline & $\begin{array}{l}\text { Japan } \\
\text { (Tsuruga) }\end{array}$ & & $\begin{array}{l}\text { Power plant } \\
\text { waste }\end{array}$ & 1977 & Sorting & 50 & 1000 & \\
\hline & (Tokaf) & & & 1979 & Sorting & 100 & 1000 & \\
\hline & $\begin{array}{l}\text { Austria } \\
\text { (SEAE-Siebersdorf) }\end{array}$ & & $\begin{array}{l}\text { Dry low-level } \\
\text { waste }\end{array}$ & $\begin{array}{l}1975 \\
\text { (Controlled) }\end{array}$ & Sorting & 60 & 1000 & $\begin{array}{l}\text { Hand loaded; no PVC } \\
\text { permissible in feed }\end{array}$ \\
\hline $\begin{array}{l}\text { Vertical retort; } \\
\text { dual chamber; } \\
\text { batch operation; } \\
\text { oll fired }\end{array}$ & $\begin{array}{l}\text { Sweden } \\
\text { (Studsvik) }\end{array}$ & & & 1976 & Sorting. & $200-400$ & & \\
\hline $\begin{array}{l}\text { Vertical two-zone } \\
\text { Eurnace; continous } \\
\text { operation }\end{array}$ & $\begin{array}{l}\text { France } \\
\text { (Cadarache) }\end{array}$ & & $\begin{array}{l}\text { Sol1d and } \\
\text { 11quid waste }\end{array}$ & 1980 & Crushing & $\begin{array}{l}30 \text { (solid) } \\
10-15 \mathrm{l} / \mathrm{hr} \text { (1iquid) }\end{array}$ & & \\
\hline \multirow[t]{2}{*}{$\begin{array}{l}\text { 3atch pyrolysis } \\
\text { (TRECAN) }\end{array}$} & $\begin{array}{l}\text { Canada } \\
\text { (Bruce Nuclear Power }\end{array}$ & Develop) & $\begin{array}{l}\text { Low-level solid } \\
\text { waste and organic } \\
\text { liquids }\end{array}$ & 197: & Sorting & $\begin{array}{l}2270 \mathrm{~kg} / \text { batch (solid) } \\
45 \mathrm{hl} / \mathrm{hr} \text { (liquid) }\end{array}$ & $\begin{array}{l}870-900 \\
\text { (afterburner) }\end{array}$ & $\begin{array}{l}\text { Bag filter in off-gas } \\
\text { stream }\end{array}$ \\
\hline & (Chalk R1ver) & & & $\begin{array}{l}\text { Under } \\
\text { construction }\end{array}$ & Sorting & $1135 \mathrm{~kg} / \mathrm{batch}$ & & 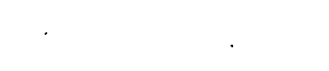 \\
\hline $\begin{array}{l}\text { Jụal chamber: } \\
\text { =ontrolled air }\end{array}$ & $\begin{array}{l}\text { United Kingdom } \\
\text { (Windscale) }\end{array}$ & & Plutonium & 1972 & Sorting & $3-5$ & 900 & Wet scrubber system \\
\hline $\begin{array}{l}\text { Oontinuous dual } \\
\text { =hamber, electric- } \\
\text { ally heated }\end{array}$ & $\begin{array}{l}\text { France } \\
\text { (Marcoule) }\end{array}$ & & Plutonium & 1970 & Cutting & · & & \\
\hline \multirow[t]{2}{*}{$\begin{array}{l}\text { Batch dual } \\
\text { =hamber }\end{array}$} & $\begin{array}{l}\text { France } \\
\text { (Marcoule) }\end{array}$ & . & Solid waste & $\begin{array}{l}\text { Before } \\
1970\end{array}$ & Hand sorting & 80 & & $\begin{array}{l}\text { Off-gas passes through } \\
\text { rotating filter }\end{array}$ \\
\hline & (CEN-FAR) & & $\begin{array}{l}\text { Animal carcasses } \\
\text { only }\end{array}$ & & & 50 & 900 & $\begin{array}{l}\text { Bag filter on off-gas } \\
\text { stream }\end{array}$ \\
\hline $\begin{array}{l}\text { Horizontal con- } \\
\text { tinuous furnace }\end{array}$ & $\begin{array}{l}\text { France } \\
\text { (Gadarache) }\end{array}$ & $\cdot$ & $\begin{array}{l}\text { L1quids, organo- } \\
\text { chlorides, and } \\
\text { organo phosphates }\end{array}$ & 1980. & & $50 \ell / \mathrm{hr}$ & . & $\cdot \cdot$ \\
\hline Actd digestion & $\begin{array}{l}\text { Unfted Kingdom } \\
\text { (Harwell) }\end{array}$ & & Pu recovery & (1981) & Shredding & 10 & & \\
\hline
\end{tabular}


THIS PAGE

WAS INTENTIONALLY

LEFT BLANK 
SOME REPRESENTATIVE RADIOACTIVE LIQUID-WASTE TREATMENT SYSTEMS AT SELECTED DOE SITES AND A FORMERLY USED COMMERCIAL

FUEL REPROCESSING PLANT

Figures

$\underline{\text { Page }}$

Argonne National Laboratory . . . . . . . . . . . . . 122

Brookhaven National Laboratory . . . . . . . . . . 123

Hanford Reservation (200-Area) . . . . . . . . . . . 124

Idaho National Engineering Laboratory

Chemical Processing Plant . . . . . . . . . . . 125

Naval Reactor Facility . . . . . . . . . . . 126

Test Reactor Area . . . . . . . . . . . . . . . 127

Los Alamos Scientific Laboratory . . . . . . . . . . . . . 128

Mound Facility . . . . . . . . . . . . . . . . . 129

Oak Ridge National Laboratory . . . . . . . . . . . 130

Rocky Flats Plant . . . . . . . . . . . . . . . 131

Savannah River Plant

Savannah River Laboratory . . . . . . . . . . . 132

100-Area Reactors .................... 133

Chemical Separations Canyons . . . . . . . . . . . . 134

Fuel and Target Fabrication. . . . . . . . . . . . . 135

Nuclear Fuel Services Fuel Reprocessing Plant . . . . . . . . 136 


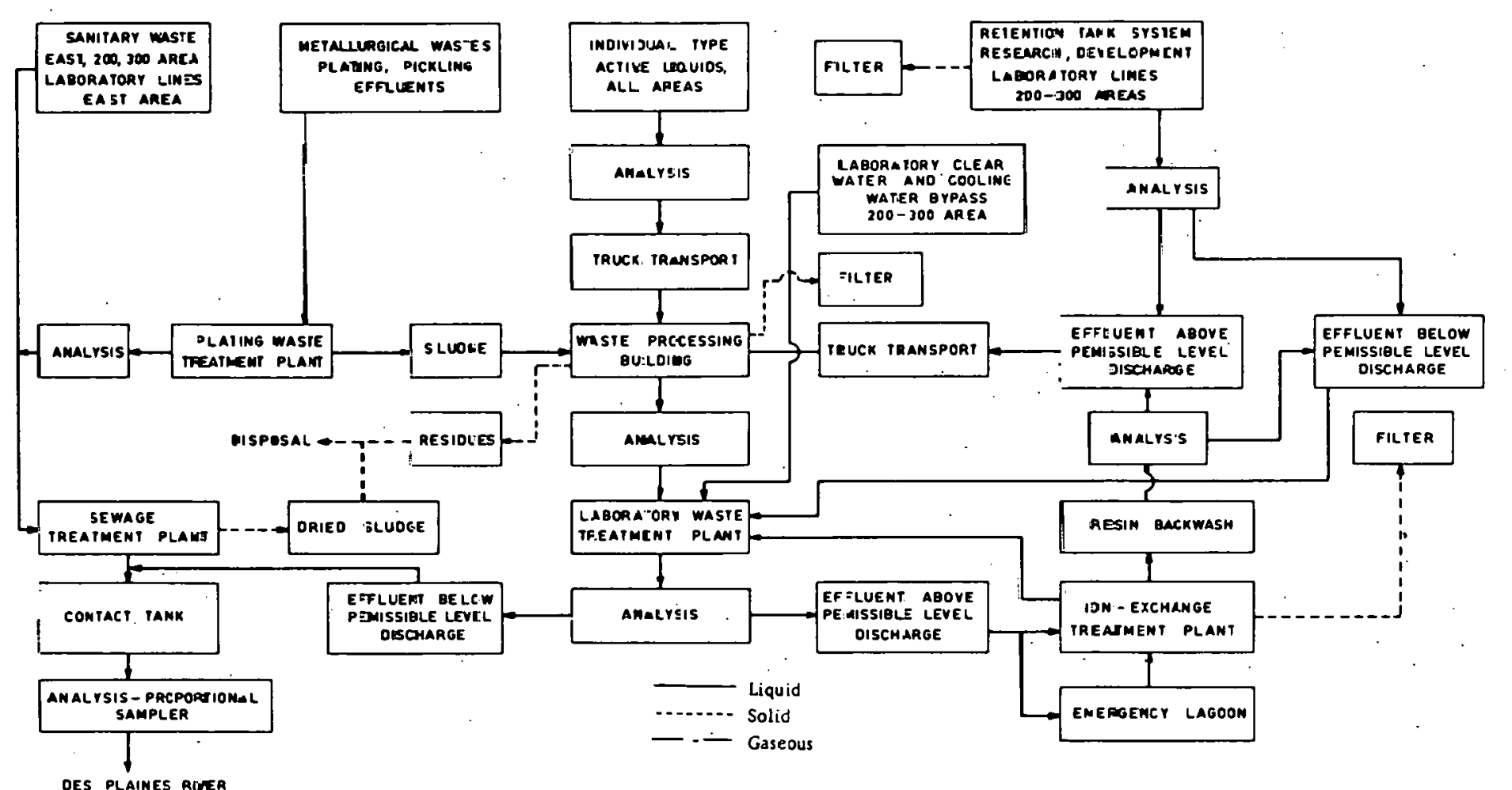

Fig. B.1. Radioactive 1iquid-waste treatment system at Argonne Nationzl Laboratory. (Source: Technology of Radioxctive iasie Momagement Lvoiding Environmental Disoosal, Technical Report Series No. 27, IAEA, Vienna, 1964.) 


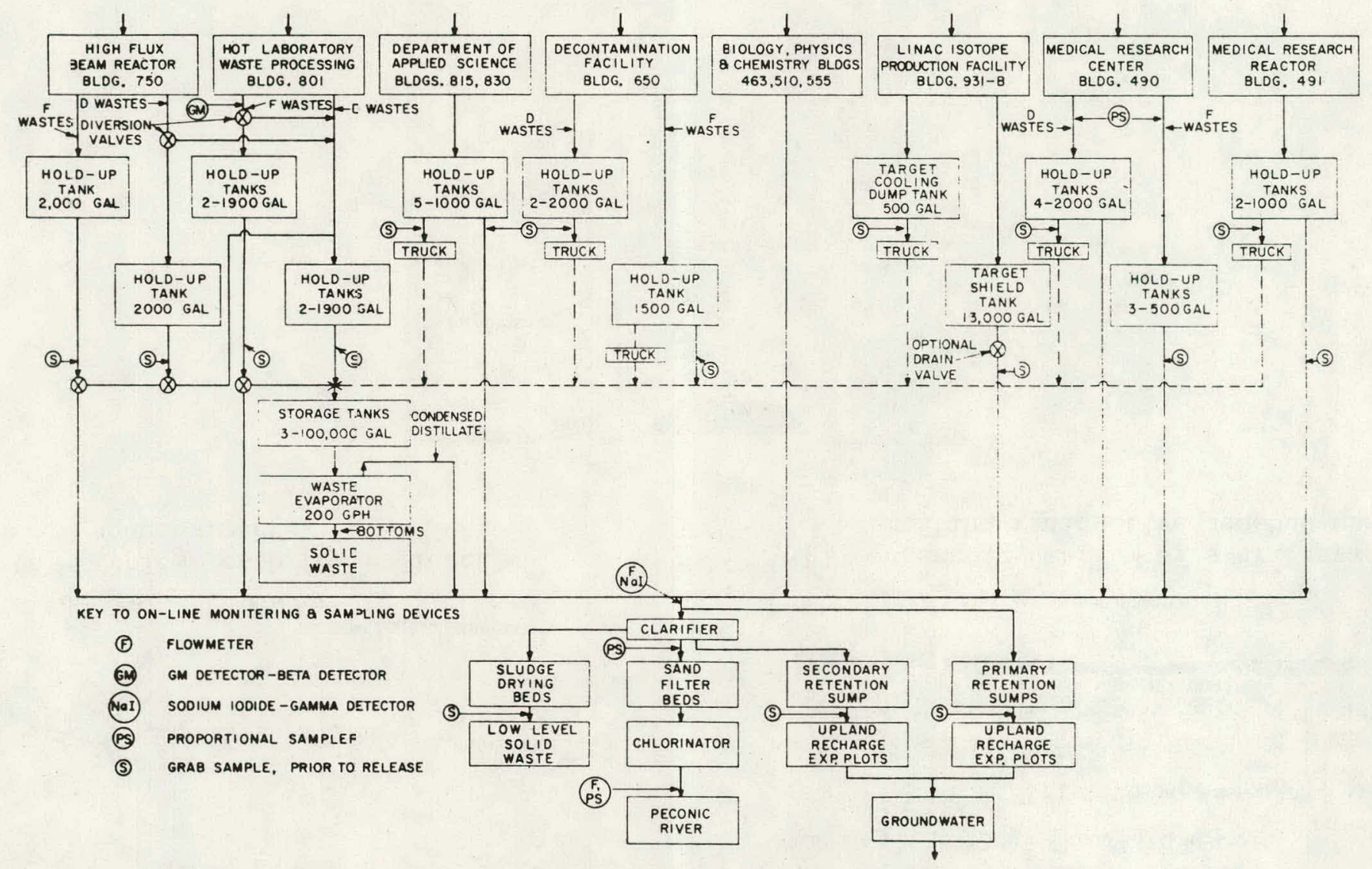

Fig. B.2. Radioactive 1iquid-waste treatment system at Brookhaven National Laboratory. [Source: Final EIS, Brookhaven National Laboratory, ERDA-1540 (July 1977).] 


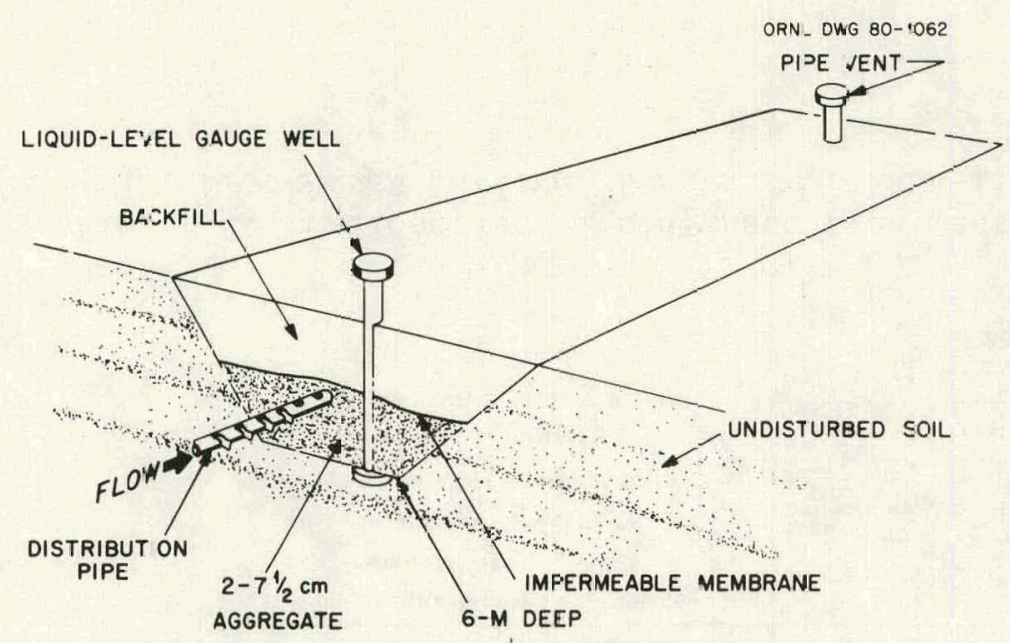

(a) Typical crij for radisactive aqueous waste.

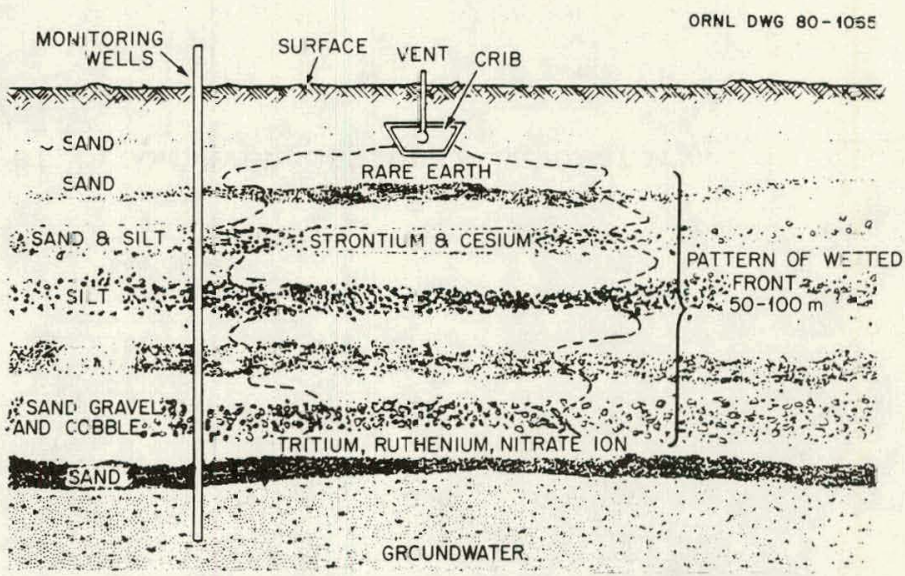

(b) Schematic diagram of a crib system for treating radioactive aqueous waste.

CRVL DWG $80-1064$

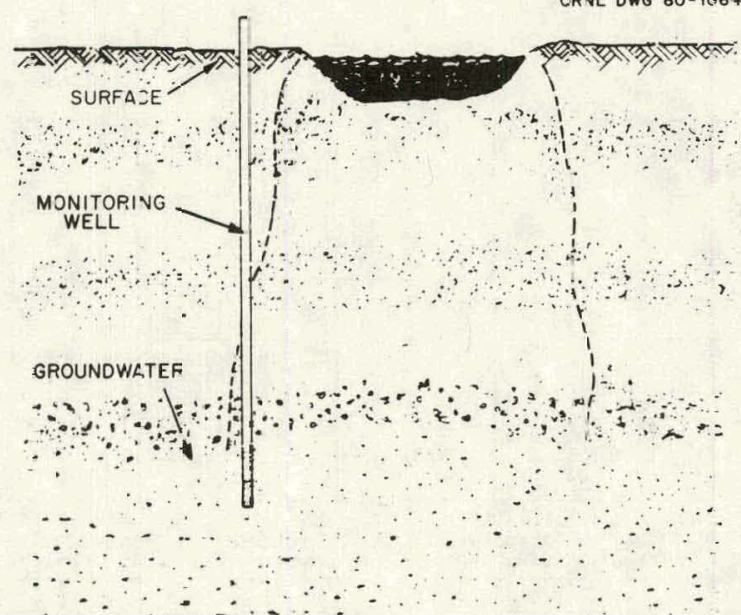

(c) Schenatic diagram of a typical pond receiving low-level radioactive waste water.

Fig. B.3. Typical radiozctive liquid-waste treatment systems at the Hanford (200-Area). [Taken from Final Environmental Statemert, Waste Management Operations, Hanford Reservation, ERDA-1538 (December 1975).] 


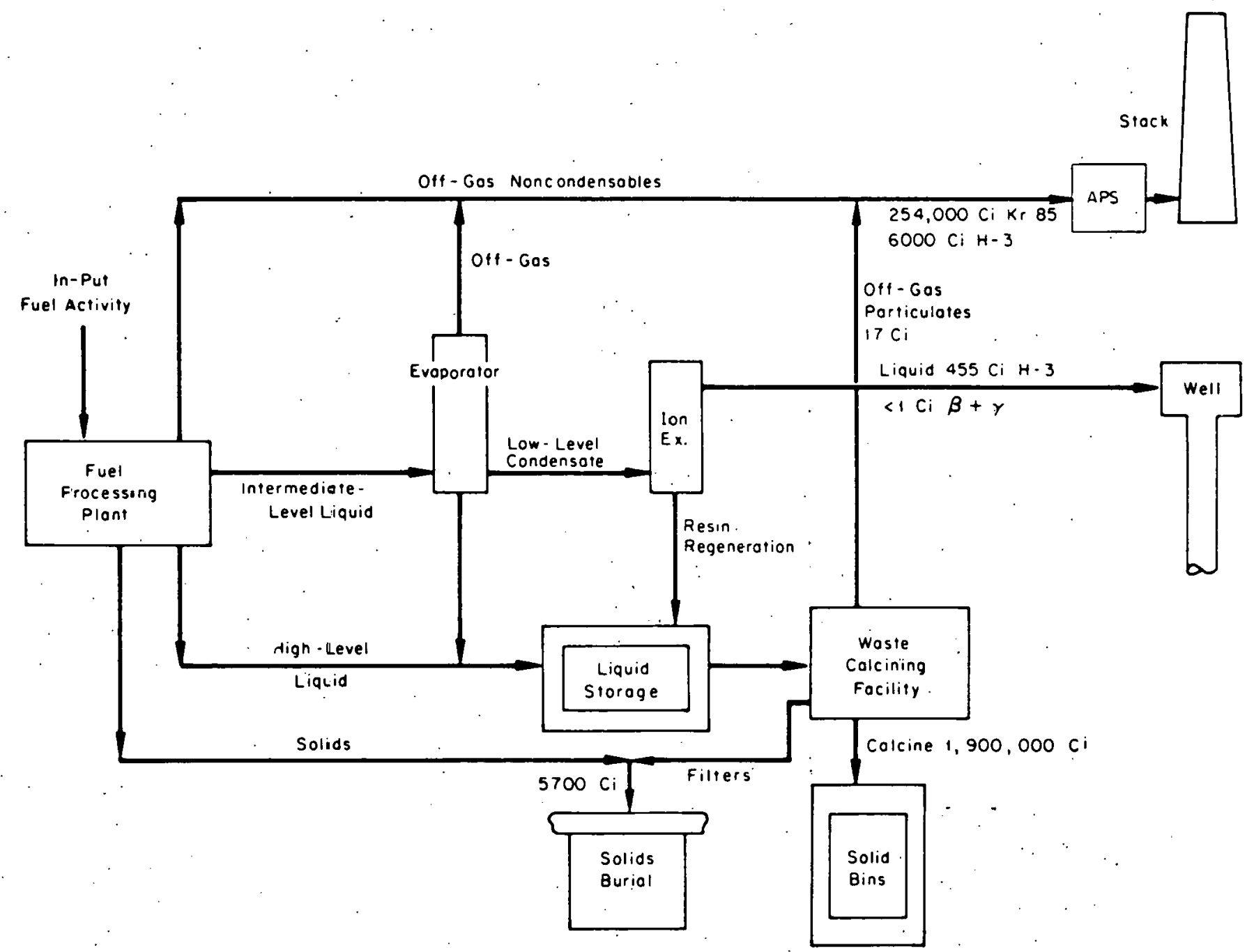

Fig. B.4. Radioactive liquid-waste treatment system at the Idaho Chemical Processing Plant at INEL. [Source: Final EIS, Waste Management Operations, Idaño National Engineering Laboratory, ERDA-1526 (September 1977).] 


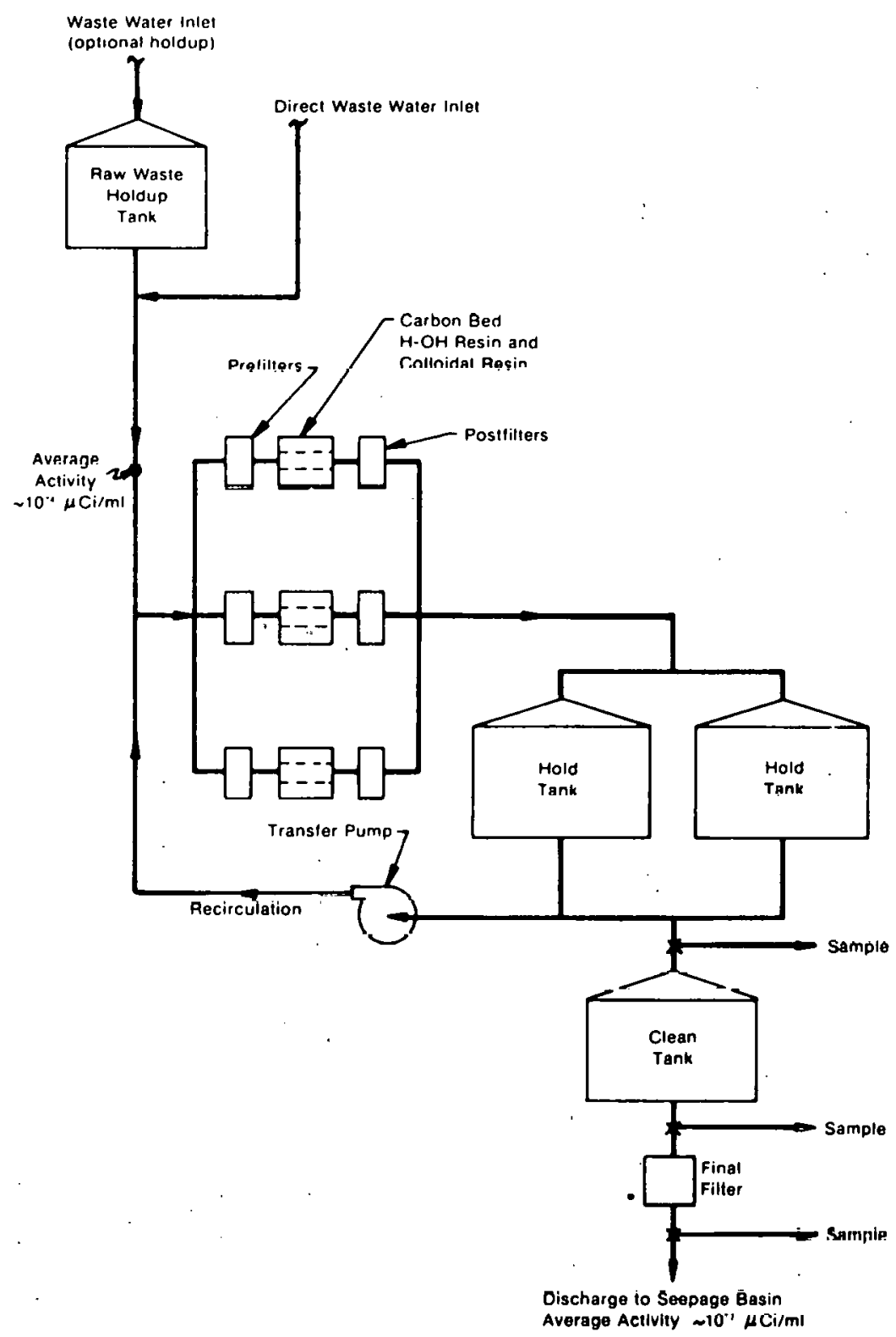

Fig. B.5. Radioactive liquid-waste treatment system at the Naval Reactor Facility at INEL. [Sourcc: Final EIS, Waste Management. Operations, Idaho National Engineering Laboratory, ERDA-1536 (September 1977).] 


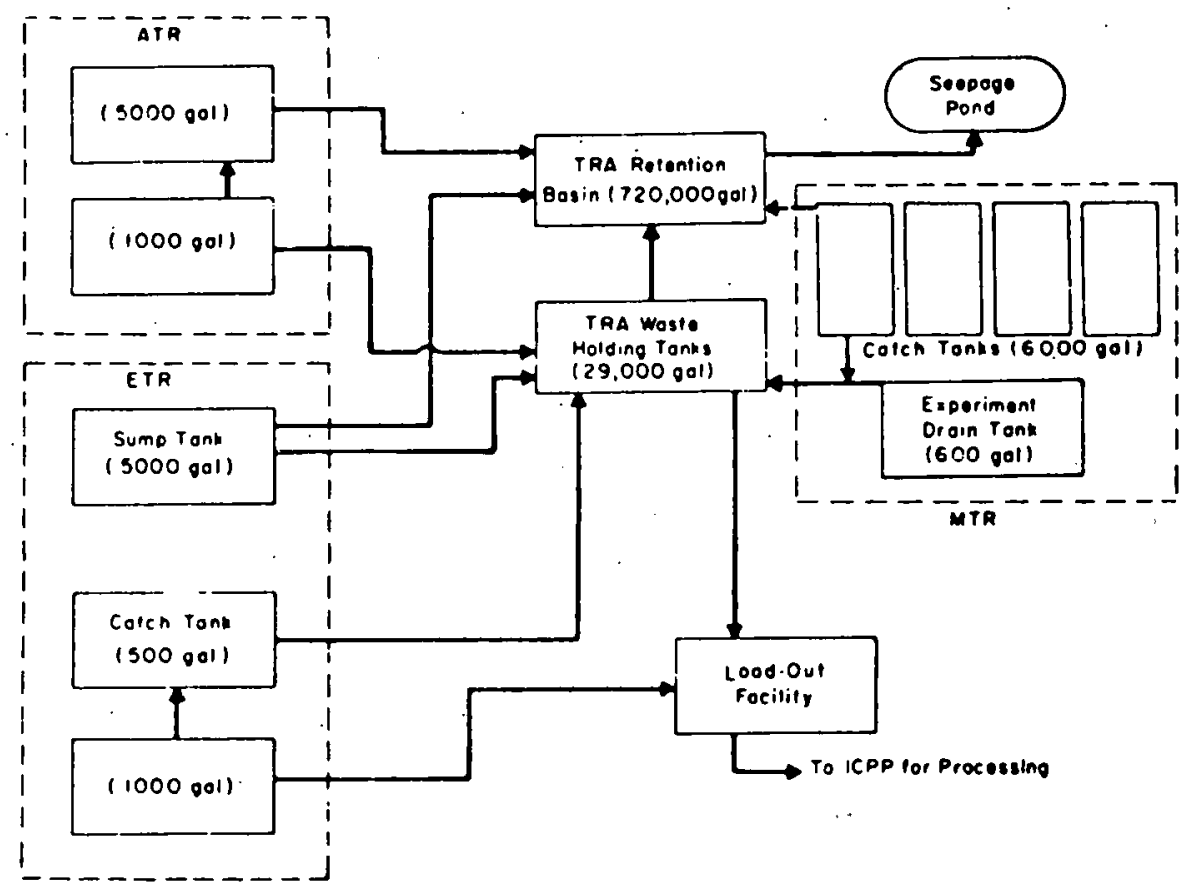

Fig. B.6. Radioactive 1iquid-waste treatment system at the Test Reactor Area at INEL. [Source: Final EIS, Waste Management Operations, Idaho National Engineering Laboratory, ERDA-1536 (September 1977).] 
ORNL OWG 80-1045

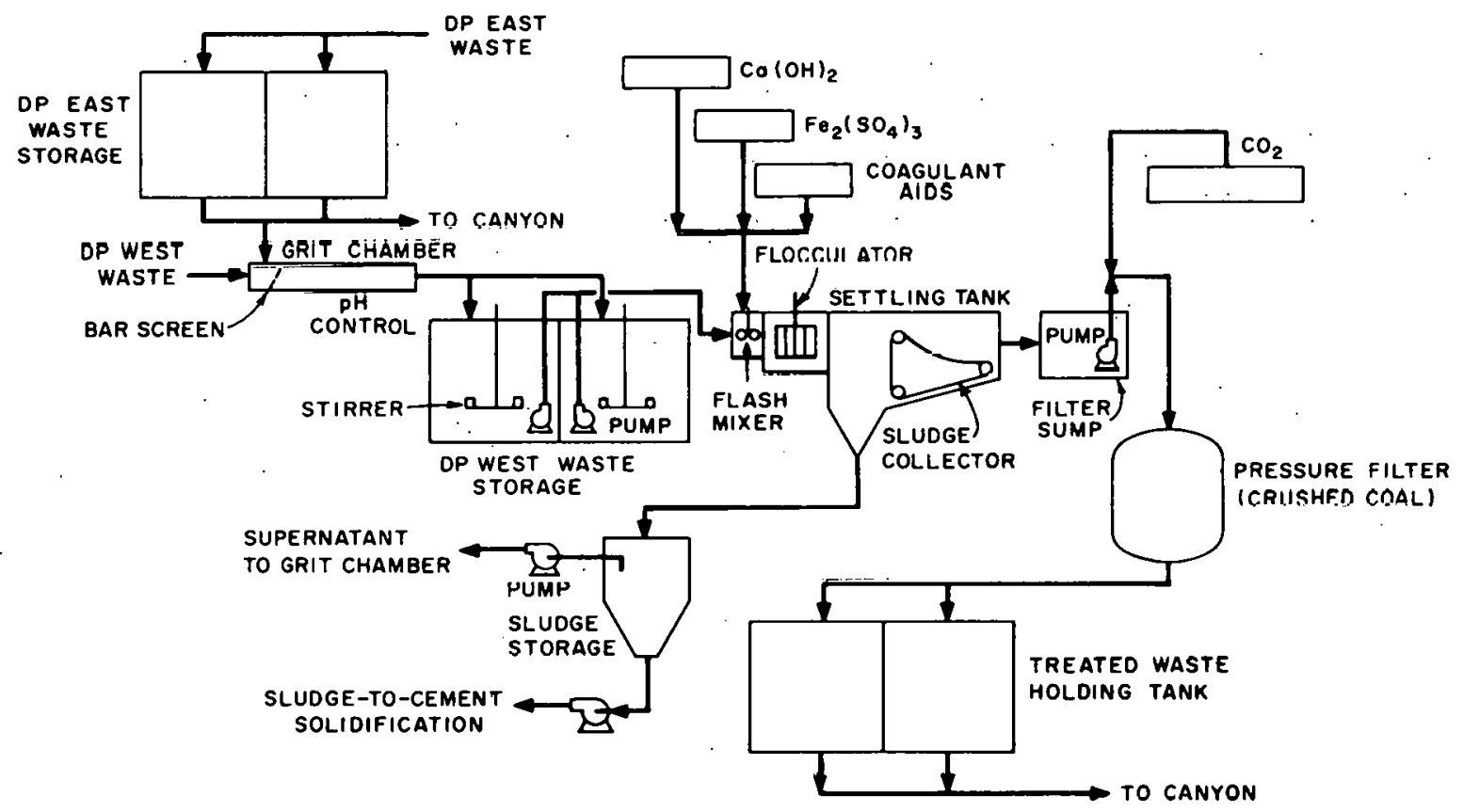

Fig. B.7. Radioactive 1iquid-waste treatment system at Los Alamos Scientific Laboratory. [Taken from L. A. Emelity, Jr., J. R. Buchholz, and P. E. McGinn1s, "Review of Radioactive Liquid Waste Management at Los Alamos," in Management of" Low-Level. Radioactive Waste, vol. 1, M. W. Carter, A. A. Moghissi, and B. Kahn, eds., Pergamon, New York, 1979.] 
ORNL-DWG $80-1137$

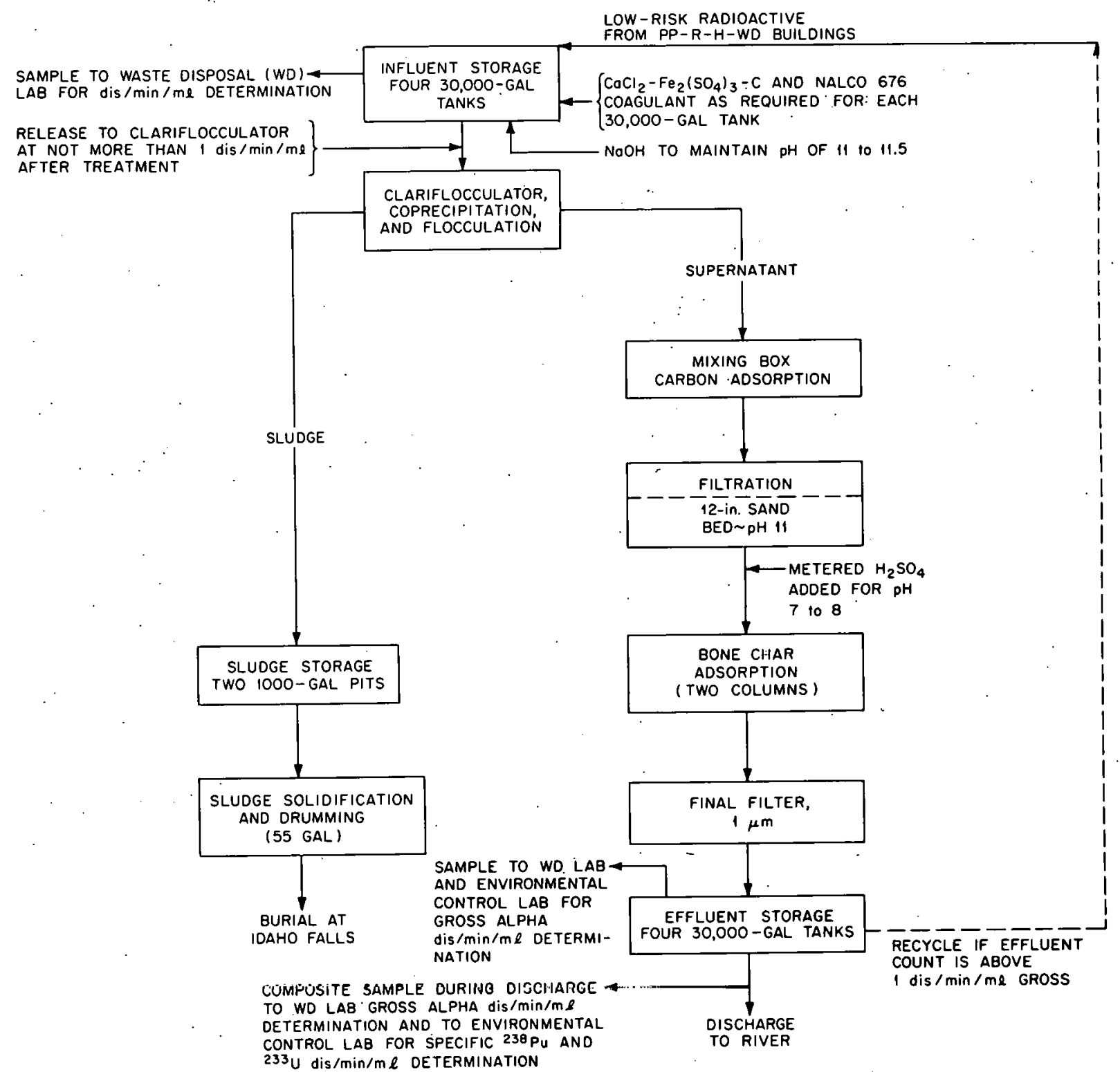

Fig. B.8. Radioactive liquid-waste treatment system at Mound Facility. (Courtesy of F. Traino, Mound, Miamisburg, Ohio, June 1979.) 


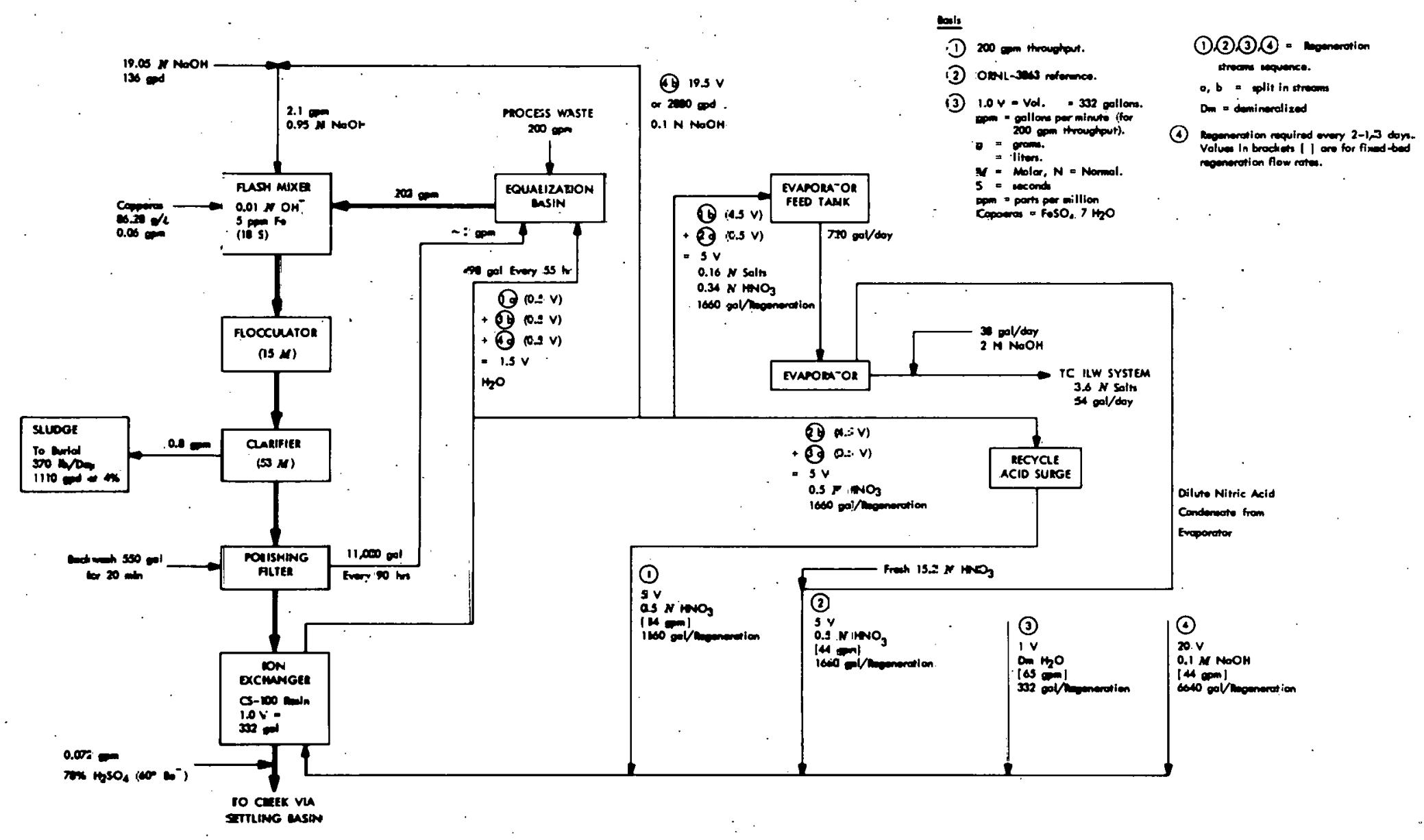

Fig. B.9. Radioactive liquid-waste treatrient system at Oak Ridge National Laboratory. (Source: R. A. Robinson and L. C. Lasher, "Low-Level Rac̈ioactive Liquid Waste Treatment at ORNL," in Management of Low-Level Radioactive Waste, vol. 1, M. W. Carter, A. A. Moghissi, and B. Kahn, eds., Pergamon, New York, 1979.) 


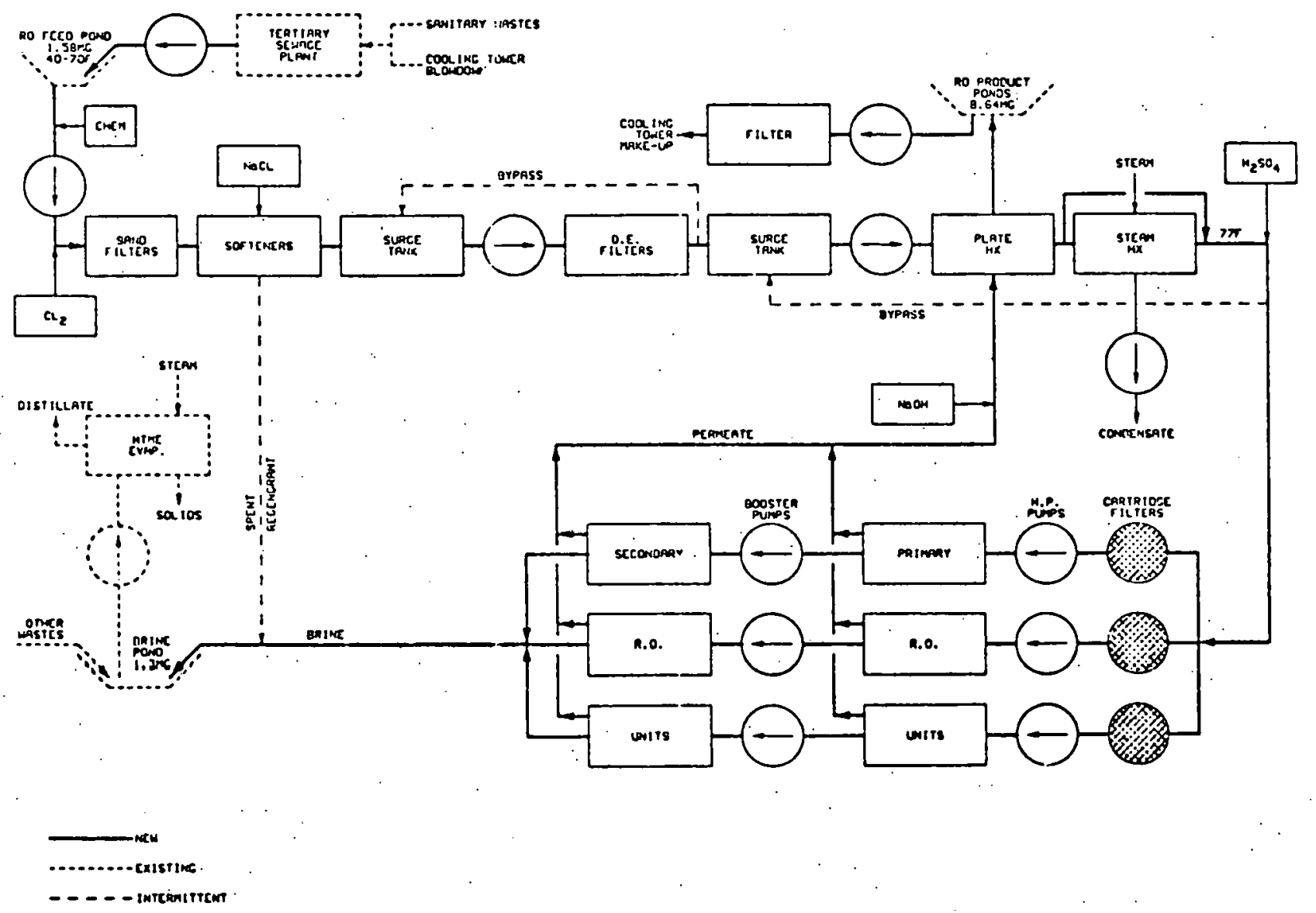

Fig. B.10. Radioactive liquid-waste treatment system at Rocky Flats Pl.ant. [Source: J. Markind and T. V. Tran, A Study of Reverse Osmosis Applicability to Light Water Reactor Radwaste Processing, NUREG/CR-0724 (Apri1 1979).] 


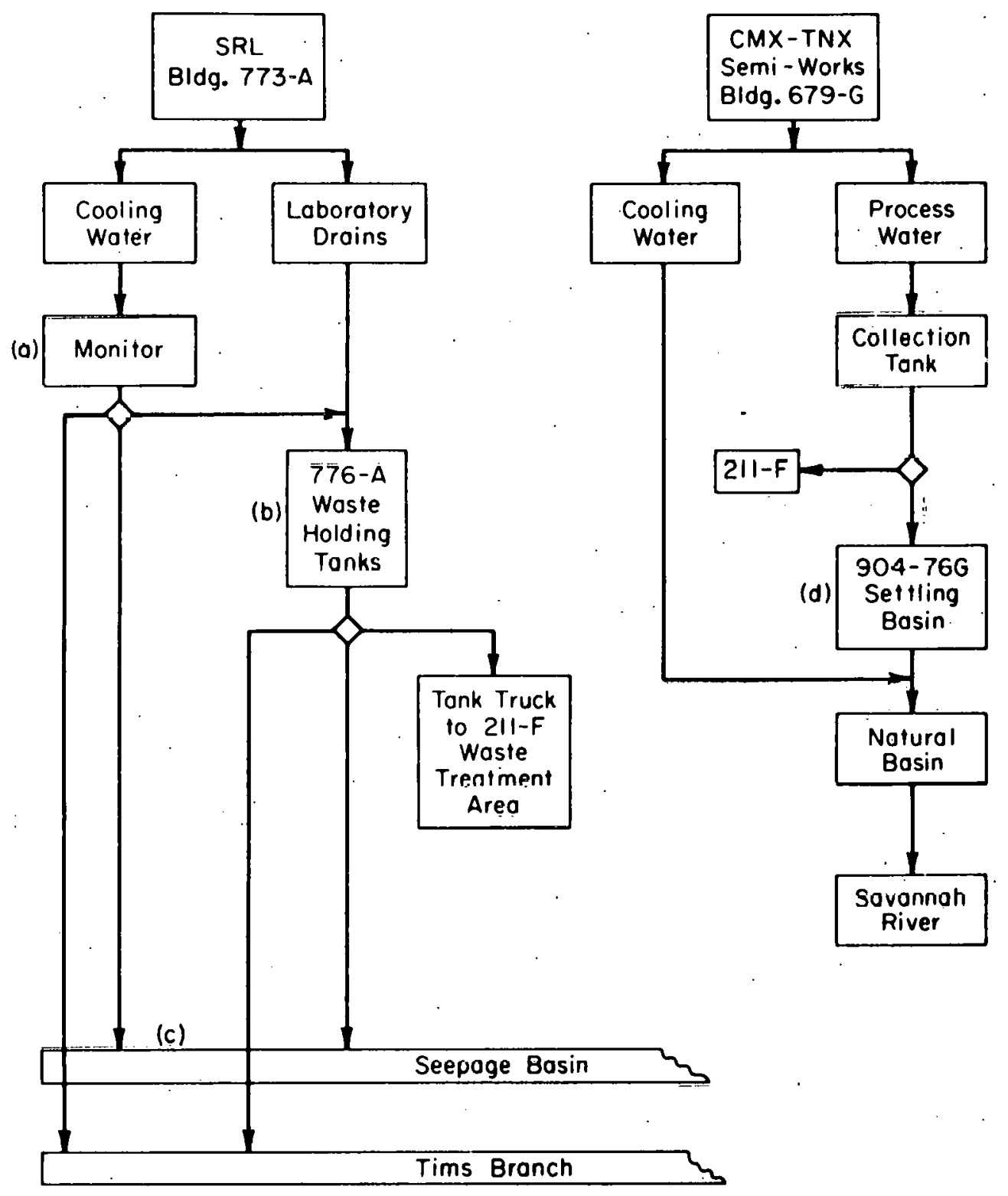

Fig. B.11. Radioactive liquid-waste treatment system at Savannah R1ver Laboratory. [Source: W. R. Jacobsen et a1., Control and Treatment of Radioactive Liquid Waste Effluents at the Savannah River Plant, DP-1349 (February 1974).] 


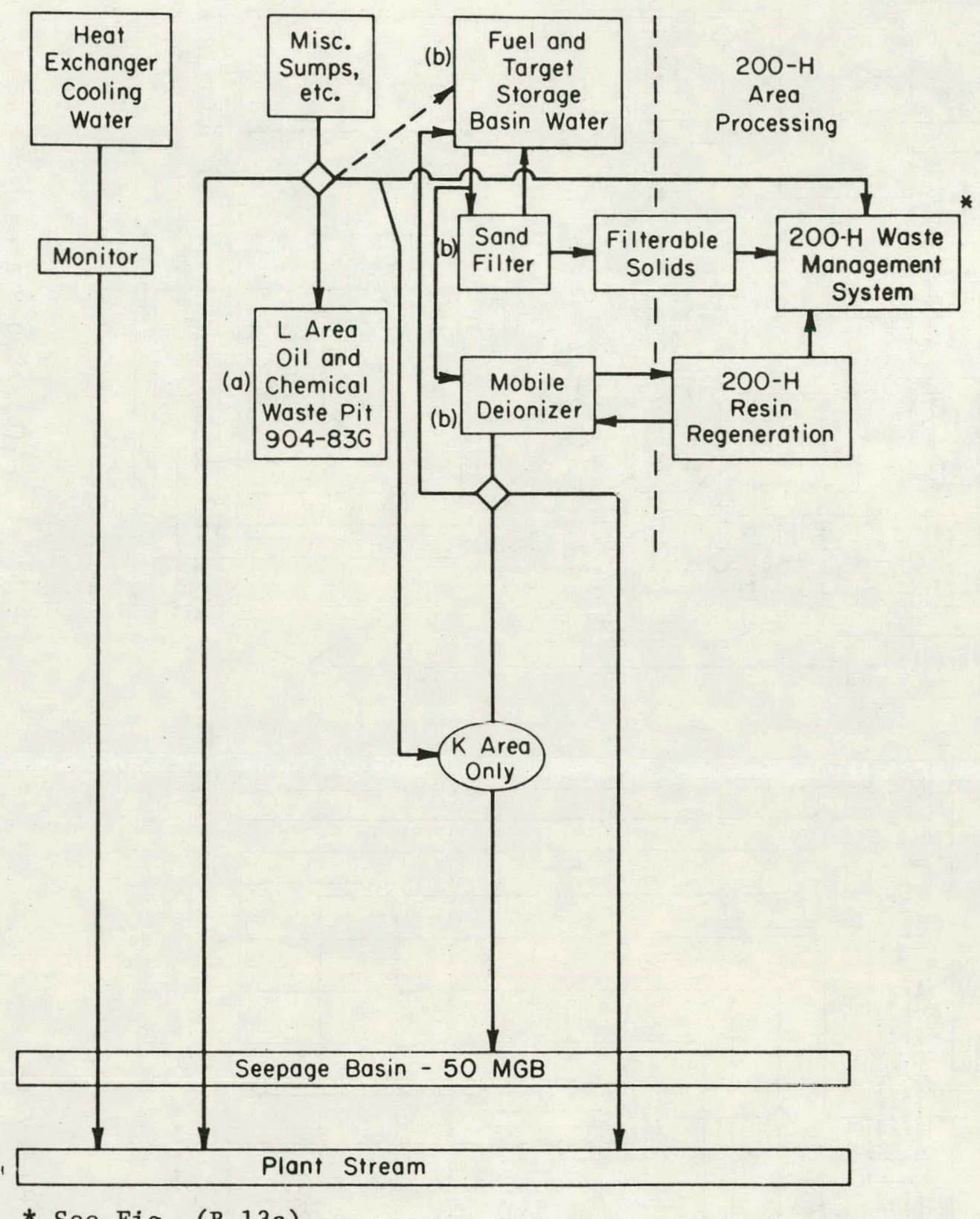

* See Fig. (B.13a).

Fig. B.12. Radioactive 1iquid-waste treatment for 100-Area Reactors at Savannah River Laboratory. [Source: W. R. Jacobsen et a1., Control and Treatment of Radioactive Liquid Waste Effluents at the Savannah Kiver Plant, DP-1349 (February 1974).] 


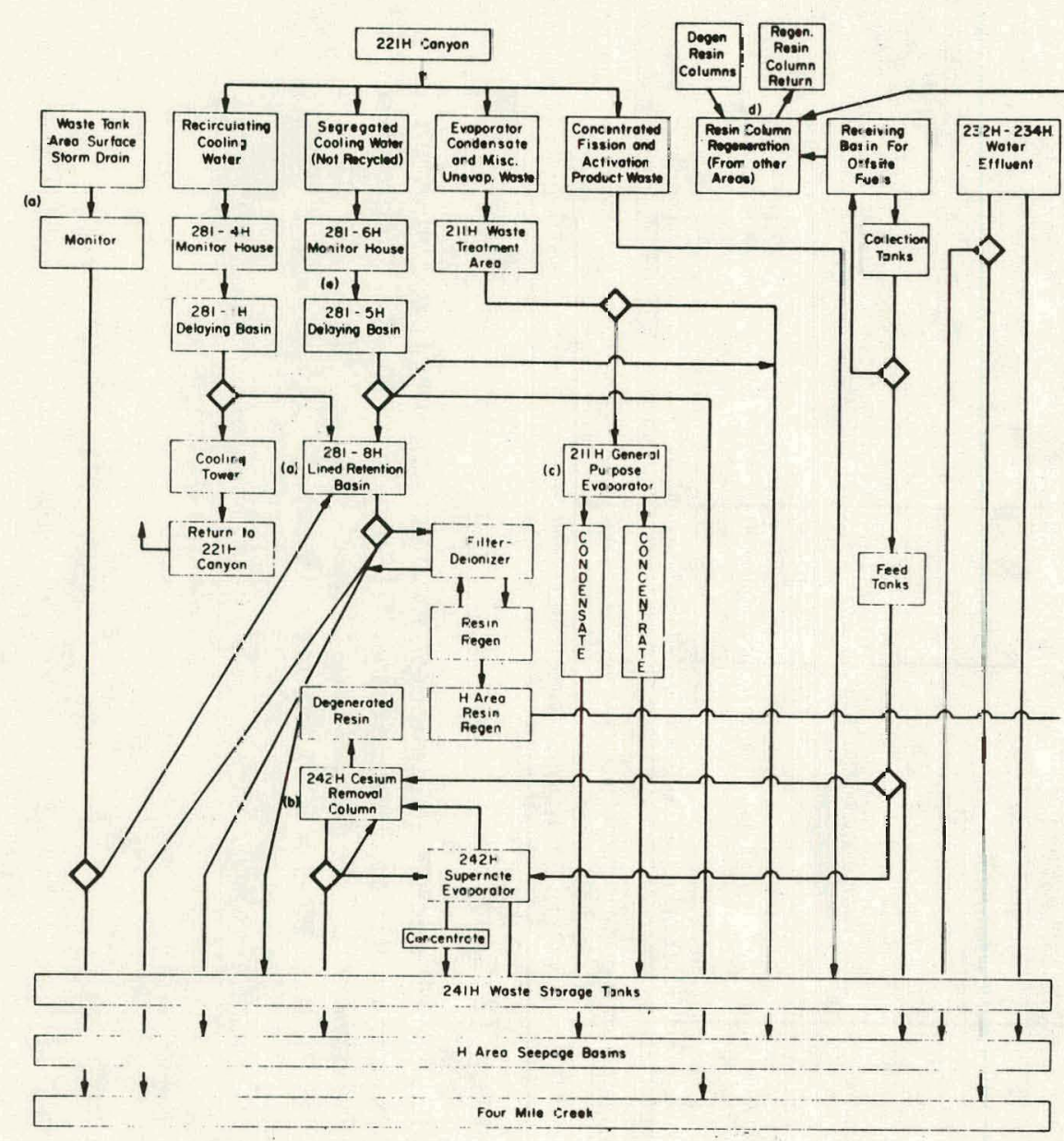

(a) 200-H Area

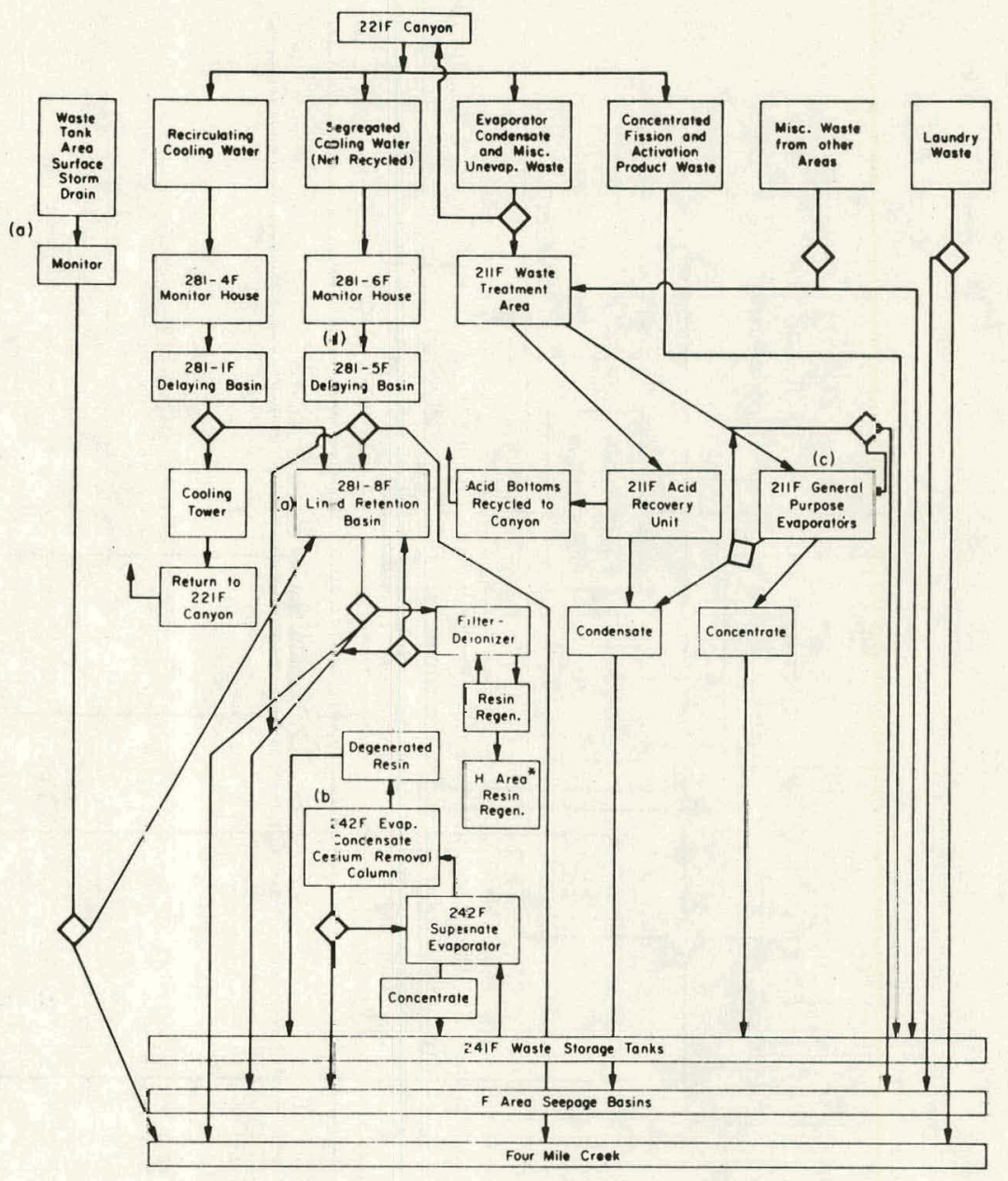

*See Fig. (B.13a).

Fig. B.13. Radioactive -iquid-waste treatment systems for the Chemical Separations Canyons at Savannah River Plant. -Source: W. R. Jacobsen et al., Control and Treatmert of Radioactive Liquid Waste Effluents at the Savannah River Pant, DP-1349 (February 1974).] 


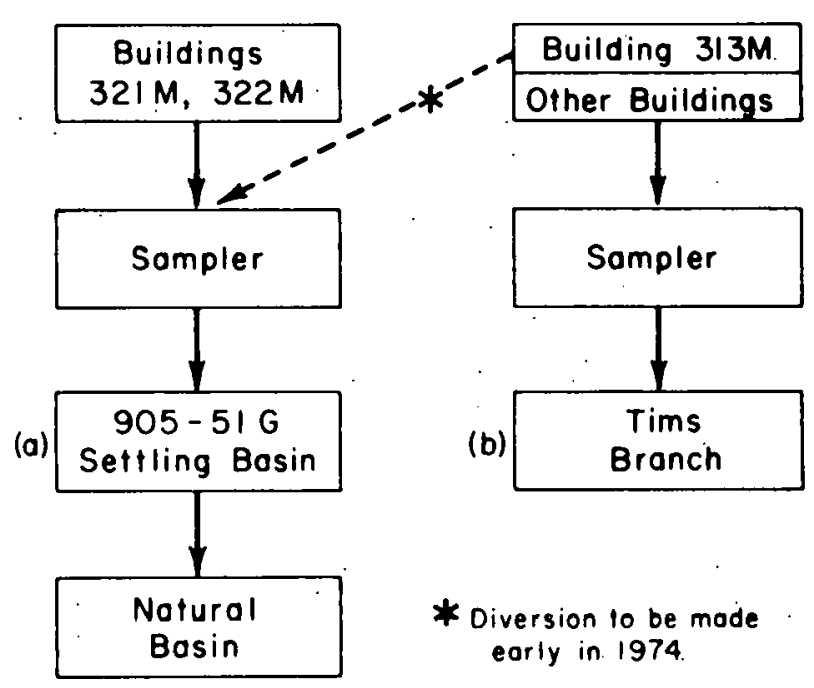

Fig. B.14. Radioactive liquid-waste treatment system for the 300-M Area fuel and target fabrication buildings at Savannah River Plant. [Source: W. R. Jacobsen et a1., Control and Treatment of Radioactive Liquid Waste Effluents at the Savannah River Plant, DP-1349 (February 1974).]. 


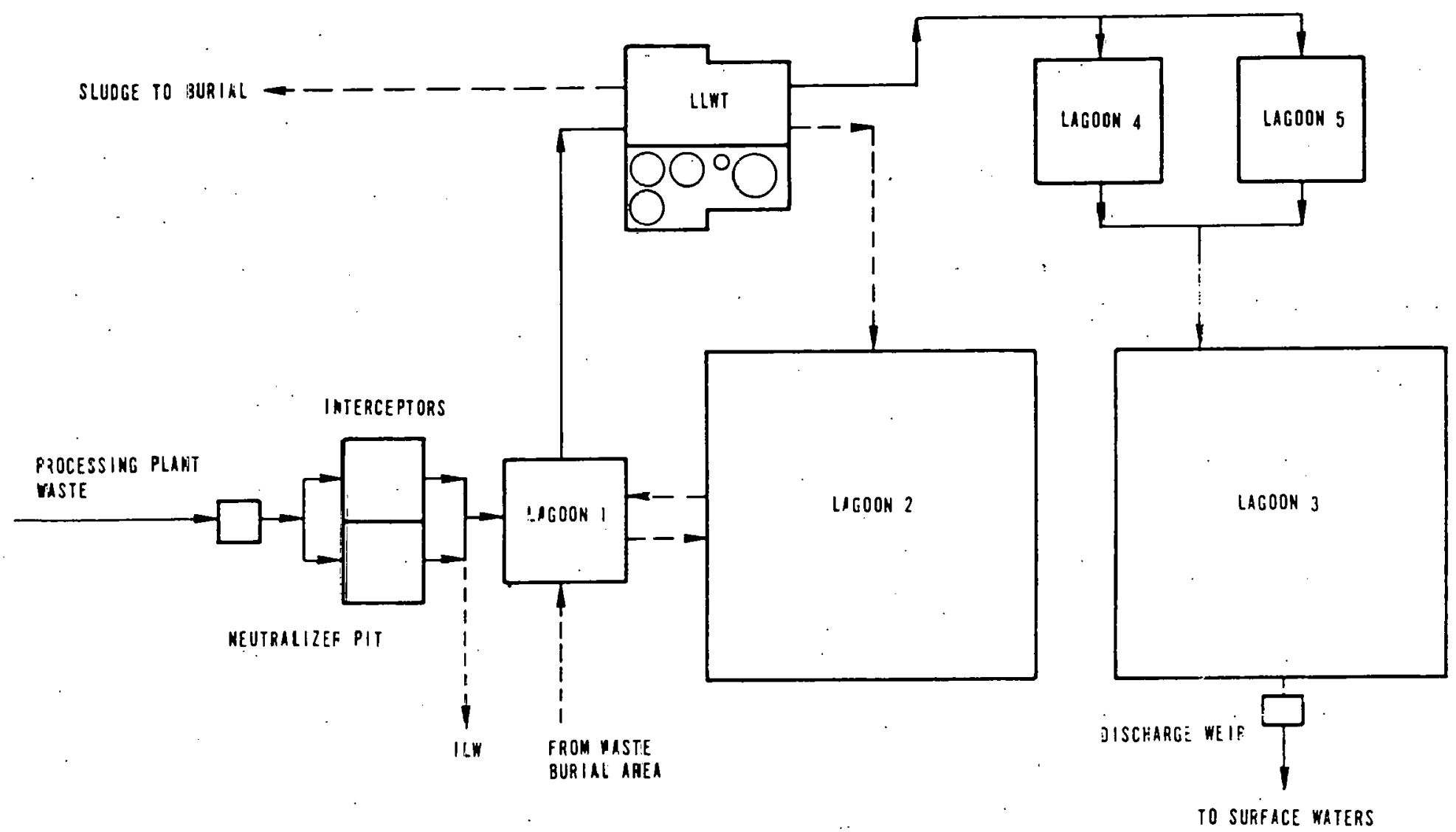

$\ddot{\omega}$

Fig. B.15. Radicactive liccuid-waste treatment system at the formerly operated fuel reprocessing plant owned by Nuclear Fuel Seriices, Inc., Nest Valley, New York. (Source: Safety Analysis Report, Nuclear Fuel Services, inc., Fuel Rerrocessing Plant, vol. I, Docke= No. 50-201.) 
Appendix C

OTHER EQUIPMENT BEING MARKETED IN THE UNITED STATES FOR SINGLE-STEP VOLUME REDUCTION AND SOLIDIFICATION OF RADIOACTIVE LIQUID WASTES

Figures

$\underline{\text { Page }}$

C.1 Vertical thin-film evaporator . . . . . . . . . . 138

C. 2 Heated drum mixer ................ . . 139

C.3 Ribbon blender volume-reduction system . . . . . . . . . 140 


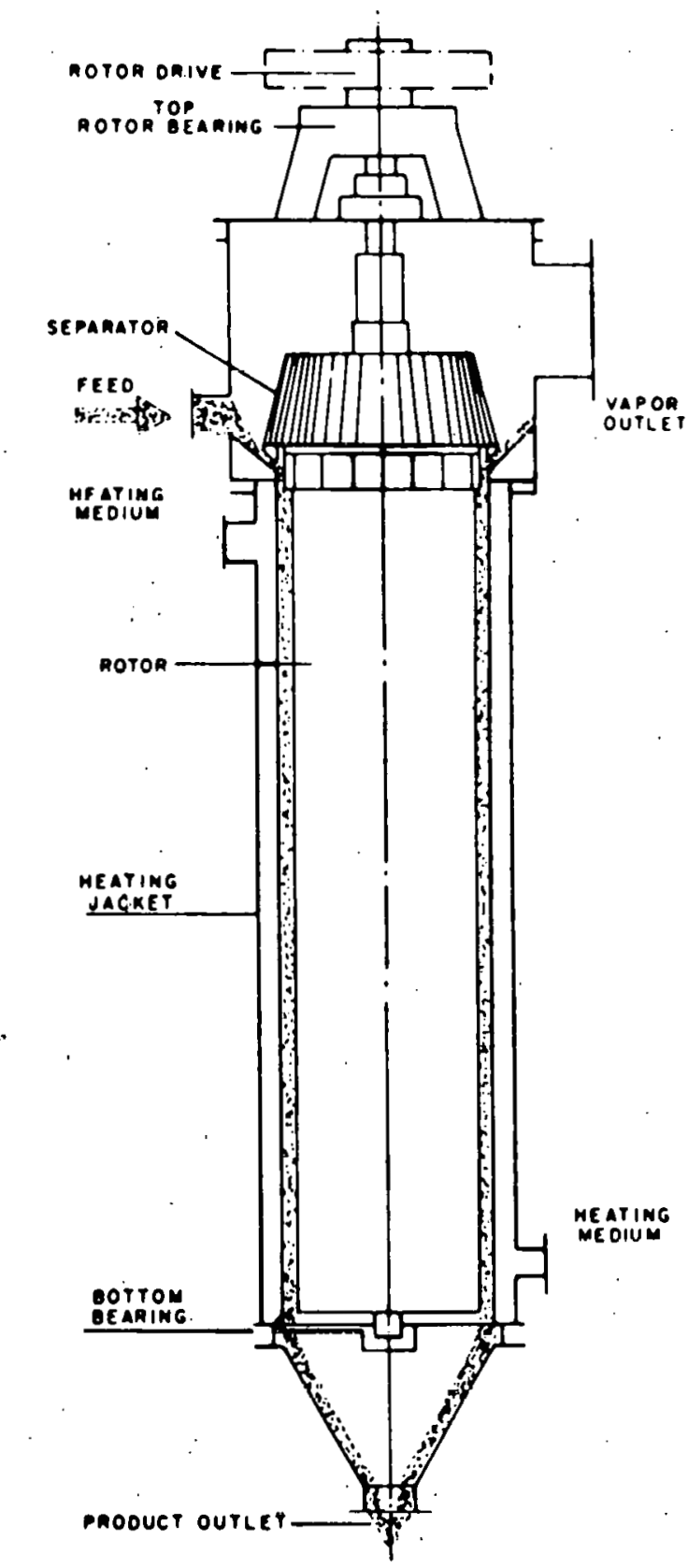

Fig. C.1. Vertical thin-film evaporator. 
ORNL-DWG 80-1023
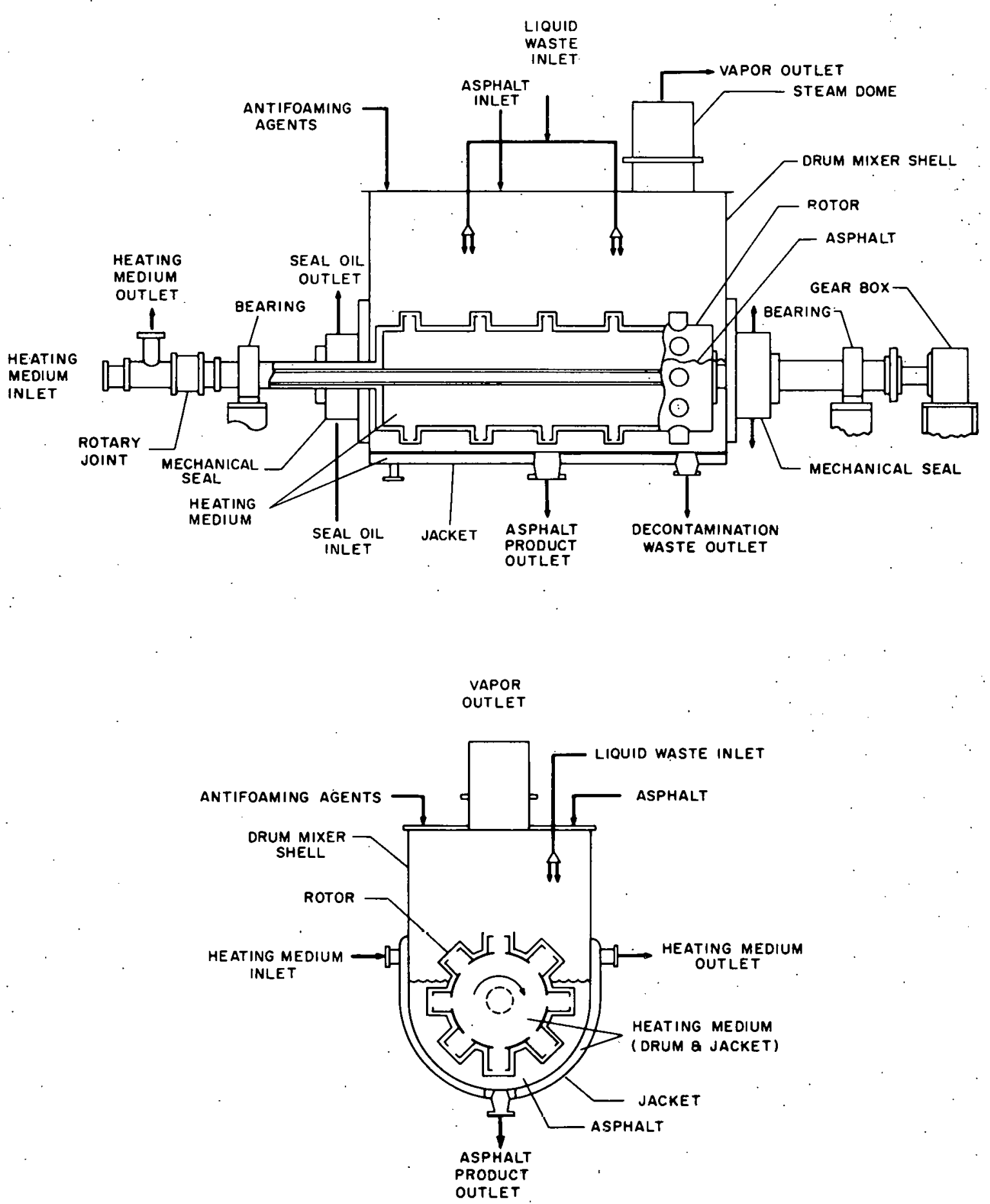

Fig. C.2. Heated drum mixer. 


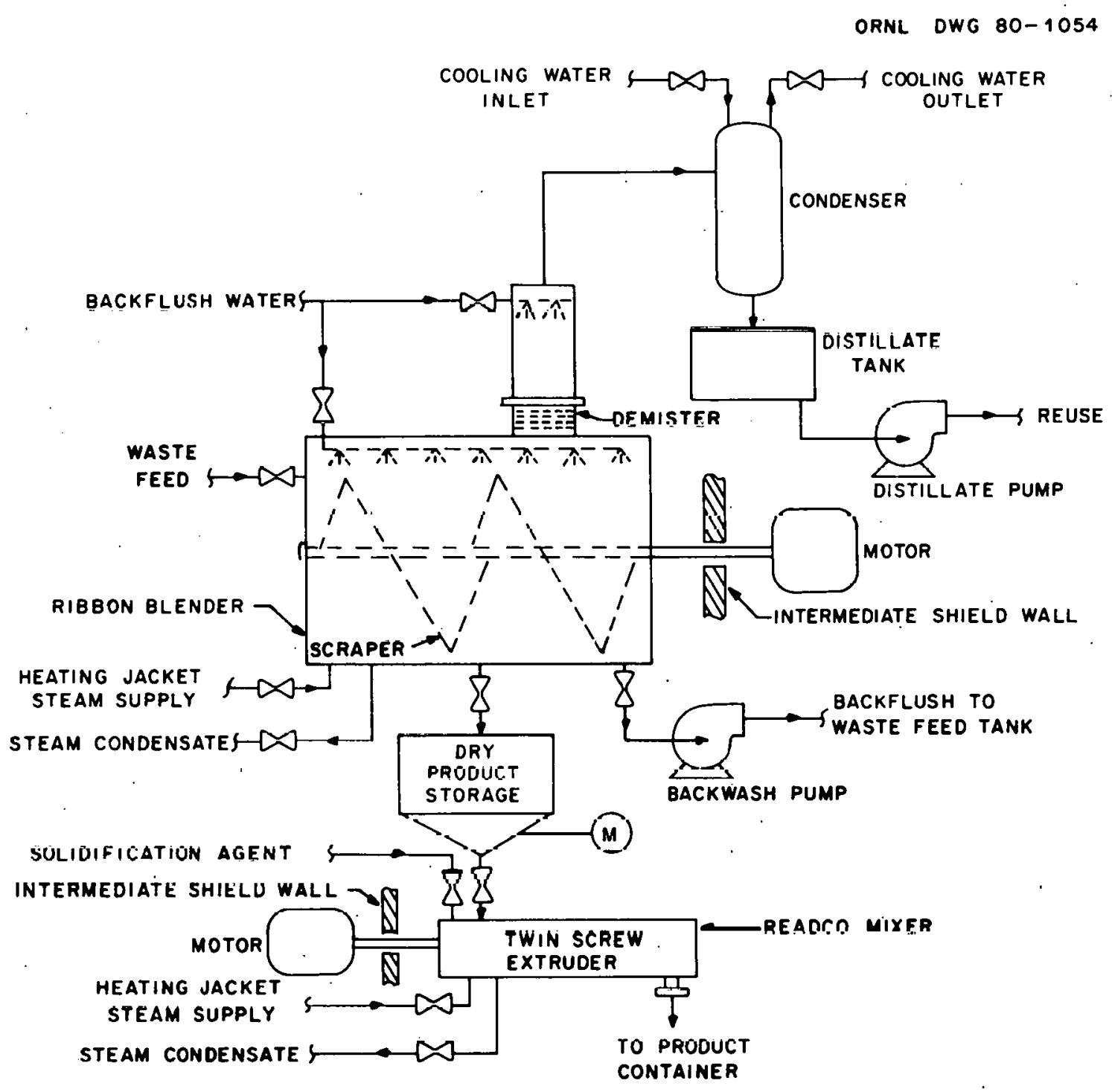

Fig. C.3. Ribbon blender volume-reduction system. 
ORNL/TM-7427

Dist. Category UC-70

INTERNAL DISTRIBUTION

$\begin{aligned} \text { 1. } & \text { C. W. Alexander } \\ 2 . & \text { R. E. Blanco } \\ 3 . & \text { J. O. Blomeke } \\ \text { 4. } & \text { W. D. Bond } \\ 5 . & \text { R. E. Brooksbank } \\ 6 . & \text { P. F. Brown } \\ 7 . & \text { W. D. Burch } \\ 8 . & \text { D. O. Campbe11 } \\ 9 . & \text { J. M. Chandler } \\ 10 . & \text { H. C. Claiborne } \\ 11 . & \text { E. L. Compere } \\ 12 . & \text { J. H. Coobs } \\ 13 . & \text { A. G. Croff } \\ 14 . & \text { N. H. Cutshall } \\ 15 . & \text { W. Davis, Jr. } \\ 16 . & \text { D. E. Ferguson } \\ 17 . & \text { B. C. Finney } \\ 18 . & \text { R. B. Fitts } \\ 19 . & \text { C. S. Fore } \\ 20 . & \text { C. W. Forsberg } \\ 21 . & \text { E. J. Frederick } \\ 22 . & \text { R. W. Glass } \\ 23 . & \text { J. R. Gissel } \\ 24-38 . & \text { H. W. Godbee } \\ 39 . & \text { K. W. Haff } \\ 40 . & \text { F. E. Harrington } \\ 41-55 . & \text { A. H. Kibbey } \\ 56 . & \text { L. J. King } \\ 57 . & \text { W. J. Lackey } \\ 58 . & \text { L. C. Lasher } \\ & \end{aligned}$

1. C. W. Alexander

2. R. E. Blanco

3. J. 0. Blomeke

4. W. D. Bond

5. R. E. Brooksbank

6. P. F. Brown

7. W. D. Burch

8. D. 0. Campbell

9. J. M. Chandler

11. E. L. Compere

12. J: H. Coobs

13. A. G. Croff

14. N. H. Cutshall

15. W. Davis, Jr.

16. D. E. Ferguson

17. B. C. Finney

18. R. B. Fitts

20. C. W. Forsberg

21. E. J. Frederick

22. R. W. Glass

23. J. R. Gisse1

39. K. W. Haff

40. F. E. Harrington

56. L. J. King

58. L. C. Lasher
59. R. E. Leuze

60. K. H. Lin

61. T. F. Lomenick

62. A. L. Lotts

63. R. S. Lowrie

64. M. S. Moran

65. F. R. Mynatt

66. E. Newman

67. K. J. Notz

68. T. W. Oakes

69. E. B. Peelle

70. W. W. Pitt, Jr.

71. R. A. Robinson

72. T. H. Row

73. A. D. Ryon

74. C. D. Scott

75. L. B. Shappert

76. J. W. Snider

77. Debbie Stevens

78. S. M. Tiegs

79. D. B. Trauger

80. J. E. Van Cleve, Jr.

81. J. E. Vath

82. H. O. Weeren

83. R. G. Wymer

84-85. Central Research Library

86. Document Reference Section

87-88. Laboratory Records

89. Laboratory Records (RC)

90. ORNL Patent Section

\section{EXTERNAL DISTRIBUTION}

91. J. A. Adam, Low-Level Waste Branch, Mail Stop 426-SS, NRC, Washington, DC 20555

92. M. A. Aguilar, Rockwell International, Rocky Flats Plant, P.0. Box 464, Golden, CO 80401

93. P. G. Agu1lar, Rükwell Intcrnational, Rocky Flats Plant, P.0. Box 464, Golden, CO 80401

94. C. R. Allen, Westinghouse Hanford Operations, Hanford Engineering Development Laboratory, P.0. Box 1970, Richland, WA 99352

95. 0. U. Anders, 1602 Building, Dow Chemical U.S.A., Midland, MI 48640

96. C. W. Ange11, Artisan Industries, Inc., 73 Pond Street, Waltham, MA 02154 
97. L. J. Andrews, Chem-Nuclear Systems, Inc., P: 0. Box 1866, Bellevue, WA 98009

98. A. Askew, 2220 Austin Nationa1 Rank. Tower, 515 Congless Ave., Austin, TX 78701

99. E. L. Albenesius, E. I. du Pont de Nemours and Company, Savannah River Laboratory, Aiken, SC 29801

100. J. E. Ayer, Office of Nuclear Safety and.Safeguards, Mail Stop 396-SS, NRC, Washington, DC 20555

101. T. S. Baer, Nuclear Engineering Company, Inc., P. O. Box 7246, Louisville, KY 40207

102. R. L. Bangart, Effluent Treatment Systems Branch, Mail Stop P-730, NRC, Washington, DC 20555

103. P. D. Baynard, Nuclear Support Services, Florida Power Corporation, P. O. Box 14042 , 3t. Petersburg, FL 33733

104. T. Beboer, Empire State Plaza, Albany, NY 12223

105. T. Bedrosian, 1181 Wagon Wheel Circle, Reno, NV 89503

106. G. A. Benda, Chem-Nucle ear Syৎteme, Inc،, Г. O. Bux 18b́6, Beilevue, WA 98009

107. G. J. Bèrglund, Wéstinghouse Hanford Operations, Hanford Engineering Development Laboratory, P.0. Box 1970, W/C-32, Richland, WA 99352

108. T. Bergstrom, University of Michigan, Ann Arbor, MI 48109

109. R. Bernero, Materials Safety Standards, Mall Stop NL-5650, NRC, Washington, DC 20555

110. M. L. Birch, Duke Power Co., P. O. Box 33189, Charlotte, NC 28242

111. R. K. Blauve1t, Mound Facility, P. O. Box 32, Miamisburg, OH 45342

112. W. H. Bond, Mound Facility, P.O. Box 32, Miamisburg, OH 45342

113. W. F. Bonner, Battelle Pacific Northwest Laboratory, P.0. Box 999, Richland, WA 99352

114. L. C. Borduin, Los Alamos Scientific Laboratory, Post Office Box 1.663, Los Alamos, NM 87545

115. L. Bradley, 2726 Country Club Drive, Olympia, WA 98502

116. R. L. Brodzinski, Battelle Northwest. Laboratory, $329 \mathrm{Bldg}$., 300 Area, Richland, WA. 99352

117. D. G. Brookins, Department of Geology, University of New Mexico, Albuquerque, NM 87131

118. R. Broseus, National Institutes of Health, 9000 Rockville Pike, Bethesda, MD 20205

119. H. Brown, National Governors Association, 444 Capital Ave., NE', Washington, DC 20002

120. M. Brownstein, Atcor-Washington, Inc., Division of CNSI, The Exchange, Suite 203, 270 Farmington Avenue, Farmington, CT 06032

121. 0. I. Buttedah1, Rockwe11 International, Rocky Flats Plant, Golden, CO 80401

122. R. W. Ch1ckering, Westinghouse Electric Corp., Advanced Reactor Div., Box 158, Madison, PA 15663

12.3. A. T. Clark, Office of Nuclear Safety and Safeguards, Mail Stop 396-SS, NRC, Washington, DC 20555

124. D. E. Clark, Westinghouse Hanford Operat1ons, Hanlurd Englneering Development Laboratory, P. O. Box 1970, Richland, WA 99352

125. P. Colombo, Brookhaven National Laboratory, Bldg. 701, Upton, NY 11973 
126. L. R. Cooley, Radiation Safety Office, University of Maryland, 660 West Redwood Street, Baltimore, MD 21201

127. B. V. Coplan, Stone \& Webster Engineering Corp., 245 Summer Street, Boston, MA 02107

128. P. Costello, Office of the Governor, Statehouse, Boise, ID 83702

129. L. R. Crisler, TRU Waste Office, B1dg. T790W, Rockwell International, Rocky Flats Plant, P. O. Box 464, Golden, CO 80401

130. G. H. Daly, Office of Nuclear Waste Management, Division of Waste Products, Mail Stop B-107, DOE, Washington, DC 20545

131. J. J. Davis, Office of Nuclear. Regulatory Research, Mail Stop 1130SS, NRC, Washington, DC 20555

132. J. L. Deichman, Rockwell Hanford Operation, 2750 E. Bldg. 200 E Area, P. O. Box 800, Richland, WA 99352

133. B. R. Dickey, Exxon Nuclear Idaho, ICPP, 550 2nd St., Idaho Falls, ID 83401

134. W. P. Dornsife, Bureau of Radiation Protection, Pennsylvania Department of Environmental Resources, P. 0. Box 2063, Harrisburg, PA 17120

135. J. W. Doty, Mound Facility, P. O. Box 32, Miamisburg, OH 45342

136. R. D. Doyle, Werner \& Pfleiderer Corporation, 663 E. Crescent Ave., Ramsey, NJ 07446

137. A. L. Dressen, Division of Waste Products, Mail Stop B-107, DOE Washington, DC 20545

138. J. 0. Duguid, Battelle Project Management Division, ONWI, 505 King Ave., Columbus, OH 43201

139. P. G. Edwards, Brookhaven National Laboratory, Bldg. 535A, Upton, NY 11973

140. J. L. Ellis, Gilbert/Commonwealth Companies, P. O. Box 1498, Reading, PA 19603

141. L. C. Emma, Brookhaven National Laboratory, Upton, NY 11973

142. D. N. Enegess, Werner \& Pfleiderer Corporation, 663 E. Crescent Ave., Ramsey, NJ 07446

143. R. W. Ericson, Werner \& Pfleiderer Corporation, 663 E. Crescent Ave., Ramsey, NJ 07446

144. D. P. Ferrigno, Gilbert Commonwealth Companies, P. O. Box 1498, Reading, PA 19603

145. H. E. Filter, Dow Chemical U.S.A., Lark1n Laburalory, Midland, MI 48640

146. L. Franks, Bureau of Consumer Health Protection, 505 E. King Avenue, Carson City, NV 89701

147. E. N. Fray, EG\&G Idaho, P. O. Box 1625, Idaho Falls, ID 83401

148. G. D. Frieling, Wisconsin Electric Power Co., Milwaukee, WI 53201

149. R. M. Fry, Radiation Control Branch, Kentucky Department of Human Resources, 275 East Main Street, Frankfort, KY 40601

150. K. A. Gablin, 6749 Towne Lane Road, McLean, VA 22101

151. H. R. Galbraith, St. Jude Children's Hospital, 322 N. Lauderdale, Memphis, TN 38101

152. R. Garcia, Aerojet Energy Conversion Company, P. O. Box 13222, Sacramento, CA 95813 
153. P. M. Garrett, Technology for Energy Corporation, 10770 Dutchtown Road, Knoxville, TN 37922

154. C. A. Gerber, Radwaste Operations, Niagara Mnhawk. Power Corporation; Nine Mile Point. Nuclear Station, Lycoming, NY 13093

155. K. V. Gilbert, Mound Facility, P. O. Box 32, Miamisburg, OH 45342

156. P. J. Gillis, Jr., TTI Engineering, Rt. 2 \& Rt. 184 Circle, North Stonington, CT 06359

157. S. I. Glassman, Ebasco Services, Inc., 2 Rector Street, New York, NY 10006

158. E. S. Goldberg, Savannah River Operations Office, DOE, P.O. Box A, Aiken, SC 29801

159. G. Goldstein, Secretary of Health \& Environment, State of New Mexico, Santa Te, NM 87503

160. C. D. Good, Liquid Process Engineering, General Public Utilities, TMI, Box 480, Rt. 4415, Middletown, PA 17057

161. C. C. Goodlett. E. I. du Pont. de Nemours and Co., Savannah Rivei Laboratory, Aiken, SC 29801.

162. F. F. Gorup, ChIcago Uperations Office, DOE, 9800 South Cass Ave., Argonne, IL 60439

163. R. W. Granlund, Pennsylvania State University, 228 Academic Projects Bldg., Univers1ty Park, PA 16802

164. W. 0. Greenhalgh, Westinghouse Hanford Operations, Hanford Engineering Development Laboratory, P. O. Box 1980, Richland, WA 99352

165. W. T. Gregory, III, Chem-Nuclear Systems, Inc., 234 Shoreline Drive, Columbia, SC 29210

166. P. F. Gustafson, Environmental Impact Studies Div., Argonne National Laboratory, 9700. South Cass Ave., Argonne, IL 60439

167. 3. C. Hawlllun, Ruckwell International, Rocky Flats Plant, P.0. Box 464, Golden, Co 80401

168. J. F. Hayes, Delaware Custom Materiel, Inc., 444 East College Ave., State College, PA 16801

169. H. W. Heacock, UNC Nuclear Industries, 2900 George Washington Way, Richland, WA 99352

170: E. E. Held, Office of Nuclear Regulatory Research, Mail stop 1130-SS, NRC, Washington, DC. 20555

171. J. H. Hershey, E. I. du Pont de Nemours and Company, Savannah River Plant, 704-F Building, Aiken, SC 29801

172. G. W. Hogg, Exxon Nuclear Idaho, P.0. Box 2800, CPP-637, 1955 Fremont Ave., Idaho Fal1s, ID 83401

173. W. F. Holcomb, Radiation Source Analysis Branch (ANR-459), Office of Radiation Programs, EPA, Washington, DC 20460

174. .H. E. Hootman, E. I. du Pont de Nemours and Company, Savannah River Laboratory, Aiken, SC 29801

175. D. R. Howard, Commonwealth Edison Company, P. 0. Box 767, Chicago, IL 60690

176. J. L. Ingwersen, Power Production, Tennessee Valley Authority, 606 Edney Building, Chattanooga, TN 37401

177. Bruce Irving, VIKEM, 48 Pleasant Street, Newburyport, MA 01950

178. D. G. Jacobs, Evaluation Research Corporation, 25 E. Tennessee Ave. Oak Ridge, TN 37830 
179. L. J. Jardine, Chemical Engineering Division, Argonne National Laboratory, 9700 South Cass Ave., Argonne, IL 60439

180. D. Jessop, Associated Technologies Inc., 222 South Church Street, Charlotte, NC 28202

181. J. L. Johnson, Los Alamos Scientific Laboratory, P. O. Box 1663, Los Alamos, NM 87545

182. T. C. Johnson, Low-Level Waste Licensing Branch, Mail Stop 426-SS, NRC, Washington, DC 20555

183. J. R. Kannard, Newport News Industrial Corp., 230 41st St., Newport News, VA 23607

184. T. K. Keenan, Los Alamos Scientific Laboratory, MS-518, P.0. Box 1663, Los Alamos, NM 87545

185. R. C. Keith, Aerojet Energy Conversion Company, P. O. Box 13222, Sacramento, CA 95813

186. F. W. Kellie, Sacramento Municipal Utility District, Rancho Seco Nuclear Plant, Rt. I, Box. 550, Herald, CA 95638

187. K. S. Kim, Waste Management Research Branch, Office of Nuclear Regulatory Research, NRC, Washington, DC 20555

188. J. F. Kircher, Battelle Columbus Laboratories, ONWI, 505 King Ave., Columbus, OH 43201

189. J. H. Kittel, Waste Management, Argonne National Laboratory, 9700 South Cass Ave., Argonne, IL 60439

190. B. G. Kniazewycz, Waste Management Services, TERA Corporation, 2150 Shattuck, Suite 1200, Berkeley, CA 94704

191. K. E. Kolb, General-Electric Company, 175 Curtner Ave., San Jose, CA 95125

192. W. Koste, Northeast Utilities Service Co., P. O. Box 270, Hartford, CT 06101

193. E. Kuhn, Ebasco Services, Inc., 2 World Trade Center, New York, NY 10048

194. T. S. LaGuardia, Nuclear Energy Services, Inc., Shelter Rock Road, Danbury, CT 06810

195. D. E. Large, Oak Ridge Operations, DOE, Oak Ridge, TN 37830

196. W. W. Larson, 81 Highland Circle, Wayland, MA 01778

197. T. R. Lash, Natural Resources Defense Council, Inc., 25 Kearny Street, San Francisco, CA 94108

198. D. Lavine; Deadhill Bną, Durham, CT 06422

199. J. A. Lenhard, Oak Ridge Operations, DOE, Oak Ridge, TN 37830

200. L. S. Leonhart, Rockwel1 Hanford Operations, P. O. Box 800, Richland, WA 99352

201. R. E. Lerch, Westinghouse Hanford Operations, Hanford Engineering Development Laboratory, P. O. Box 1970, Richland, WA 99352

202. G. B. Levin, EG\&G Idaho, P. O. Box 1625, Idaho Falls, ID 83401

203. L. Lewis, Office of Nuclear Regulatory Research, Mai.1. Stop 1130-SS, NRC, Washington, DC 20555

204. J. C. Limpert, Westinghouse E.lectric Corp., Nuclear Fuel Div., P.0. Box 355, Pittsburgh, PA 19103

205. P. Loyson, Office of Nuclear Material Safety and Safeguards, Mail Stop 396-SS, NRC, Washington, DC 20555

206. M. E. Maas, Rockweil International, Rocky. Flats P1ant, P.0. Box 464 , Golden, CO 80401 
207. R. Mahalingam, Washington State University, Pullman, WA 99614

208. H. Mahlman, TVA, W10 852, 400 Commerce Ave., Knoxville, TN 37802

209. C. W. Mäliory, Hittman Nuclear \& Development Corporation, 9190 Red Branch Road, Columbia, MD 21045

210. S. Mann, Chicago Operations Office, DOE, 9800 South Cass Ave., Argonne, IL 60439

211. C. W. Manry, Rockwell Hanford Operations, P. 0. Box 800, Richland, WA 99352

212. J. Markind, TERA Corporation, 7001 Wisconsin Ave., Bethesda, MD 20014

213. J. B. Martin, Division of Waste Management, Mail Stop 396-SS, NRC, Washington, DC 20555

214. T. McLaughlin, EPA, $401 \mathrm{M}$ Strect, S.W., Washington, DC 20460

215. G. L. Meyer, EPA, 401 M Street, S.W., Washington, DC 20460

216. A. D. Miller, Electric Power Research Institute, P.0. Box 10412,3412 Hillview Ave., Palo Alto, CA 94303

217. D. Mitchei1, Rockwe11 International, Rocky Flats Plant, P.o. Box 464, Golden, CO 80401

218. A. A. Moghissi, Office of Research \& Development, EPA, Washington, DC 20460

219. C. R. Montgomery, GPU Service Corporation, 100 Interpace Parkway, Parsippany, NJ 07065

220. L. Morgenstern, Massachusetts Energy Siting Council, Massachusetts Office of Energy Resources, 73 Tremont Street, Boston, MA 03108

221. G. P. Mot1, Chem-Nuclear Systems, Inc., P. 0. Box 726, Barnwe11, SC 29812

222. R. M. Neilson, Jr., Building 701, Brookhaven National Laboratory, Upt..nn, NY 11973

223. P. O'Brien, Sandia National Laboratory, P. O. Box 5800, Albuquerque, NM 87185

224. G.K.H. Oertel, Director, Division of Waste Products, Office of Waste Management, DUE', Washington, DC 20545

225. J. B. Owen, Dow Chemical U.S.A., 47 Building, Midland, MI 48640

226. J. W. Peel, Idaho Qperations, DnF, 550 Second Etrect, Idaliu Falls, ID 83401

227. R. W. Peterson, Battelle-Columbus Laboratories, ONWI, 505 KIng Ave.; Columbus, $\mathrm{OH} .43201$

228. J. W. Phillips, Hittman Nuclear \& Development Corporation, 9190 Red Branch Road, Columbia, MD 21045

229. S. J. Phillips, Battelle Pacific Northwest Laboratory, P. 0. Box 999, Richland, WA 99352

230. W. S. Phillips, Stock Equipment Company, 16490 Chillicothe Road, Chagrin Fäls, OH 44022

231. A. M. Platt, Battelle Pacific Northwest Laboratory, P.0. Box 999, Richland, WA 99352

232. M. J. Plodinec, E. I. du Pont de Nemours and Co., Savannah River Laboratory, Aiken, SC 29801

233. R. O. Poh1, Cornell Ũniversity, Clark Hall, Ithaca, NY 14853

234. R. Pope, Sandia Laboratories, P.O. Box 5800, Albuquerque, NM 87115

235. R. G. Post, Nuclear Engineering Dept., University of Arizona, Tucson, AZ .857.21 
236. P. P. Psomas, Emergency and Preparedness Branch, Mail Stop 396-SS, NRC, Washington, DC 20555

237. T. E: Quaka, Commonwealth Edison Company, LaSalle County Station, 2601 N. 21st Road, Marseilles, IL 61341

238. R. R. Raw1, Department of Transportation, Washington, DC 20590

239. D. Reid, Office of the Governor, State House, 1100 Gervais St., Columbia, SC 29201

240. L. A. Reiter, PSE \&G, Room 403 MP, 80 Park Place, Newark, NJ 07101

241. R. R. Rietz, Rockwell Hanford Operations, 200 Area, P.0. Box 800; Richland, WA 99352

242. G. L. Richardson, Westinghouse Hanford Operations, Hanford Engineering Development Laboratory, P. O. Box 1970, Richland, WA. 99352

243. J. R. Robertson, USGS, National Center, MS 410, Reston, VA 22092

244. K. L. Rohde, Exxon Nuclear Idaho, P. O. Box 2800, CPP-637, 1955 Fremont Ave., Idaho Falls, ID 83401

245. E. M. Romney, UCLA, 900 Veteran Ave., Los Angeles, CA 90024

246. D. M. Saiki, Rockwel1 Internationa1, Rocky Flats Plant, P. 0. Box 464, Golden, CO 80401

247. H. A. Schlesinger, Gibbs \& Hill, 393 7th Avenue, New York, NY 10001

248. M. Schletter, RWMC, EG\&G Idaho, P. O. Box 1625, Idaho Falls, ID 83401

249. R. J. Schmidt, Consumers Power Co., Room P24-618, 1945 West Parnal1 Road, Jackson, MI 49201

250. L. Schrager, 2-N-2 Green Ha11, Princeton University, Princeton, NJ 08544

251. J. Sedlet, Occupational Health \& Safety Div., Argonne National Laboratory, 9700 South Cass Ave., Argonne, T. 60439

252. H. G. Shealey, Bureau of Radiological Health, 2600 Bull Street, Columbia, SC 29201

253. R. D. Sheeline, United Technologies Chemical Systems Division, 1050 E. Arques, Box 358, Sunnyvale, CA 94088

254. S. Sklar, 119 Cross Keys Road, Baltimore, MD 21210

255. E. B. Skolnikoff, MIT, Center for International Affairs, 77 Massachusetts Avenue, Cambridge, MA 02139

256. R. D. Smith, Low-Level Waste Licensing Branch, Division of Waste Management, Mail Stop 396-SS, NRC, Washington, DC 20555

257. D. E. Solberg, Office of Nuclear Regulatory. Research, Mail Stop 1130-SS, NRC, Washington, DC 20555

258. J. G. Steger, Los Alamos Scientific Laboratory, P. O. Box 1663, Los Alamos, NM 87545

259. R. T. Steen, Washington Public Power Supply System, 300 George Washington Way, Richland, WA 99352

260. J. E. Stewart, Werner \& Pfleiderer Corporation, 663 E. Crescent Ave., Ramsey, NJ 07446

261. A. J. Stock, Stock Equipment Company, 16490 Chillicothe Road, Chagrin Falls, OH 44022

262. R. Jon Stouky, Quadrex Corp/NSC, 1700 De11 Ave., Campbe11, CA 95008

263. R. V. Subramanian, Dept. of Material Sciences \& Engineering, Washington State University, Pullman, WA 99164

264. A. L. Taboas, Albuquerque Operations Office, DOE, Albuquerque, NM 87115

265. C. N. Tesitor, Rockwell International, Rocky Flats Plant, P.0. Box 464, Golden, CO 80401 
266. M. M. Thomas, Black \& Veatch Consulting Engineers, P.0. Box 840, Kansas City, MO 64114

267. J. D. Thompson, EG\&G Idaho, Inc., P. 0. Box 1625, Idaho Falls, ID 83401

268. R. J. Tosseti, Bechtel Power Corporation, 50.Beale Street, San Francisco, CA 941.19

269. F. Traino, Mound Facility, P. O. Box 32, Miamisburg, OH 45342

270. R. F. Tucker, Sargent \& Lundy, 55 East Monroe St., Chicago, IL 60603

271. W. J. Tyrre11, Argonne National Laboratory, 9700 South Cass Ave., Argonne, IL 60439

272. J. N. Vance, Bechtel Power Corporation, P. 0. Box 1000, Ann Arbor, MI 48106

273. M. E. Wacks, University of Arizona, Colllege of Engineering, Tucson, AZ 85721

274. J. E. Watson, Jr., University of North Carolina, Chapel Hill, NC. 27514

275. M. D. Weingart, Ebasco Services, Inc., 160 Chubb Ave,, Lyndhurst, NJ 07071

276. B. R. Wheeler, Exxon Nuclear Idaho, P. O. Box 2800, CPP-637, 1955 Fremont Ave., Idaho Falls, ID 83401

277. J. B. Whitsett, Idaho Operations, DOE, 550 Second Street, Idaho Fails, ID 83401

278. J. R. Wiley, E. I. du Pont de Nemours and Company, Savannah River Laboratory, Aiken, SC 29801

279. D. Wilkie, Hittman Nuclear \& Development Corporation, 9190 Red Branch Road, Columbia, Maryland 21045

280. P. C. Williams, Stock Equipment Company, 16490 Chillicothe Road, Chagrin Falls, OH 44022

281. R. F. Williams, Electric Power Research Inst.itute, P, O, Box 10/12, 3212 Hillview Ave., Palo Alto, CA 94303

282. L. C. Witbeck, Argonne National Laboratory - West, P.0. Box 2528, Idaho Falle, ID 83401

203. T. Wulff, Environmentài Improvement Division, P. O. Box 968, Santa Fe, NM 87503

284. G. Yuan, Natural Resources Defense Council, 25 Kearny Street, San Francisco, CA 94108

285. D. L. Ziegler, Rockwell International, Rocky Flats Plant, P.O. Box 464, Golden, CO 80401

286. P. Ziemer, Chairman, Department of Bionucleonics, School. of Pharmacy, Purdue University, West LaFayette, IN 47906

\section{FOREIGN DISTRIBUITUN}

287. S. G. Amarantos, Greek Atomic Energy Commission, Nuclear Research Center "DEMOKRITOS", Aghia Paraskevi, Attiki, Athens, GREECE

288. S. G. Burnay, Materials Development Division, AERE Harwell, Didcot, Oxfordshire OXI1 ORA, ENGLAND

289, H. R. Burri, Nuclear Division, Electrowatt Engineering Services Ltd., Bellerivestrasse 36, CH-8022 Zurich, SWITZERLAND 
290. D. H. Charlesworth, Atomic Energy of Canada, Ltd., Chalk River Nuclear Laboratories, Chalk River, Ontario KOJ 1JO, CANADA

291. H. Christensen, Chemical Process Engineering, ASEA-ATOM, Box 53, Vasteras, SWEDEN 72104

292. J. C. Claes, Waste Processing Group, CEN/SCK Centre d'Etude Nucleaire, Boeretang 200, B-2400 Mo1, BELGIUM

293. Th. Dippe1, Kernforschungszentrum Karlsruhe GmbH, Institut fur Nukleare Entsorgungstechnik (INE), Postfach 36 40, 7500 Karlsruhe 1, FEDERAL REPUBLIC OF GERMANY

294. A. Donato, CNEN - Centre De Casaccia, B.P. No. 2400, 00100 Roma, ITALY

295. T. S. Drolet, Ontario Hydro, 700 University Ave., Toronto, Ontario, MSG1X6, CANADA

296. B. Edwall, Nuclear Reactor Office, Sydkraft AB, Fack, S-200 70 Malmo 5, SWEDEN

297. J. R. Grover, Radioactive Waste Management R\&D, AERE Harwell, Didcot, Oxfordshire OX11 ORA, ENGLAND

298. C. Harfors, Barseback Nuclear Power Plant, Sydkraft AB, Fack, S-200 70 Ma1mo 5, SWEDEN

299. W. Hild, Eurochemic, Boeretang 200, B-2400 Mo1, BELGIUM

300. T. Ishihara, Radioactive Waste Management Center, 2-6-10 Toranomon, Minato-ku, Tokyo 105, JAPAN

301. R. Kohout, Ontario Hydro, 700 University Ave., Toronto, Ontario M5G 1X6, CANADA

302. M. Laser, Kernforschungsanlage Julich, KFA Julich GmbH, Postfach 1913, D-5170 Julich 1, FEDERAL REPUBLIC of GERMANY

303. H. W. Levi, Hahn-Meitner-Institut fur Kernforschung Berlin GmbH, Glienicker Strasse 100, D-1000 Berlin-39, FEDERAL REPUBLIC of GERMANY

304. J. B. Lewis, Process Technology Division, AERE Harwe11, Didcot, Oxfordshire OX11 ORA, ENGLAND

305. W. Lutze, Hahn-Meitner-Institut fur Kernforschung Berlin GmbH, Glienicker Strasse 100, D-1000 Berlin-39, FEDERAL REPUBLIC of GERMANY

306. J-C. Nomine, Laboratoire Betons et Revetements, CEN Saclay, DMECN/DTECH/ STA, B.P. No. 2, 91190 Gif-sur-Yvette, FRANCE

307. E. Peltonen, Technical Research Centre of Finland Reactor Laboratory, SF-02150 Espoo 15, FINLAND

308. P. E. Pottier, Department de Chimie Appliquee, CEN/Cadarache, B.P. No. 1, 13115 Saint-Paul-lez Durance, FRANCE

309. F. H. Passant, Central Electricity Generating Board, Plant. Engineering Dept., Barnwood, Gloucester, GL4 7RS, ENGLAND

310. H. H. Queiser, Kraftwerk Union, Nuclear. Processing, P. O. Box 700649 , Frankfurt D-600, FEDERAL REPUBLIC of GERMANY

311. N.S.S: Rajan, Bhabha Atomic Research Centre, Trombay, Bombay :85, INDIA

312. G. Rudolph, Kernforschungszentrum Karlsruhe, Postfach 3640, D 7500 Karloruhe 1, FEDERAL REPUBLIC of GERMANY.

313. R.A.J. Sambell, Materials Development Division, AERE Harwell, Building 552, Didcot, Oxfordshire OX11 ORA, ENGLAND

314. C. G. Sombret, Commisșariat a 1'Energie Atomique, Establissement de la Vallee du Rhone, Boite Postale 171, 30200 Bagnols-sur-Ceze, FRANCE. 
315. D. G. Thackrah, Nuclear Installations Inspectorate, Silkhouse Court, Tithebarn, Liverpool L2 2LZ, ENGLAND

316. C. Thegerstrom, Dept. of Radiation Protection and Waste Management, Studsvik Energileknik AB, S-611 82 Nykoping, SWEDEN

317-630. Given distribution as shown in TID-4500 under Nuclear Waste Management Category (UC-70) 